San Jose State University

SJSU ScholarWorks

Master's Theses

Master's Theses and Graduate Research

Fall 2018

\title{
Airborne Doppler Radar Observations of PyroCu/Cb Plume \\ Kinematics and Thermodynamics During the 2016 Pioneer Fire
}

Bruno Rodriguez

San Jose State University

Follow this and additional works at: https://scholarworks.sjsu.edu/etd_theses

\section{Recommended Citation}

Rodriguez, Bruno, "Airborne Doppler Radar Observations of PyroCu/Cb Plume Kinematics and

Thermodynamics During the 2016 Pioneer Fire" (2018). Master's Theses. 4979.

DOI: https://doi.org/10.31979/etd.9h75-q8r3

https://scholarworks.sjsu.edu/etd_theses/4979

This Thesis is brought to you for free and open access by the Master's Theses and Graduate Research at SJSU ScholarWorks. It has been accepted for inclusion in Master's Theses by an authorized administrator of SJSU ScholarWorks. For more information, please contact scholarworks@sjsu.edu. 


\author{
A Thesis \\ Presented to \\ San José State University \\ In Partial Fulfillment \\ of the Requirements for the Degree \\ Master of Science
}

The Faculty of the Department of Meteorology and Climate Science

by

Bruno Rodriguez

December 2018 
(C) 2018

Bruno Rodriguez

ALL RIGHTS RESERVED 
The Designated Thesis Committee Approves the Thesis Titled

AIRBORNE DOPPLER RADAR OBSERVATIONS OF PYROCU/CB PLUME
KINEMATICS AND THERMODYNAMICS DURING THE 2016 PIONEER FIRE

by

Bruno Rodriguez

APPROVED FOR THE DEPARTMENT OF METEOROLOGY AND CLIMATE SCIENCE

SAN JOSÉ STATE UNIVERSITY

December 2018

Craig B. Clements, Ph.D.

Minghui Diao, Ph.D.

Neil Lareau, Ph.D.

David Kingsmill, Ph.D.
Department of Meteorology and Climate Science

Department of Meteorology and Climate Science

Assistant Professor, Atmospheric Science Program, Univ. Nevada Reno

Research Scientist, Cooperative Institute for Research in Environmental Sciences 


\title{
ABSTRACT \\ AIRBORNE DOPPLER RADAR OBSERVATIONS OF PYROCU/CB PLUME KINEMATICS AND THERMODYNAMICS DURING THE 2016 PIONEER FIRE
}

\author{
by Bruno Rodriguez
}

During a period of explosive growth of the Pioneer Fire (Idaho, August 2016), deep pyroconvective plumes were sampled by aircraft. The research aircraft was equipped with both remote sensing and in situ instrumentation, including a W-Band Doppler radar which provided high-resolution vertical velocity retrievals from within the developing pyrocumulus. Being the first direct observations of vertical velocity within a pyrocumulus cloud, they have provided unique insights into the dynamical processes governing pyroconvective environments, with important implications for the fire modeling community. The observations were quality-controlled and corrected for issues such as Doppler velocity aliasing, and the plume's kinematic structure was examined and contextualized using flight-level and surface thermodynamic data collected by the Boise National Weather Service, RAWS observations, and NEXRAD radar-derived plume echo tops. The analyses indicated an extreme pyroconvective environment, with updrafts approaching $60 \mathrm{~m} \mathrm{~s}^{-1}$ several kilometers above ground level. Interestingly, the observations yielded no secondary peak in vertical velocity aloft linked to latent heat release from condensation. Moreover, updraft magnitude was found to increase with height above the surface and below the condensation level. A wide updraft core acting to isolate the plume center from lateral entrainment processes is hypothesized as a possible explanation for the observed characteristics of the vertical velocity profiles. 


\section{ACKNOWLEDGMENTS}

First and foremost, I would like to express immense gratitude to my committee chair and advisor, Craig Clements, for his continued help and motivation throughout the thesiswriting process, as well as his patience and flexibility with a seemingly never-ending chain of less-than-ideal life events. Second, I would like to acknowledge Neil Lareau for guiding me through Matlab's many intricacies, providing invaluable suggestions/advice regardless of time of day. Huge thanks to Dave Kingsmill for challenging and pushing me to ensure scientifically rigorous work, and providing extremely useful insights from a different scientific perspective. Many thanks also to Minghui Diao, for accommodating such a short-notice change to the thesis committee, with the added workload that entails. Lastly, I would like to acknowledge several people from my immediate personal sphere, starting with my excellent friend Jenn Varian. I cannot express enough how thankful I am for her emotional support throughout the past two years. Without her motivation, numerous deadlines would not have been met, and this thesis would not have turned out

quite the same. I cannot forget a heartfelt thank you to my boyfriend Eric for keeping me sane and putting up with an emotional roller coaster that any normal person would have run away from. And of course, I'd like to acknowledge my parents for their constant support in every shape and form, despite the over 6,000 miles of separation between us. Finally, this thesis was made possible with the support from NSF grant 1151930. 


\section{TABLE OF CONTENTS}

List of Figures.................................................. vii

Chapter 1: Introduction................................................ 1

Chapter 2: Methods.................................................... 12

2.1 Instrumentation................................................ $\quad 12$

2.2 Data Pre-Processing............................................. 13

2.3 Flight Campaign Summary and Synoptic Context...................... 15

2.4 Radar Dealiasing................................................ 20

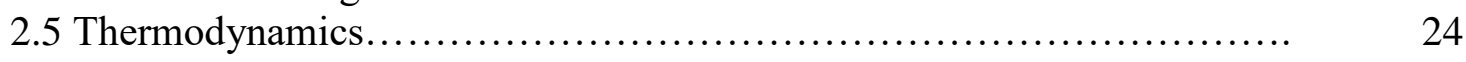

2.6 Statistical Analyses........................................... 25

Chapter 3: Analysis.................................................... 27

3.1 Thermodynamics and WCR Cross-Sections.......................... 27

3.2 Cross-Wind Statistics............................................. 45

3.3 Along-Wind Statistics........................................ 50

3.4 Frequency Distributions...................................... 58

Chapter 4: Summary and Conclusions................................ 62

References.................................................... 66

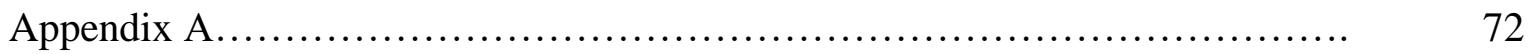




\section{LIST OF FIGURES}

Fig. 1. Fire perimeter maps showing 24-hour change in acreage between Aug

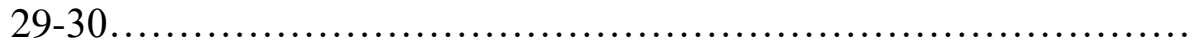

Fig. 2. University of Wyoming Skew-T for (a) 00Z 29 August 2016 and (b) 12Z 29 August 2016.

Fig. 3. Terra MODIS (a) and Aqua MODIS (b) satellite imagery over Idaho on 29 August 2016.

Fig. 4. Map of RAWS locations and elevations relative to fire perimeter......

Fig. 5. (a) Cross-section of Doppler vertical velocities during the penetration leg and (b) Flight-level data corresponding to the same leg

Fig. 6. Skew-T valid 00Z 30 August showing environmental temperature and dewpoint profiles, in addition to RAWS surface temperatures and dewpoints

Fig. 7. KCBX (NEXRAD) 3.4-degree tilt reflectivities at $23.48 Z$ on 29 August 2016 and flight track for legs 3 and 4.

Fig. 8. Flight-level data for the period between and including legs 3 and 4, corresponding to a brief high-altitude plume penetration

Fig. 9. Cross-sectional view of vertical velocities during cross-wind leg 9... 36

Fig. 10. Cross-sectional view of vertical velocities during cross-wind leg $10 \ldots$

Fig. 11. Cross-sectional view of vertical velocities during cross-wind leg $13 \ldots 38$

Fig. 12. NEXRAD-derived plume echo tops at the time of the cross-wind overpasses.

Fig. 13. Cross-sectional view of reflectivity returns during cross-wind leg $9 \ldots \quad 42$

Fig. 14. Cross-sectional view of reflectivity returns during cross-wind leg $10 \ldots$

Fig. 15. Cross-sectional view of reflectivity returns during cross-wind leg $13 \ldots 44$

Fig. 16. Profile of (a) vertical velocity statistics and (b) reflectivity statistics for the aggregate of cross-wind legs. 
Fig. 17. Cross-sectional view of vertical velocity during along-wind leg $16 \ldots$

Fig. 18. Cross-sectional view of vertical velocity during along-wind leg $21 \ldots$

Fig. 19. Cross-sectional view of vertical velocity during along-wind leg $25 \ldots$

Fig. 20. Profile of (a) vertical velocity statistics and (b) reflectivity statistics for areas within $4 \mathrm{~km}$ either side of the defined plume source for the aggregate of along-wind legs

Fig. 21. Profile of (a) vertical velocity statistics and (b) reflectivity statistics for areas within 4-8 km either side of the defined plume source for the aggregate of along-wind legs

Fig. 22. Profile of (a) vertical velocity statistics and (b) reflectivity statistics for areas within 8-12 km either side of the defined plume source for the aggregate of along-wind legs

Fig. 23. Vertical frequency distributions of number of data points by altitude for the three horizontal groupings identified for the along-wind legs..

Fig. 24. Frequency distributions of vertical velocity and reflectivity for lower, middle, and upper portions of the plume sampled in a cross-wind

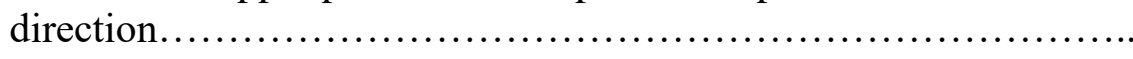

Fig. 25. Frequency distributions of vertical velocity and reflectivity for lower, middle, and upper portions of the plume sampled in an along-wind direction...................................................... 


\section{Introduction}

Wildfires represent an increasing and serious threat to life and property in the United States, and their economic impact on a federal level has reached record levels. Over recent years, the total annual cost of wildfire suppression has steadily increased. In fact, 2015-17 have been the three costliest years for the U.S. since records began in terms of wildfire suppression, with 2017 being the most expensive with federal suppression costs exceeding 2.9 billion USD per the National Interagency Fire Center (NIFC, 2017). This uptick in economic impacts is likely attributable to a combination of factors. Widespread urban sprawl is resulting in a growing number of homes being built in areas designated as Wildland-Urban Interface (WUI) (Hammer et al. 2007), with 60\% of post-1990 homes being located in such zones (ISO, 2016), thereby increasing exposure to wildfires. Moreover, many regions have experienced increasing frequency and severity of wildfires in addition to a lengthening of the traditional wildfire season, due in part to more prolonged periods of drought (Westerling et al. 2006). Numerous studies have shown that some recent large fire complexes can be attributed to anthropogenic climate change, and that our changing climate is likely to result in more frequent and intense wildfire activity throughout North America (Barbero et al. 2015; Gillett et al. 2004; Kasischke and Turetsky, 2006; Westerling et al. 2006). With this increasing risk comes a need for better understanding of wildfire behavior and characteristics, including the coupled relationship between plume structure and dynamics, and the surrounding atmosphere.

The notion that wildfires can significantly alter atmospheric conditions in their vicinity, often in such a way that they create a feedback mechanism between atmospheric 
processes and fire behavior, is now well-established within the wildfire research community (Clark et al., 1996). These fire-atmosphere interactions have been explored using both numerical modeling techniques (e.g. Trentmann et al., 2006; Freitas et al., 2007; Val Martin et al., 2012) and through field experiments of varying scales (e.g. Clark et al, 1999; Clements et al., 2016; Lareau and Clements, 2017; McCarthy et al., 2018;). This fire-atmosphere coupling is best exemplified by the plume updraft. The updraft represents the central component of the general wildfire circulation, being the vertical branch that links surface and upper-level circulations. Moreover, updrafts are especially relevant to fire-atmosphere interactions that directly affect plume dynamics above the surface, such as entrainment of ambient air. Despite its significance, updraft properties are arguably the least quantified out of the various plume circulations studied.

Perhaps the first large-scale study aimed at quantifying key fire and plume parameters via remote sensing, Banta et al. (1992) used radar and lidar to observe a large Crown fire and prescribed burn, respectively. They showed the existence of a widespread area of low-level convergence extending several kilometers radially from the core of the main convective plume. By using the Doppler-shifted frequency of the lidar backscatter intensity to estimate radial wind components, vertical velocities on the order of $25 \mathrm{~m} \mathrm{~s}^{-1}$ were derived and found to be increasing with height (up to approximately $2 \mathrm{~km}$ AGL). They hypothesized that the differential velocity pattern with height contributed to the formation of a pair of counter-rotating vortices in the fire. Updrafts above the head fire have been observed to induce low-level convergence and inflow of ambient air (Charland et al., 2013). It has been suggested that such areas of surface convergence may be directly 
linked to so-called "rear inflows" behind the head of the fire which in itself could serve as a driving mechanism for the development of other fire-induced flows (Charland et al. 2013; Peace et al., 2017).

Other studies have aimed to determine the environmental mechanisms conducive to the formation of vortex patterns in fires by observing rotational development under differing ambient conditions, fuel types and terrain influences, among others (e.g. McRae and Flanigan 1990; Palmer 1981). Their findings suggest that vortex formation is generally favored under conditions of light ambient wind and a gradual increase in fire intensity. In the case of prescribed burn experiments, the use of radial ignition patterns has also been associated with vortex development (McRae and Flanigan, 1990). Typically, pre-existing ambient vorticity must be present (often the case) as an initial vorticity source, and the fire can then act to tilt the ambient vorticity into the vertical (Forthofer and Goodrick, 2011). This is yet another example of a frequently-observed fire-atmosphere coupling.

In addition to radar and lidar, infrared (IR) image flow analysis techniques have been used to quantify the magnitude and direction of fire-induced winds (Clark et al. 1999; Coen et al. 2004). This method involves the use of an IR imager pointed directly at the fire line sensitive to specific wavelengths. The images are then subjected to an image flow analysis technique (Verri et al. 1990; Clark et al. 1999; Coen et al. 2004) that produces estimates of vertical and horizontal velocities adjacent to the fire. Potential maxima in vertical velocity are then statistically estimated, with Clark et al. (1999) calculating peak vertical velocities of $\sim 30 \mathrm{~m} \mathrm{~s}^{-1}$, similar to those found by Banta et al. 
(1992), whereas Coen et al. (2004) estimated peak velocities of approximately $60 \mathrm{~m} \mathrm{~s}^{-1}$. Both of these values were constrained to the nearest $30 \mathrm{~m}$ AGL. The range of vertical velocity estimates is a testament to the difficulty in obtaining observations in such a complex environment, and highlights the ongoing uncertainties regarding the vertical structure of convective plumes.

Another subset of studies has focused on determining plume injection heights (Trentmann et al. 2006; Freitas et al. 2007; Val Martin et al. 2010; Val Martin et al. 2012; Jian and Fu 2014; Gonzi et al. 2015; Peterson et al. 2015), the height at which smoke particles detrain from the core of the smoke plume and enter the free atmosphere. Plume injection heights are particularly important in the fire modeling community for representing long-range smoke transport and emission patterns, which is essential for regional air quality forecasting and assessing potential health implications on the population. Certain ground-based observations using lidar backscatter intensity can provide insight into plume injection heights for smaller plumes (Clements et al. 2007; Lareau and Clements, 2018), but satellite observations are most typically used (Val Martin et al. 2010; Peterson et al. 2015). Using fuel conditions and radar-derived echo plume tops from the 2001 Chisholm fire in Alberta, Canada, in addition to radiosonde data for model initialization, Trentmann et al. (2006) evaluated plume-rise simulations to determine smoke injection heights and produce profiles of vertical velocity within the plume. The simulations estimated a peak vertical velocity of $\sim 50 \mathrm{~m} \mathrm{~s}^{-1}$ directly above the fire, with updraft velocity decreasing with height. A weak secondary peak was seen at around $8 \mathrm{~km}$, and was attributed to latent heat release above the condensation level, a 
pattern that has been observed in similar simulations of traditional mid-latitude convection. A secondary peak in vertical velocity also appears in pyroCu/Cb simulations by Freitas et al. (2007).

Stereographic satellite imagery has traditionally served as the primary observational resource for plume injection modeling studies. Accurate determinations of plume injection heights are particularly relevant for cases of extreme pyroconvection, whereby a pyroCb has sufficient buoyancy to result in stratospheric intrusions, and are an essential input for large-scale chemical transport models (Paugam et al., 2016; Val Martin et al., 2010; Trentmann et al., 2006). Spaceborne remote sensing instruments can be a reliable source for determining plume echo tops, although are often limited by their overpass schedule. For example, plume heights derived using Terra's MISR stereo-imager are known to be biased toward less mature, early afternoon (and thus lower altitude) convective plumes (Paugam et al., 2016; Val Martin et al., 2010).

In addition to satellite imagery, some more recent studies have made use of research aircraft to obtain observations from wildfires (Johnson et al. 2008; Karl et al. 2007; Yokelson et al. 2008), placing emphasis on smoke emission and transport characteristics, as well as the chemical properties of plumes. These flight campaigns most typically sample the more dilute, downwind portion of plumes, and avoid the plume updraft core where the most vigorous plume dynamics occur. As such, the kinematic structure and dynamics of large convective plumes has not yet been actively studied with the use of airborne observations, limiting our scope of measurement to those obtained from periodic ground-based studies. 
PyroCb plumes are vital in understanding long range smoke transport and improving plume rise models, but also play a major role in terms of large-scale fire-atmosphere interactions. PyroCb and even PyroCu plumes are known to directly influence surface weather conditions and circulations, often creating unexpectedly dangerous conditions (Dowdy et al., 2017). Pyrogenic lightning, for example, has been frequently observed during pyroconvective events (Fromm et al., 2006; Rosenfeld et al., 2007) which can often result in new fire starts. Erratic surface winds are commonly associated with cases of pyroconvection, driven by momentum fluxes into the updraft (Rothermel 1991; Banta et al., 1992; Peterson et al., 2015), and can result in long-range spotting (e.g. Koo et al., 2010). All of these factors pose a serious hazard to emergency response personnel on the ground, and can substantially limit fire suppression efforts during period of pyroconvective activity.

In addition to the phenomena described above, recent lidar measurements collected in close proximity to two large wildfires provided unique evidence of the production of smoke-induced density currents (Lareau and Clements, 2015). Dynamically similar to density currents typically observed during midlatitude convection in the form of outflow boundaries, these density currents were induced by smoke-shading effects from the towering PyroCb from the fire, altering the radiative balance at the surface and producing a strong temperature gradient as a result.

At first glance, pyroconvection appears to share many similarities with traditional midlatitude convection, particularly in terms of its circulation and overall convective structure. However, the mechanisms driving pyroconvection are inherently different. 
Sensible heat release from the fire is assumed to be the largest contributor to the initiation of convection (Trentmann et al., 2006), and the associated temperature perturbations within the plume are an important thermodynamic consideration. Peterson et al. (2017) highlighted a number of distinct differences in the formation of pyroCu/Cb relative to non-pyroconvective situations. For example, they suggest that a primary pyroconvective driving mechanism takes the form of entrainment of moist, mid-level tropospheric air. This is a feature that has been frequently observed in model simulations (e.g. Trentmann et al., 2006). Ultimately, pyroconvection appears to share more characteristics with highlevel convection, as opposed to moist low-level convection (such as a supercell thunderstorm). Dry near-surface conditions, combined with relatively moist mid- and upper-tropospheric air (commonly referred to as an "inverted-V" profile) are more characteristic of an environment favorable for pyroCu/ $\mathrm{Cb}$ development. Microphysically, pyro $\mathrm{Cu} / \mathrm{Cb}$ are also notably distinct from non-pyrogenic convection. For example, concentrations of smoke particles have been found to be very high throughout a pyroconvective plume, with high concentration often extending into the UpperTroposphere/Lower-Stratosphere (UTLS) (Jensen et al., 2004). These elevated droplet concentrations have been proposed as a driver for enhanced pyrogenic lightning (Andreae et al., 2004), and even a surge in lightning heat and duration to changes in the convective polarity (Rudlosky and Fuelberg, 2011). Moreover, the comparatively smaller surface area of the smoke particles in pyroconvective anvils has been associated with longer anvil lifespans, relative to anvils that are not fire-sourced (Andreae et al., 2004; Rosenfeld et al., 2007). 
At the surface, the process of combustion is also responsible for the injection of moisture into the atmosphere directly above the fire. However, the extent to which combustion moisture can influence the plume's overall thermodynamic properties has remained somewhat unclear, and has only recently been addressed. Potter (2005) suggested that moisture release during combustion processes could be a significant source of moisture in the plume, potentially even of equal magnitude to that released via latent heat release during condensation at higher levels. Subsequent studies have provided evidence to the contrary, indicating that mixing of ambient air likely contributes significantly to plume dilution. For example, Tory et al. (2018) estimated pyroconvective plumes to reach more than $95 \%$ dilution just below the condensation level. In fact, dilution of less than $95 \%$ below cloud base could prevent condensational processes from taking place. Nonetheless, excessive entrainment can still occur, and thus be detrimental to plume condensation due to the reduction in positive buoyancy (Tory et al., 2018). In modeling a case of pyroconvection, Trentmann et al. (2006) found that despite combustion being a major source of water vapor directly above the fire, entrainment processes resulted in plume moisture content decreasing rapidly with height below the condensation level. In fact, the contribution from this surface moisture to the total moisture content of the plume above a height of $4 \mathrm{~km}$ AGL was estimated to not exceed $10 \%$, suggesting that latent heat release is the primary driver behind net plume water vapor content (and therefore pyroCb development). Luderer et al. (2009) further suggested that plume dynamics, particularly at lower levels, are primarily driven by sensible heat release from the fire. Although mid-level entrainment in considered to be an 
essential ingredient in the modification of pyrconvective plume properties, the quantification of this process in such a complex environment has proved difficult for researchers.

Closely related to the role of moisture release on plume thermodynamic properties is the condensation level specific to pyroconvection. The extent to which in-plume condensation levels compare to those encountered in midlatitude convection has been the subject of much debate - understandable given the thermodynamic complexities in a fire environment. Combustion moisture undoubtedly would act to lower condensation levels. Simultaneously, sensible heat release and the resulting positive temperature perturbations within the plume would act to counteract the effect of moisture release, and is even further complicated by mixing of ambient air. Low and mid-level entrainment processes, aided by the turbulent near-surface conditions, act to dilute the plume properties. Freitas et al. (2007) used a simple, one-dimensional plume rise model (Latham, 1994) to explore some of these thermodynamic processes. As well as providing additional support for the role of latent heat release at the Lifting Condensation Level (LCL) for the generation of additional buoyancy, the study showed a rapid decrease of temperature with height between the surface and LCL. Moreover, increased buoyancy was observed with more moist mid-level ambient conditions, compared to a drier scenario.

Lareau and Clements (2016) were able to detect the in-plume condensation level using lidar instrumentation, and related their measurements to upper-air observations collected in the vicinity of the fire. Their results show that the Convective Condensation Level (CCL) is likely a better estimate of the condensation level in a pyroconvective 
environment than the LCL, probably owing to sensible heat release and the extreme temperatures nearest the fire. The results were consistent with other studies previously mentioned, suggesting the observed condensation levels in plumes are higher than that found from ambient thermodynamic conditions (e.g. Tory et al., 2018).

Despite the many advancements that have been made in understanding near-surface plume properties, thermodynamic processes during pyroconvection, and wildfire modeling and smoke dispersion, there remains a great deal to be explored and understood as it relates to this phenomenon. A lack of comprehensive observational data certainly plays a part in this knowledge gap (Val Martin et al., 2010) and highlights the need for more large-scale field experiments. Numerical simulations have provided reasonable initial estimates of a plumes' vertical velocity structure; however, these need to be constrained and evaluated against observational data to examine their representativeness. Safety concerns and logistical complications have played a part in limiting a majority of field observations to small, controlled grass-fire situations, raising issues of representativeness with respect to pyroconvective environments. Moreover, the few field studies concerning larger crown fires have applied estimation techniques (such as imageflow analysis) to obtain values of updraft vertical velocities, and as yet have not been able to measure this quantity directly. The updraft is a key component in the plume's dynamic and kinematic structure, and is intrinsically linked to many different processes in the wildfire system, including but not limited to plume injection heights, smoke dispersion, convective activity, and both large and small-scale circulations ranging from the upper troposphere to the surface. Thus, accurate measurements of the vertical velocities would 
be of great importance in the fire science community, and could serve as a resource for the improvement and evaluation of current and future numerical models.

Here, the first direct measurements of vertical velocity within a wildfire plume are presented, as measured during an exploratory flight campaign over a wildfire exhibiting highly turbulent and violent pyroconvective behavior. Using airborne Doppler radar with dual-beam configuration, vertical profiles of vertical velocities and reflectivity were retrieved and are used to describe the kinematic structure of the plumes. These observations are further examined and contextualized using upper-air data, surface RAWS observations, and NEXRAD radar-derived plume echo tops. Ultimately, these observations will serve to fill a void in our understanding of the kinematic structure of a pyroconvective updraft, providing insights into the dynamical processes governing the vertical branch of a wildfire plumes' circulation, with important implications for a wide realm of pyroconvective research applications. 


\section{Methodology}

\subsection{Instrumentation}

The primary instrument on the UWKA is the Wyoming Cloud Radar (WCR), a 95 GHz dual-Doppler radar. The WCR possesses a total of four antennas - down (near nadir), down-fore, side, and side-fore. The down-fore antenna is oriented at approximately $30^{\circ}$ from nadir, while the side-fore antenna is oriented approximately $35^{\circ}$ away from the side-pointing antenna. In addition, the side antenna is equipped with a reflector that can be repositioned in order to redirect the beam directly upwards. Such a configuration allows the WCR to simultaneously sample vertically above and below the aircraft, allowing for the retrieval of the cross-sectional view in the vertical plane. As such, this configuration was chosen to obtain direct measurements of the vertical velocity field within the plumes.

Range gates on the WCR are centered every $15 \mathrm{~m}$. However, range gates located within $120 \mathrm{~m}$ and $105 \mathrm{~m}$ from the radar for the nadir and zenith beams, respectively, are unreliable, therefore resulting in a "blind zone" extending slightly above and below the aircraft (Miao et al., 2005). Reflectivity measurements for the WCR are estimated to be accurate within $3 \mathrm{dBZ}$, with a sensitivity varying between $-25 \mathrm{dBZ}$ and $-40 \mathrm{dBZ}$ depending on beam configuration and mode of acquisition (Wang et al., 2006).

In addition to the Doppler radar, the UWKA comes equipped with a suite of cloud microphysical probes. Those which are most relevant to the Pioneer Fire dataset include the DMT LWC100 and Gerber PVM100-A, both of which measure liquid water content (LWC) in $\mathrm{g} \mathrm{m}^{-3}$ at a frequency of $25 \mathrm{~Hz}$. The DMT LWC-100 is a hot-wire probe, with an 
accuracy of $\sim 0.05 \mathrm{~g} \mathrm{~m}^{-3}$, while the PVM100-A has an accuracy of 5\%, with $2 \%$ precision for LWC. Despite not being referenced in this study, the PVM probe also provides particle surface area and effective droplet radius estimates (Gerber et al., 1994). The UWKA was also equipped with Licor-7000 $\mathrm{H}_{2} \mathrm{O}$ and $\mathrm{CO}_{2}$ gas analyzers, similarly sampling at a frequency of $25 \mathrm{~Hz}$. Relative humidity measurements in liquid $\left(\mathrm{RH}_{\text {liq }}\right)$ were obtained from the $\mathrm{H}_{2} \mathrm{O}$ analyzer and are referenced in the discussion. Standard atmospheric parameters were also measured in-situ by built-in aircraft sensors. This includes the static temperature, as well as the horizontal (East-West and North-South) and vertical winds at aircraft level, and $\mathrm{RH}_{\text {liq }}$. Aircraft altitude and GPS-derived latitude and longitude were also recorded. Vertical velocity at flight level was obtained from the Applanix POS AV410 system, which combines post-processing of the inertial reference unit with geopositioning technology (Haimov and Rodi, 2013). The manufacturer's estimated vertical velocity accuracy was $0.005 \mathrm{~m} \mathrm{~s}^{-1}$. Additional cloud microphysical probes were present on the UWKA, but are not discussed in this analysis. These include a DMT CDP, 2DP, and Nevzorov probe measuring cloud droplet size spectra, droplet concentrations and additional LWC/TWC values, as well as a Rosemount ice detector.

\subsection{Data Pre-Processing}

With the aid of the UWKA's high-accuracy inertial geopositioning system, Haimov and Rodi (2013) developed a calibration technique for the antenna beam-pointing angles. This calibration method was found to be effective and robust in reducing errors in velocity data due to aircraft motion, and followed the techniques outlines by Haimov and Rodi, 2013). This method was applied during the flight campaign to account for the 
influence of aircraft motion on the WCR data, with the accuracy of the vertical velocity data after removal of aircraft motion effects estimated to lie within $0.1 \mathrm{~m} \mathrm{~s}^{-1}$.

The WCR data have a high temporal resolution of $25 \mathrm{~Hz}$, and the reflectivity data it outputs are in the form of linear equivalent reflectivity, or "gain", thus the pre-processed reflectivity data were converted to decibels by taking log base 10 and multiplying by a factor of 10 . The noise was similarly corrected.

Quality control of the data involved a number of steps. First, a reflectivity mask was applied such that all data lying within three standard deviations of the noise floor (total background noise) were removed. To further reduce any remaining noise, the second step of the quality-control process involved removal of data points with a signal-to-noise ratio (SNR) less than $8 \mathrm{Db}$. This value was determined by trial and error to be roughly equivalent to the applied reflectivity mask. Ground data contamination was widespread, and at times coincided with areas of true near-surface returns. Thus, it was deemed best to simply remove data within $200 \mathrm{~m}$ of the surface, which the ground clutter was confined to, rather than attempting to remove the ground clutter via other methods such as continuity tests as this would compromise near-surface returns near the plume source(s). The velocity data corresponding to the removed reflectivity points were also removed from the dataset.

To better compare individual flight legs to each other, coordinate transformations were applied to each leg such that all legs could be represented through a reference spatial coordinate system. All flight legs oriented in an along-wind (AW) direction were grouped together, as they shared similar orientation and location relative to the fire. The 
mean orientation for all AW legs combined was computed, as was the mean center point of the legs. This center point $(44.2116 \mathrm{~N}, 115.6126 \mathrm{~W})$ was subsequently used as the reference origin for the new coordinate system. The mean orientation of the AW legs, which ran roughly southwest-northeast, represented the $\mathrm{x}$-axis for the common spatial reference system, with the $y$-axis being represented by the normal to this line (positive $\mathrm{Y}$ in the northwest direction). Each latitude/longitude pairing was converted from its respective geodetic system to local Cartesian coordinates. Coordinate transformations were then performed such that the new coordinates were aligned relative to the rotated reference coordinate system defined above.

The flight legs oriented in a cross-wind $(\mathrm{CW})$ direction exhibited much greater variability between them, particularly in terms of their orientation, and were therefore not transferred to a common spatial reference frame. Each CW leg was transformed into local Cartesian coordinates, and geometric corrections were applied to rotate the reference frame to align with the orientation of that individual leg. In other words, each reference system was unique in terms of its axis orientation, depending upon the orientation of each CW leg.

\subsection{Flight Campaign Summary \& Synoptic Context}

The research flight in question was conducted during the afternoon of 29 August, 2016 between approximately 4:30 and 7:30 PM local time. The Pioneer Fire was exhibiting explosive growth that afternoon, and extreme fire behavior. The rapid growth of the fire is evident when looking at the change in fire perimeter, as derived by aircraft, between 29-30 August 2016 (Fig. 1). The incident maps show that the fire grew more 
than 29,000 acres between 29-30 August, the 24-hour period during which the Pioneer Fire exhibited the most extreme fire behavior. Fig. 1 also demonstrates the complex topography of the area.

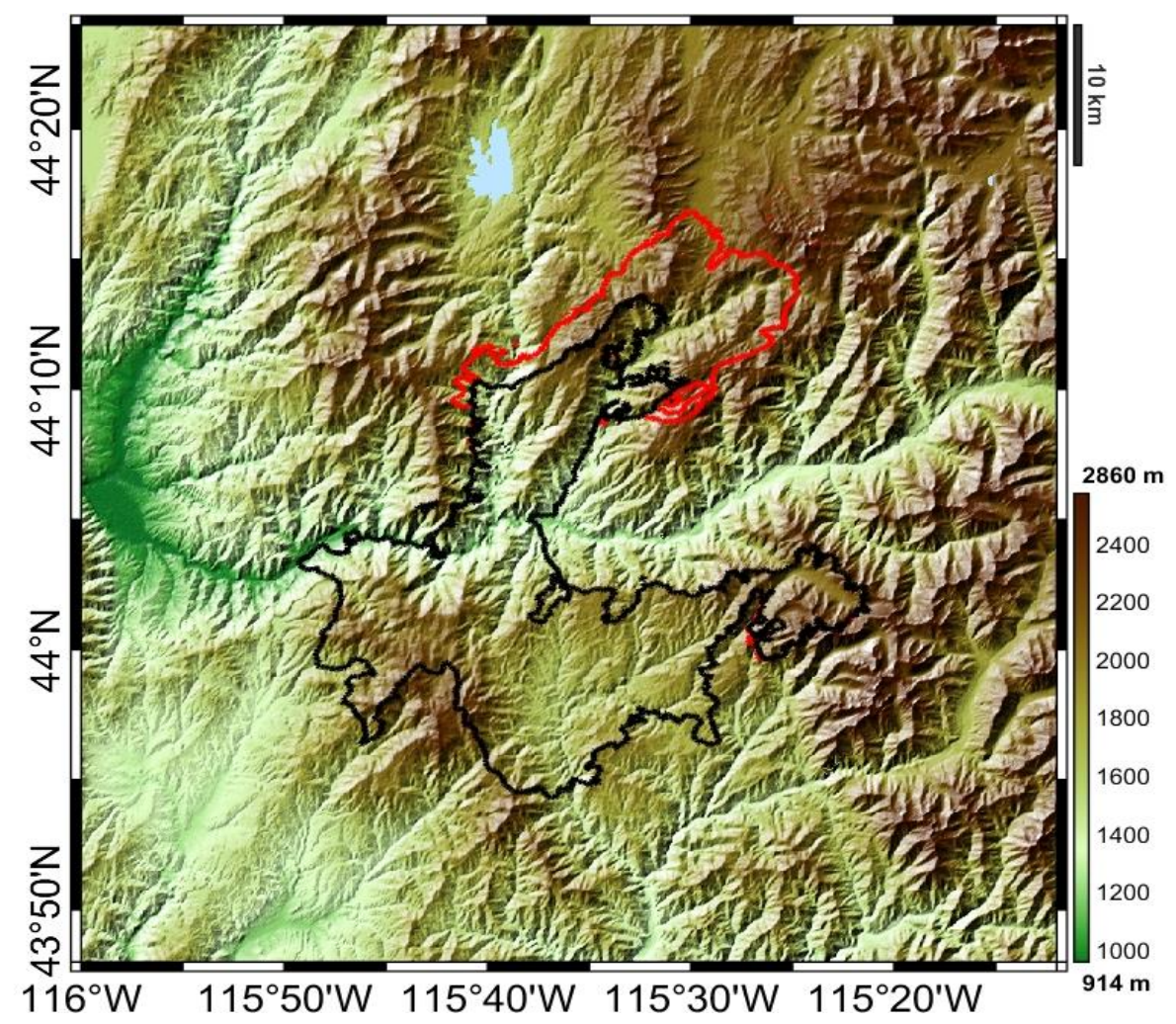

Fig. 1. Fire perimeter map showing 24-hour change in acreage between 29 Aug (black line) and 30 August (red line).

Synoptically, the area was under generally easterly flow aloft the days prior to the flight campaign. However, the eastward movement of a longwave trough over the Gulf of Alaska, and an associated shortwave trough approaching the northwest United States resulted in backing flow aloft, with winds shifting to a southwesterly direction. This flow pattern helped advect some high-altitude moisture and cloud cover over Oregon and Idaho, much of which stemmed from tropical storm Madeline in the eastern Pacific Ocean (see visible MODIS imagery in Figs. 3a-b). The southwesterly flow across the 
region significantly increased daytime high temperatures on the $29^{\text {th }}$ compared to the previous day.

The upper-air observations corresponding to the twice-daily radiosonde launches by the Boise National Weather Service WFO (1200 UTC 29 August and 0000 UTC 30 August, Figs. 2a-b) show hot $\left(\sim 33^{\circ} \mathrm{C}\right)$ and dry conditions near the surface on 29 August 2016. The atmosphere remained dry up to $\sim 400 \mathrm{mb}$, where a shallow moist layer was present owing to the southwesterly flow aloft. Widespread cloud cover associated with this layer was visible on satellite imagery (Figs. 3a-b). During the morning hours of 29 August, dry conditions prevailed throughout the depth of the troposphere with a stable atmosphere overall. The evening upper-air observations indicate the presence of an even drier lower troposphere, with a shallow moist layer near $400 \mathrm{mb}$. With strong diurnal heating in place during the $29^{\text {th }}$, the surface inversion visible in the $12 \mathrm{Z}$ sounding eroded quickly, and a near-uniform lapse rate was observed during the afternoon hours. Surfacebased Convective Available Potential Energy (CAPE) was negligible $\left(\sim 30 \mathrm{~J} \mathrm{~kg}^{-1}\right)$, and Convective Inhibition was significant $\left(\sim-350 \mathrm{~J} \mathrm{~kg}^{-1}\right)$. Combined with a positive Lifted Index, the conditions were not supportive for non-pyrogenic convection that afternoon. 

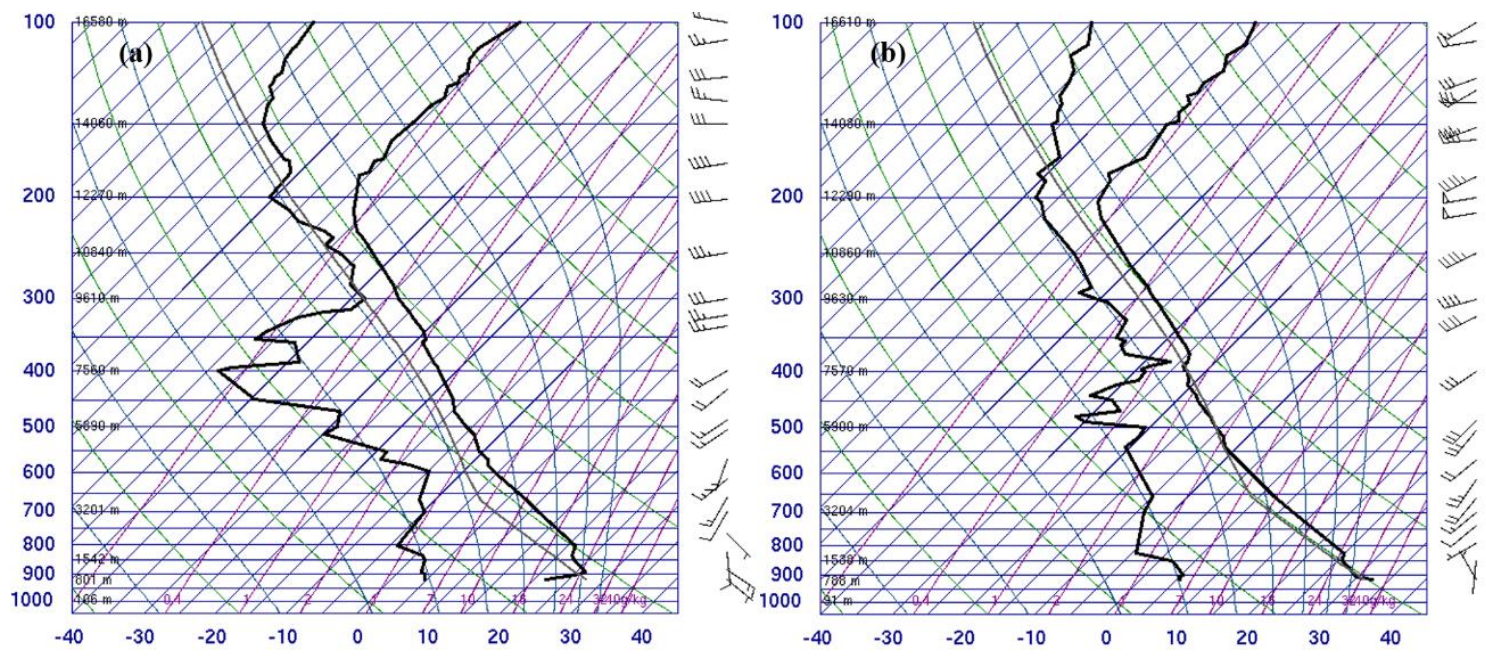

Fig. 2. University of Wyoming Skew-T for (a) 1200 UTC 29 August 2016 and (b) 0000 UTC 30 August 2016.

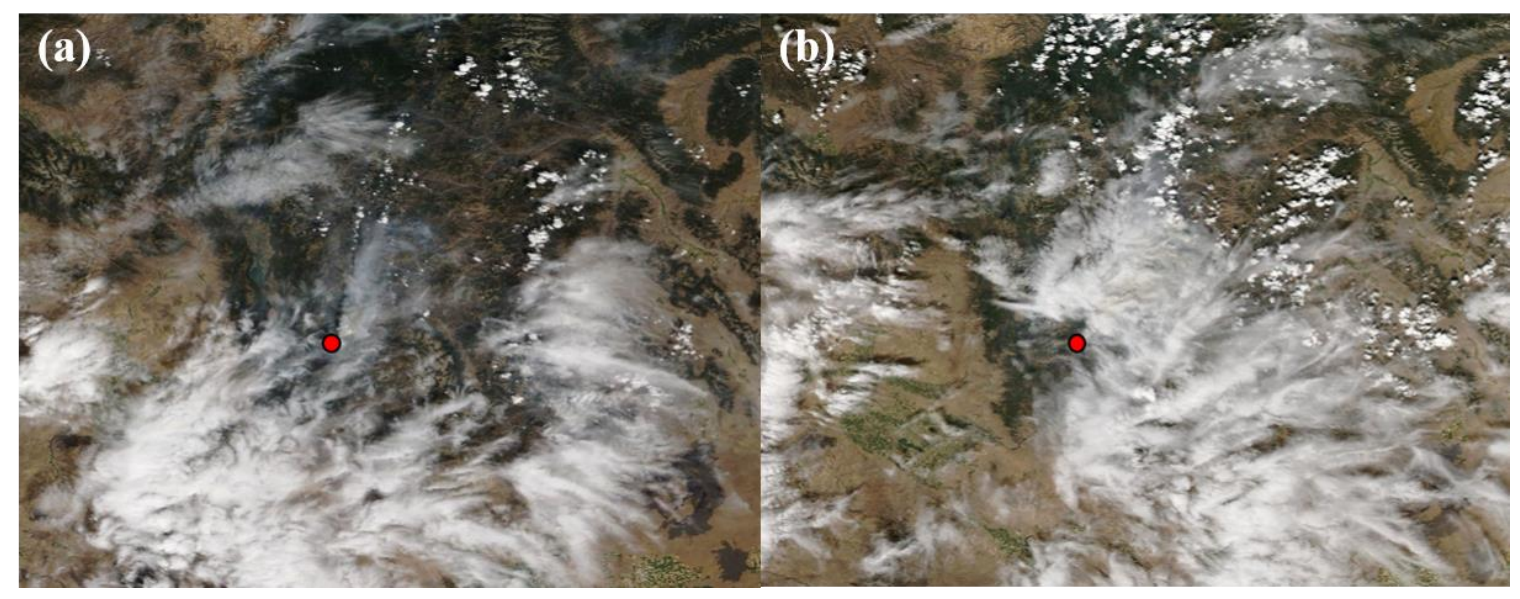

Fig. 3. Terra MODIS (a) and Aqua MODIS (b) satellite imagery over Idaho on 29 August 2016.

A total of five temporary RAWS sites were set up in the vicinity of the Pioneer Fire as part of the incident (i-RAWS), covering a range of conditions and elevations. The locations of the five sites are highlighted in Fig. 4, along with each sites' elevation. At the time the research flight was conducted, the higher-elevation sites $(7,500-8,500 \mathrm{ft})$ reported temperatures $22^{\circ} \mathrm{C}$ and above, relative humidity values mostly under $20 \%$, and generally light to moderate winds 5-10 mph, gusting locally to $25-30 \mathrm{mph}$. The valleys 
were significantly warmer at the time with temperatures above $32^{\circ} \mathrm{C}$ and relative humidity $10-15 \%$, with light winds.

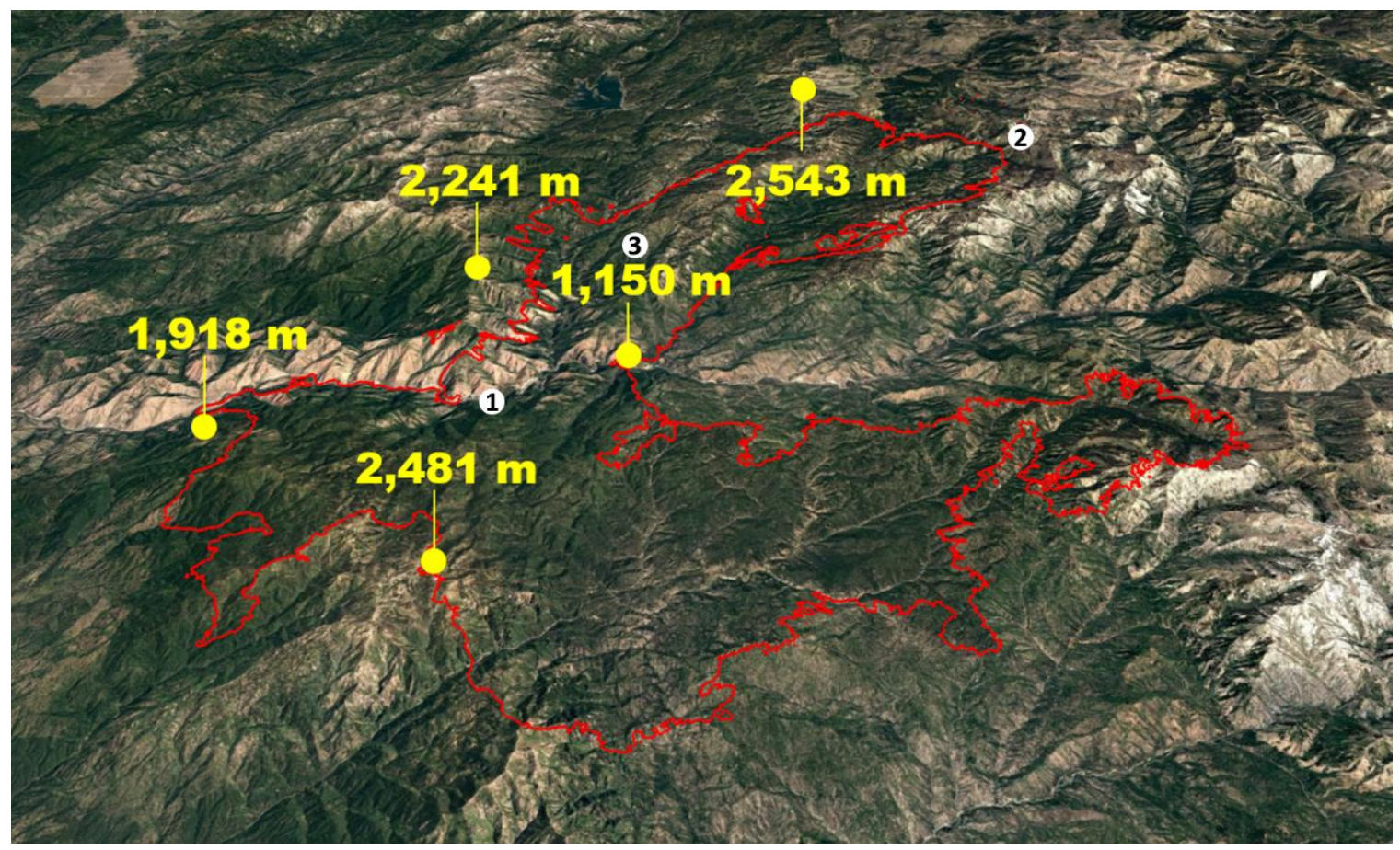

Fig. 4. Map of RAWS locations and elevations relative to fire perimeter. The locations of three geographic features referenced in the text - Clear Creek Drainage (1), Red Mountain (2), and Deadwood Ridge (3) - are also shown.

During this period, the fire was most active in its northeastern area. Southwesterly winds were pushing the fire towards the northeast following the Clear Creek drainage, with the head of the fire approaching Red Mountain. The western flank of the fire was also quite active on this day along Deadwood Ridge, with high fire intensity through the evening, and separate pyroCu/pyroCb were generated at both locations. Both of the areas mentioned above - the primary fire front and the western flank, generated pyroCu/pyroCb, and were sampled separately from above by the UWKA. 
In its majority, the overall flight pattern consisted of back-and-forth flight legs above the two most active burning areas generating pyroconvective activity. To avoid the inclusion of data obtained during periods the aircraft was turning, ascending, or descending, all straight and level flight legs were identified prior to any subsequent analysis of the data. Aircraft roll angle was generally limited to 5 degrees or under for classification as a 'straight' flight leg to account for the turbulent nature of the environment in which the UWKA was being flown.

In total, 26 individual flight legs were identified for the flight on 29 August. Of those, 17 sampled the western flank of the fire in an along-wind direction at an altitude of approximately $7.7 \mathrm{~km} \mathrm{MSL}$, and will hereby be referred to as the Along-Wind (AW) legs. A further 8 legs sampled the larger plume above the main header of the fire, in a cross-wind direction (also at an altitude of $7.7 \mathrm{~km} \mathrm{MSL}$ ), and will therefore be referred to as the Cross-Wind (CW) legs. Finally, one flight leg was conducted in a cross-wind direction through the main pyroCb, at a lower elevation than the rest (approximately 5 $\mathrm{km}$ MSL). This leg was unique in that it was the only flight leg during which the aircraft penetrated the plume itself for an extended period. This leg will be referenced as the 'penetration leg'.

\subsection{Radar Dealisaing}

A common problem encountered with Doppler radar data is the phenomenon of velocity aliasing (also commonly referred to as velocity “folding"). Every Doppler radar has a specified maximum unambiguous velocity - in other words, a maximum velocity threshold that defines the velocity range that can be measured directly by the radar - 
known as the Nyquist velocity. This is analogous to the maximum unambiguous range, which defines a similar threshold in terms of distance from the radar. Both quantities are closely related via the Pulse Repetition Frequency (PRF) of the radar (PRF of WCR is 1$20 \mathrm{KHz}$ ), as equations 1 and 2 show.

$$
{ }^{ \pm} V_{n}=\frac{(P R F) \lambda}{4} \quad(1) \quad R_{\max }=\frac{c}{2(P R F)}
$$

In the equations above, $\lambda$ represents the radar wavelength, $V_{n}$ the Nyquist velocity, $c$ the speed of light, and $\mathrm{R}_{\max }$ the maximum unambiguous range. The mutual dependence of $V_{n}$ and $R_{\max }$ highlights what is commonly referred to as the "Doppler Dilemma", whereby the two quantities are inversely related to the PRF, and thus manipulation of the PRF to maximize one of the quantities has effect of reducing the other quantity.

The Nyquist velocity of a radar is an important specification. If the true velocity of a point target exceeds the radar's Nyquist velocity in magnitude, it is aliased into the measurable velocity range of the radar. This leads to misrepresentation of high velocity targets, such that their direction of travel is interpreted erroneously, and the target velocity is underrepresented.

The Nyquist velocity for the WCR is $\pm 15.8 \mathrm{~m} \mathrm{~s}^{-1}$. Due to the turbulent and convective nature of the plumes sampled during the flight campaign, velocity aliasing was widespread throughout the data, with vast swaths of points aliased. Some methods exist to reduce aliasing occurrence, namely through changes in measurement techniques, such as using alternating PRFs (Tabary et al., 2000). However, these are unrealistic for a fastmoving platform, as representativeness errors would be induced (Haase and Landelius, 
2004), and aliasing issues in an environment with a wide range of expected velocities are unlikely to be completely eliminated. Thus, post-processing algorithms to correct aliased data are still common. A number of these techniques exist, with varying degrees of complexity. Many methods are intended for real-time application, which is not the nature of this field campaign, and others require information pertaining to the background wind field, for example by using radiosonde data (Tabary and Scialom, 2000). In this study, a continuity-based approach similar to that in Bargen and Brown (1980) and Eilts and Smith (1990) is used. Specifically, the WCR velocity data were analyzed sequentially along each individual profile, starting at flight level and applying continuity constraints to points along each profile with distance from the radar. A continuity constraint attempts to detect abrupt changes in data along a radial, and constrain successive data points such that the change between them remains within a particular realistic threshold.

The WCR data were dealiased radial by radial, starting with the first range gate, according to method described as follows. For each range gate, the radial velocity at that gate $\left(\mathrm{V}_{\mathrm{g}}\right)$ is compared to the mean vertical velocity computed from the previous five range gates $\left(\bar{V}_{p}\right)$. If the difference $(\Delta \mathrm{V})$ between $\mathrm{V}_{\mathrm{g}}$ and $\bar{V}_{p}$ exceeds a user-defined threshold, the vertical velocity for the range gate in question is flagged as an aliased velocity $\left(\mathrm{V}_{\mathrm{a}}\right)$. Specific thresholds varied between individual legs, as no single value proved optimal for all legs. Generally, a $\Delta \mathrm{V}_{\text {thresh }}$ of $10 \mathrm{~m} \mathrm{~s}^{-1}$ was sufficient to differentiate aliased from non-aliased points for most legs, although $\Delta \mathrm{V}_{\text {thresh }}$ up to $14 \mathrm{~m} \mathrm{~s}^{-1}$ was used in some cases. The aliased point is subsequently dealiased based on the relationship between the true (corrected) velocity $(\mathrm{V})$, and $\mathrm{V}_{\mathrm{a}}$ : 


$$
V=V_{a}+2 n V_{n}
$$

In Equation (3), $\mathrm{V}_{\mathrm{n}}$ represents the magnitude of the Nyquist velocity $\left(15.8 \mathrm{~m} \mathrm{~s}^{-1}\right)$, and $n$ is an aliasing integer that varies in value between -2 and +2 (Eilts and Smith, 1990; James and Houze, 2001). In order for the erroneous velocities to dealias correctly, you must determine the correct aliasing integer to assign to Equation (3) (Ray and Ziegler, 1977). An aliasing integer of zero is applied to those velocities that are not flagged as being aliased to start with. Typically, possible $n$ values are constrained to the range between -1 and +1 . However, due to the extremity of the observed vertical velocities, several areas experienced double folding. Therefore, the selected non-zero magnitude of $n$ depended upon whether a particular aliased point was determined to have been aliased once or twice, with double-folded points. To differentiate between single- and doublealiased velocities, some additional constraints are applied to those points identified as being aliased. All four constraints must be met for a velocity to be flagged as doublealiased:

$$
\begin{aligned}
\text { i. } & \left|\bar{V}_{p}\right|>32 \mathrm{~m} \mathrm{~s}^{-1} \\
\text { ii. } & \mathrm{V}_{\mathrm{g}}<0 \\
\text { iii. } & \mathrm{V}_{\mathrm{g}-1}>\mathrm{V}_{\mathrm{g}-5} \\
\text { iv. } & \Delta \mathrm{V}>0
\end{aligned}
$$

A point flagged as double-aliased is attributed an aliasing integer of either -2 or +2 . The sign of the aliasing integer depends upon the whether the true velocity should be positive or negative. This was determined according to the sign of $\bar{V}_{p}$, with negative 
(positive) mean velocities preceding the aliased velocity translating into a negative (positive) aliasing integer.

The method described above could not be applied to the first five range gates exactly as described, given that there were not at least five preceding range gates at the beginning of each radial. Therefore, a running average was used in place of five-member mean for range gates two through five. In addition, the vertical velocity measured at flight level by in-situ flight instrumentation (Applanix POS AV410) was used as the starting reference radial velocity, to which the velocity at the first range gate for each WCR radial was compared.

This procedure successfully unfolded the majority of the data. However, radial continuity approaches to dealiasing are very sensitive to noise and single false flags (Eilts and Smith, 1990) - either would result in all subsequent points in the radial being incorrect. As such, there was a small minority of points that required manual dealiasing or corrections after the dealiasing algorithm was applied.

\subsection{Thermodynamics}

Upper-air data were obtained from the 30 August $00 \mathrm{Z}$ sounding by the Boise National Weather Service in Boise, ID. As noted above, the temperature and dewpoint information from five i-RAWS sites in the vicinity of the fire were retrieved and used to calculate the Convective Condensation Level (CCL). The CCL was chosen as opposed to the Lifting Condensation Level (LCL), as it has been shown that the CCL can be an effective parameter when it comes to estimating the condensation level in pyroconvective environments (Lareau and Clements, 2016), and is often more accurate than the LCL, 
particularly when the environmental conditions do not support widespread convective activity. The CCL can be found on a skew-T-log-P diagram by tracing a line from the surface dewpoint parallel to the mixing ratio, until it intersects the environmental temperature, and assumes a parcel is first heated to its convective temperature before it is raised adiabatically. A CCL range was calculated based on the minimum and maximum mixing ratios from the five i-RAWS sites, in additional to the Boise surface conditions.

\subsection{Statistical Analyses}

To further contextualize the data, simple statistical profiles showing the variation in the mean, median, minimum, maximum, $10^{\text {th }}$ and $90^{\text {th }}$ percentiles with height (for both reflectivity and vertical velocity) were developed. For the $\mathrm{CW}$ legs, all data points were combined each for vertical velocity and reflectivity. However, due to the highly tilted nature of the plume sampled during the AW legs, which exhibited significant horizontal advection, all legs were stratified horizontally into groups, based on the horizontal displacement from the identified plume source for each leg. The plume source points for each of the legs were identified manually, based on areas of maximum reflectivity and vertical velocity near the surface, ensuring they were consistent with the observed plume structure. Once the source points had been defined, points were categorized as follows:

- All points within $4 \mathrm{~km}$ of the plume source in terms of horizontal displacement (in either direction)

- All points displaced 4-8 $\mathrm{km}$ horizontally from the plume source

- All points displaced 8-12 $\mathrm{km}$ horizontally from the plume source 
Some of the longer flight legs had points located more than $12 \mathrm{~km}$ away from the plume source, but these were limited in number and thus not incorporated into a fourth group. All corresponding groups were then combined to show the aggregate statistics across all of the AW legs. Moreover, only data pertaining to the downward WCR beam (i.e. below flight level) was utilized for these analyses, to avoid contamination of data by the mid-level cloud cover present above the UWKA (See Fig. 3)

Given the non-uniform aircraft altitude and varying underlying topography, data from separate flight legs had to be interpolated into a common height grid before any statistical analyses could be performed. A common height grid was first defined according to the maximum vertical and horizontal limits of the data, with evaluation points spaced every $15 \mathrm{~m}$ vertically. The data was then interpolated using Matlab's "scatteredInterpolant" function and concatenated. 


\section{Analysis}

\subsection{Thermodynamics and WCR Cross-Sections}

One aircraft penetration of a developing plume associated with the flanking fire was accomplished during the experimental mission. Penetration refers to the aircraft flying directly through a portion of the convective plume. This plume penetration was performed in an AW direction, at an altitude of approximately $5.2 \mathrm{~km} \mathrm{MSL}$. Fig. 5a displays only the Doppler velocities measured below flight-level (no upward beam was available for this flight leg). The corresponding flight-level data are shown directly below the radar velocity retrievals, and includes the temperature and vertical velocity at the UWKA's altitude, in addition to relative humidity (RH) measurements from both the aircraft and Licor 7000.

The effect of the general southwesterly winds is evident in the downwind (left-toright) tilt and advection of the WCR radar returns. The tilt complicates identification of individual updraft cores. Furthermore, due to this sampling occurring along the flanking fire, the possibility exists that some of the observed returns correspond to separate plumes/heat sources along the fire edge, that all ascend into a broader plume rather than originating a single region of combustion. With these considerations in mind, the vertical velocities during this penetration leg were quite variable both vertically and horizontally, with numerous narrow cores of stronger vertical velocities of up to $30-35 \mathrm{~m} \mathrm{~s}^{-1}$. 

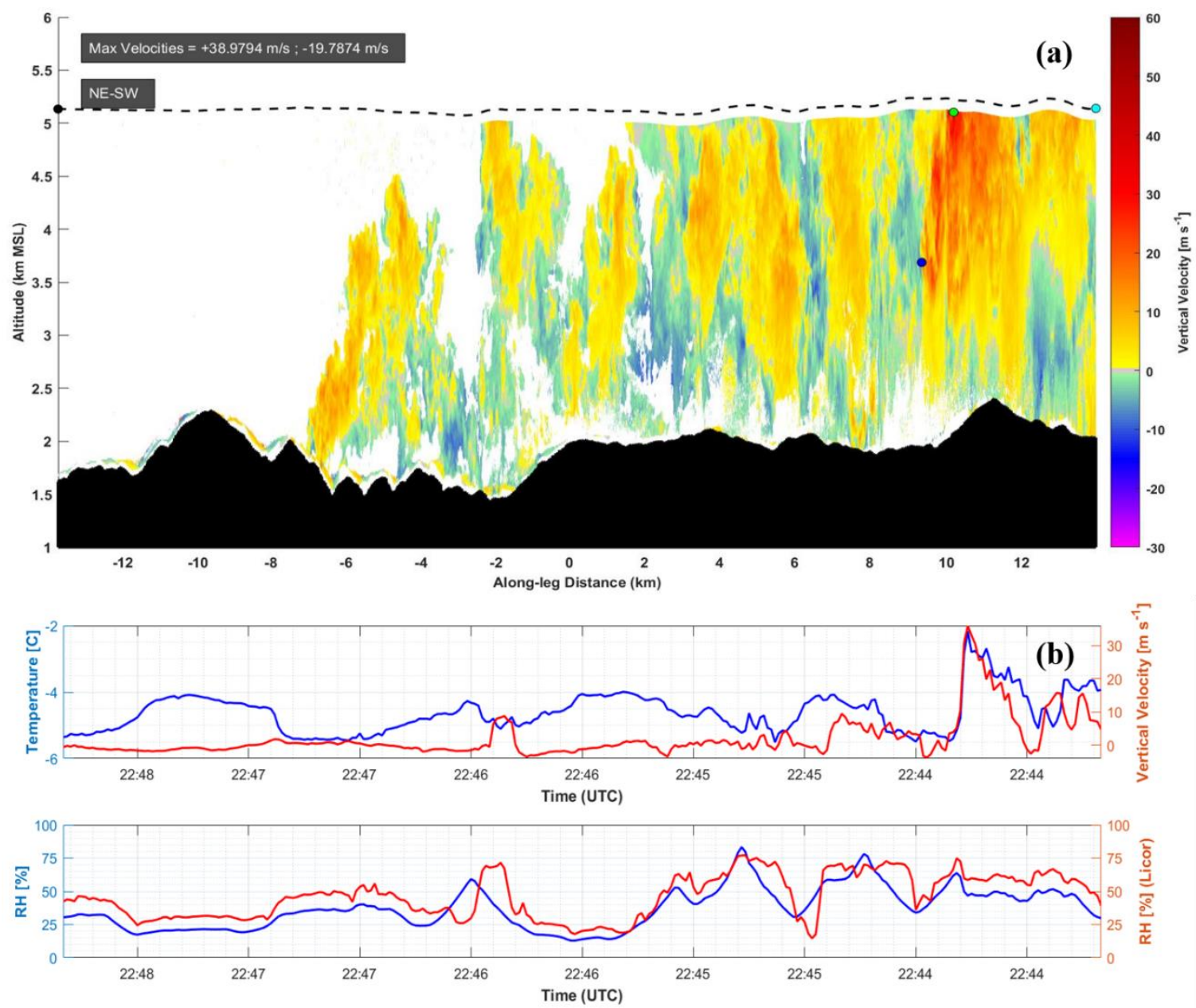

Fig. 5. (a) Cross-section of Doppler vertical velocities during the penetration leg and (b) Flight-level data corresponding to the same leg. Flight-level is represented by the black dotted line in (a), and the locations of the strongest updraft and downdraft are marked by a green and blue dot, respectively. Underlying topography shown in black shading.

At flight level, the UWKA intercepted the strongest updraft, registering a maximum vertical velocity of $35 \mathrm{~m} \mathrm{~s}^{-1}$ (Fig. 5b). Coinciding with the flight-level peak in vertical velocity, a positive temperature perturbation of $4^{\circ} \mathrm{C}$ can be observed, indicating a strong thermal influence from the fire extending to at least $3 \mathrm{~km}$ AGL. Of particular importance, however, is the corresponding peaks in $\mathrm{RH}$ observed during the penetration, with maximum $\mathrm{RH}$ values around $80 \%$. This is an indication that the plume was subsaturated 
at this level (5.2 km MSL). Liquid water content (LWC; not shown) remained negligible throughout the leg, providing further evidence for subsaturated conditions.

These observations can be contextualized by analyzing the ambient thermodynamic conditions present at the time. Fig. 6 shows a Skew-T log-p representation from the 30 August 2016 00Z sounding released by NWS Boise. The time of release corresponded well with the flight legs, which were conducted between approximately 22:30Z on 29 August and 01:30Z on 30 August, and considering the distance between the location the radiosonde was launched and the fire location was approximately 70 miles, the upper-air data should closely resemble the conditions in the vicinity of the fire. 

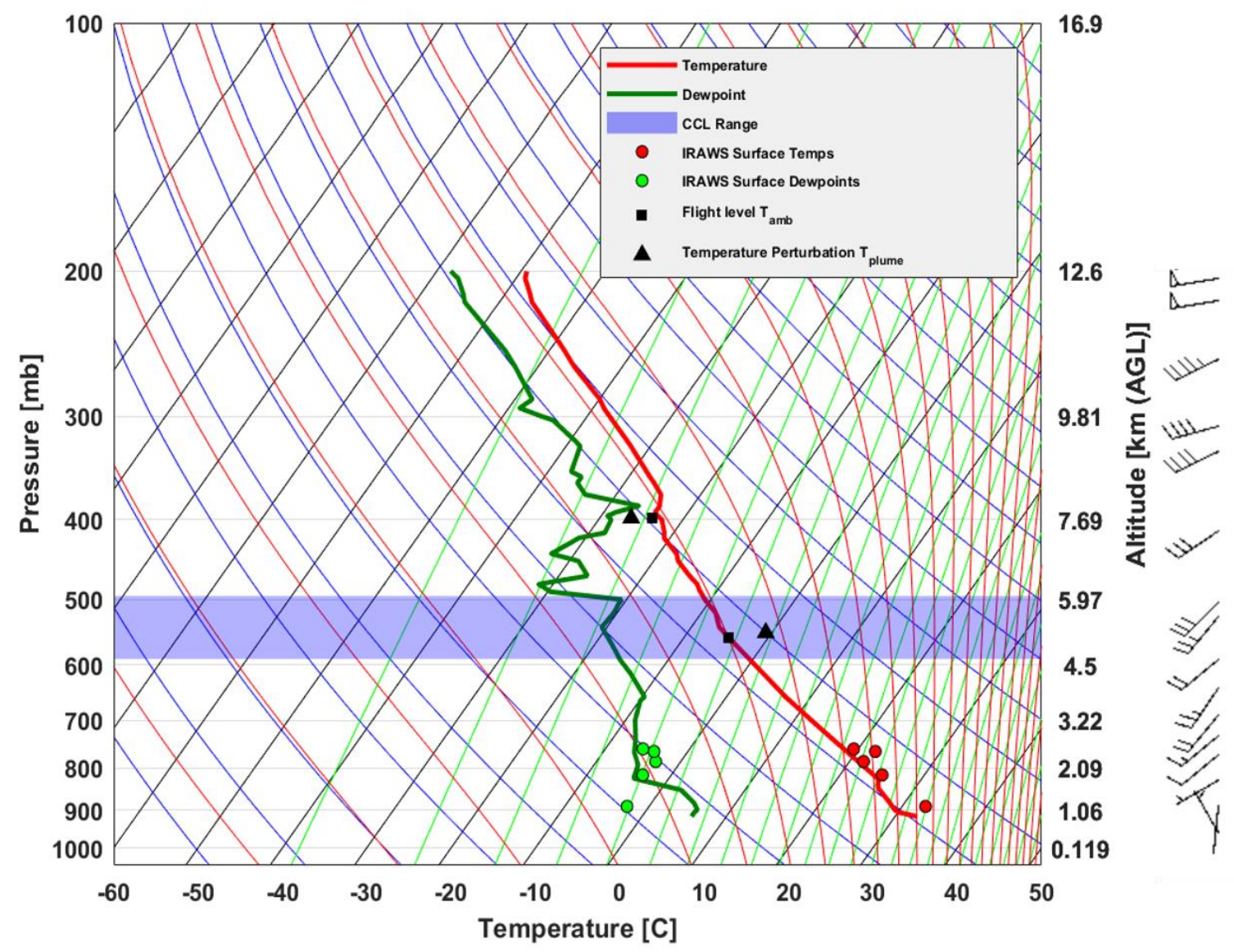

Fig. 6. Skew-T valid 00Z 30 August showing environmental temperature and dewpoint profiles, in addition to RAWS surface temperatures and dewpoints. The flight-level ambient and plume perturbation temperatures for both flight sampling heights are shown, as well as the calculated range of CCL heights.

The sounding (Fig. 6) shows a dry atmosphere from the surface up to $400 \mathrm{mb}$, where a shallow moist layer was present owing to synoptic southwesterly flow aloft, consistent with satellite imagery showing widespread cloud cover in the region (Figs. 3a-b). With strong diurnal heating in place during the $29^{\text {th }}$, the surface inversion present during the morning hours was quickly eroded, leading to a near-uniform lapse rate during the afternoon hours. As mentioned previously, CAPE was minimal during the afternoon of 
29 August (under $50 \mathrm{~J} \mathrm{~kg}^{-1}$ ), with CIN greater than $-300 \mathrm{~J} \mathrm{~kg}^{-1}$. These conditions demonstrate that the environment was not supportive of moist convection that day. The dry lower portion of the thermodynamic profile, coupled with shallow mid-tropospheric moisture near $400 \mathrm{mb}$, is more akin to the "inverted V" profile associated with high-level convection. This type of setup typically involves dynamic forcing in the upper troposphere, and is more closely related to pyroconvective development (Peterson et al., 2017). Thus, despite this profile not being supportive of moist surface-based convection, it could still favor PyroCu/Cb formation, particularly in the presence of a trigger mechanism such as thermal buoyancy generation from combustion.

The surface conditions depicted by the RAWS sites show a significant difference in low-level moisture in the vicinity of the fire, with all five RAWS sites measuring surface dew points well below that at Boise (generally $10^{\circ} \mathrm{C}$ or more below), regardless of their elevation. All RAWS dewpoint data are also relatively consistent in their mixing ratios, with most points positioned very close to the same constant mixing ratio line, independent of their altitude. This is an indication that the boundary layer was wellmixed at the time. The blue section on the Skew-T indicates the range of estimated CCL heights for all RAWS sites in addition to the surface measurement from the Boise radiosonde. Using the Boise data, the CCL was estimated at $590 \mathrm{mb}(\sim 4,600 \mathrm{~m} \mathrm{MSL})$ representing the lower bound of the CCL range. Estimates of the CCL using the surface dewpoints of the RAWS sites were substantially higher, with the highest centered at 500 $\mathrm{mb}(\sim 6,000 \mathrm{~m} \mathrm{MSL})$. Since the CCL is by definition dependent on surface moisture, the drier surface conditions in the vicinity of the fire imply the nature of the inflow air 
ingested by the fire would also be drier. As a result, it should be expected that the true $\mathrm{CCL}$ at the time was in fact much closer to the top of the given range $(500 \mathrm{mb})$ than it was based on the Boise sounding-derived CCL.

The flight-level data were superimposed onto Fig. 6 for comparison against the environmental temperature profile. Taking the ambient flight-level temperature to be the mean temperature measured by the UWKA outside of the plume (and averaged across all flights legs at the same altitude), it's clear that both ambient temperatures representing the two primary flight levels fall directly on the environmental temperature profile, suggesting that the radiosonde data are representative of conditions aloft near the fire. Based on the subsaturated conditions at flight level during the penetration leg, in addition to the dry low-level conditions confirmed by the RAWS sites, a reasonable conclusion would be for the true CCL to be somewhat close to the top end of the estimated range (500 mb), corresponding to an altitude of approximately $6 \mathrm{~km}$ MSL. 


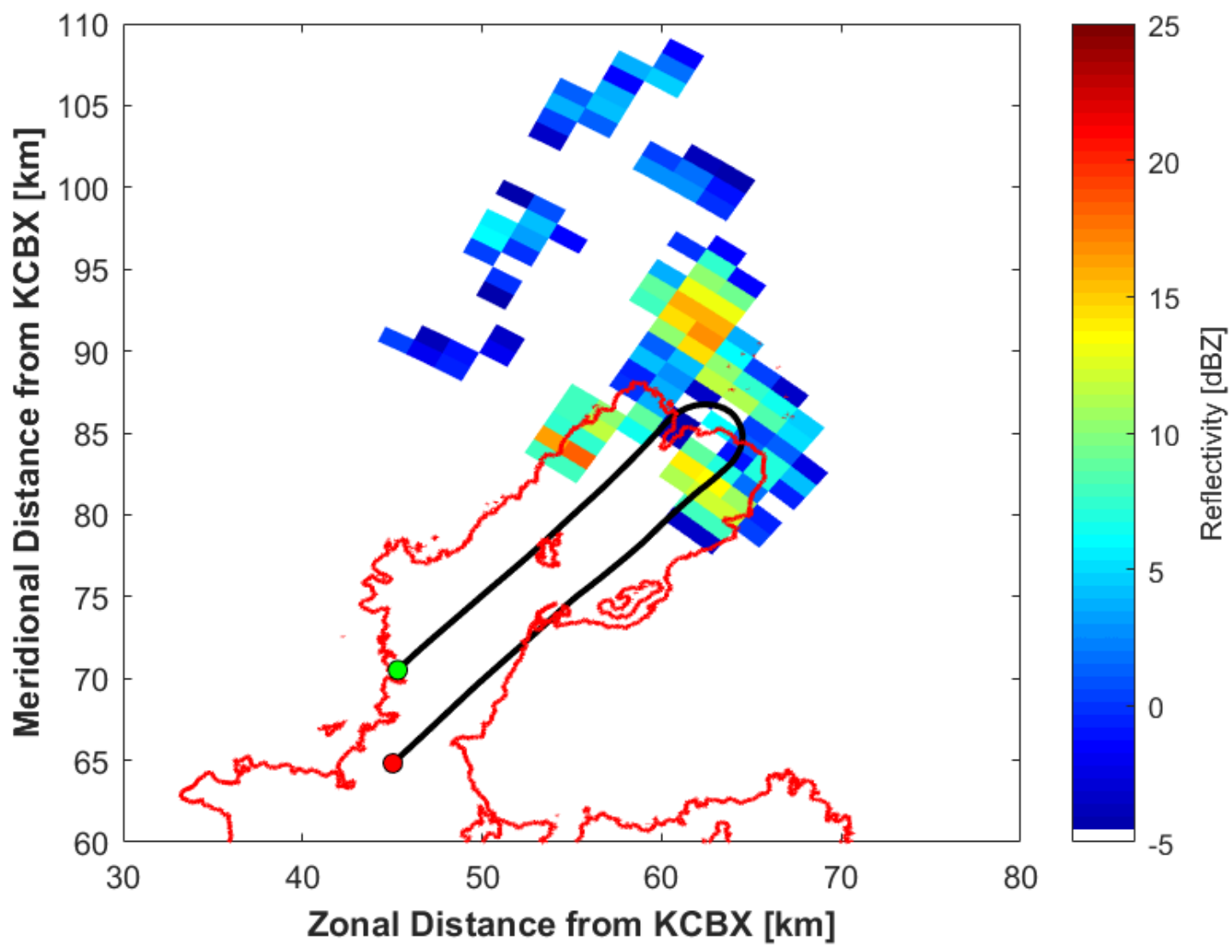

Fig. 7. KCBX (NEXRAD) 3.4-degree tilt reflectivities at 23:48Z on 29 August 2016 and flight track for legs 3 and 4. Fire perimeter shown in red. Start (end) of flight track represented by green (red) dot.

Subsequent flight legs were conducted at a higher altitude, approximately $7.7 \mathrm{~km}$ MSL. Although none of these flights legs intercepted the larger pyroCu for an extended period, the UWKA did clip the pyroCu between flight legs while turning. Despite the WCR data being unreliable during the turn, the in-situ flight-level data remain valid. Fig. 7 shows the $\mathrm{KCBX}$ radar data at a $3.4^{\circ}$ tilt angle, and the flight track corresponding to legs 3 and 4, including the turning section between both legs, where the aircraft penetrated the larger plume. 
For context, Fig. 8 shows the timeseries plots of various flight-level parameters corresponding to the flight track shown in Fig. 7, with the section between the two black dotted lines depicting the period during which the UWKA was actively turning. A weak updraft of 5-6 $\mathrm{m} \mathrm{s}^{-1}$ can be observed during the plume penetration, together with an associated negative temperature perturbation of approximately $1.5^{\circ} \mathrm{C}$. This negative temperature perturbation within the plume contrasts significantly with the positive temperatures perturbation found during the lower-altitude penetration, and implies an area of negative buoyancy or convective overshoot, with the plume unable to rise much higher than flight level.
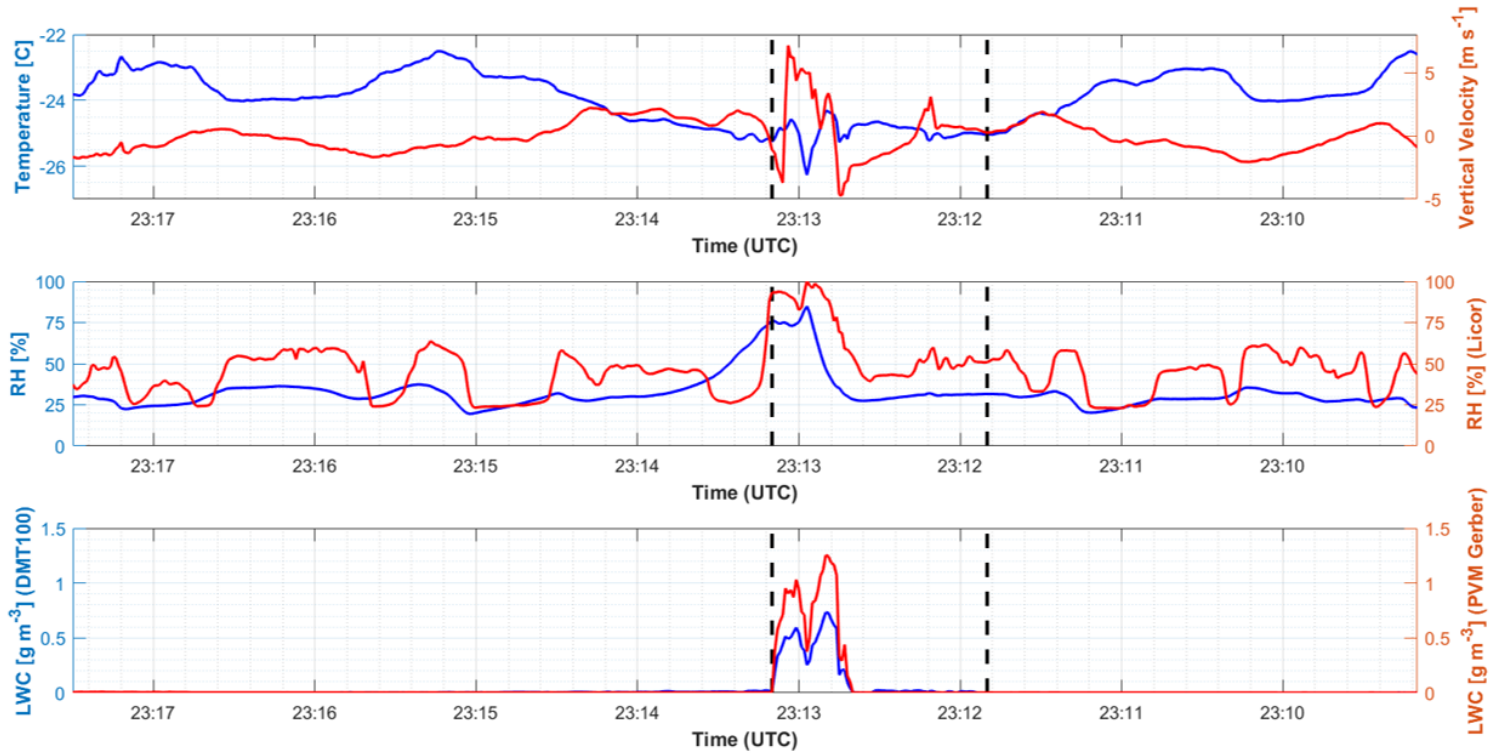

Fig. 8. Flight-level data for the period between and including legs 3 and 4, corresponding to a brief high-altitude plume penetration. 
The timeseries also shows the RH as measured by the Licor 7000 peaking at 100\% roughly coinciding with the maximum updraft and in-plume temperature perturbation. Though brief, the $100 \% \mathrm{RH}$ reading suggests that the plume was indeed saturated at flight level, confirming that the condensation level is below $7.7 \mathrm{~km}$ MSL (and likely well below). In fact, the LWC was far from negligible at this altitude, registering peak values in excess of $1.2 \mathrm{~g} \mathrm{~m}^{-3}$ within the plume.

With this information in mind, let us now take a look at the vertical cross-sections of the Cross-wind (CW) and Along-wind (AW) legs. Figs. 9-11 show the vertical crosssection of three separate CW legs (legs 9,10 and 13). All of these legs were oriented along a NW-SE axis, which is approximately normal to the southwesterly flow at flight level. As such, despite the near-vertical appearance of the plume in the figures, in reality the plume is tilting in the NE direction, or "into the page". Thus, the cross-sections do not depict the entirety of the plume rise. Specifically, the WCR shows plume tops of up to 8 $\mathrm{km}$ in the plain of the flight, whereas data from the KCBX radar provide estimates of plume echo tops of $\sim 11 \mathrm{~km}$ MSL further to the northeast at the time of the CW leg overpasses (Fig. 12). The flight legs cover a 13-minute timespan, from 17:41 to 17:54 PM MDT. The shallow velocity returns extending laterally and directly above the topography (shaded black) are a result of ground clutter, and are therefore not true measurements. 


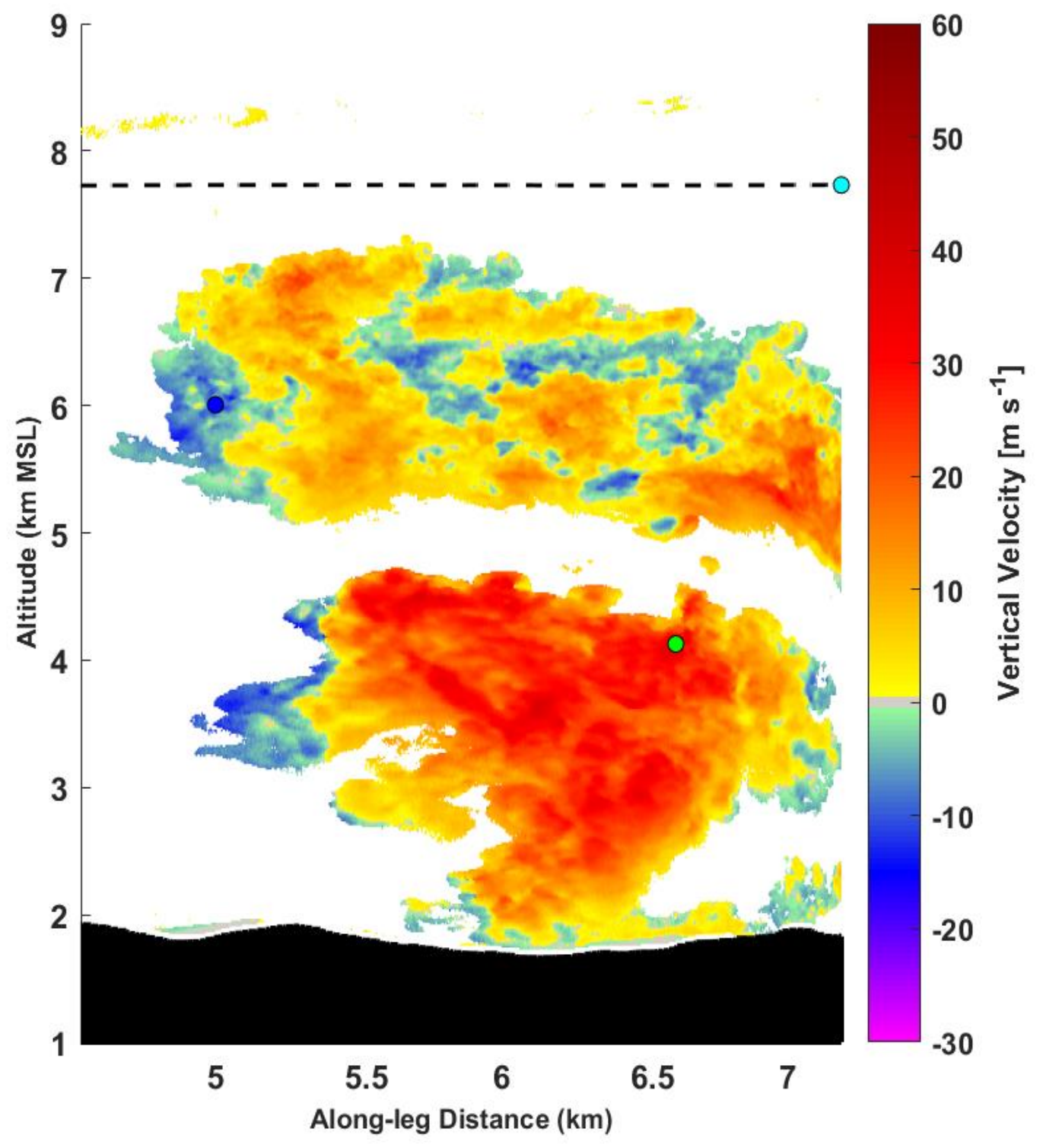

Fig. 9. Cross-sectional view of vertical velocities during cross-wind leg 9. The strongest updraft (downdraft) locations are marked by a green (blue) dot. 


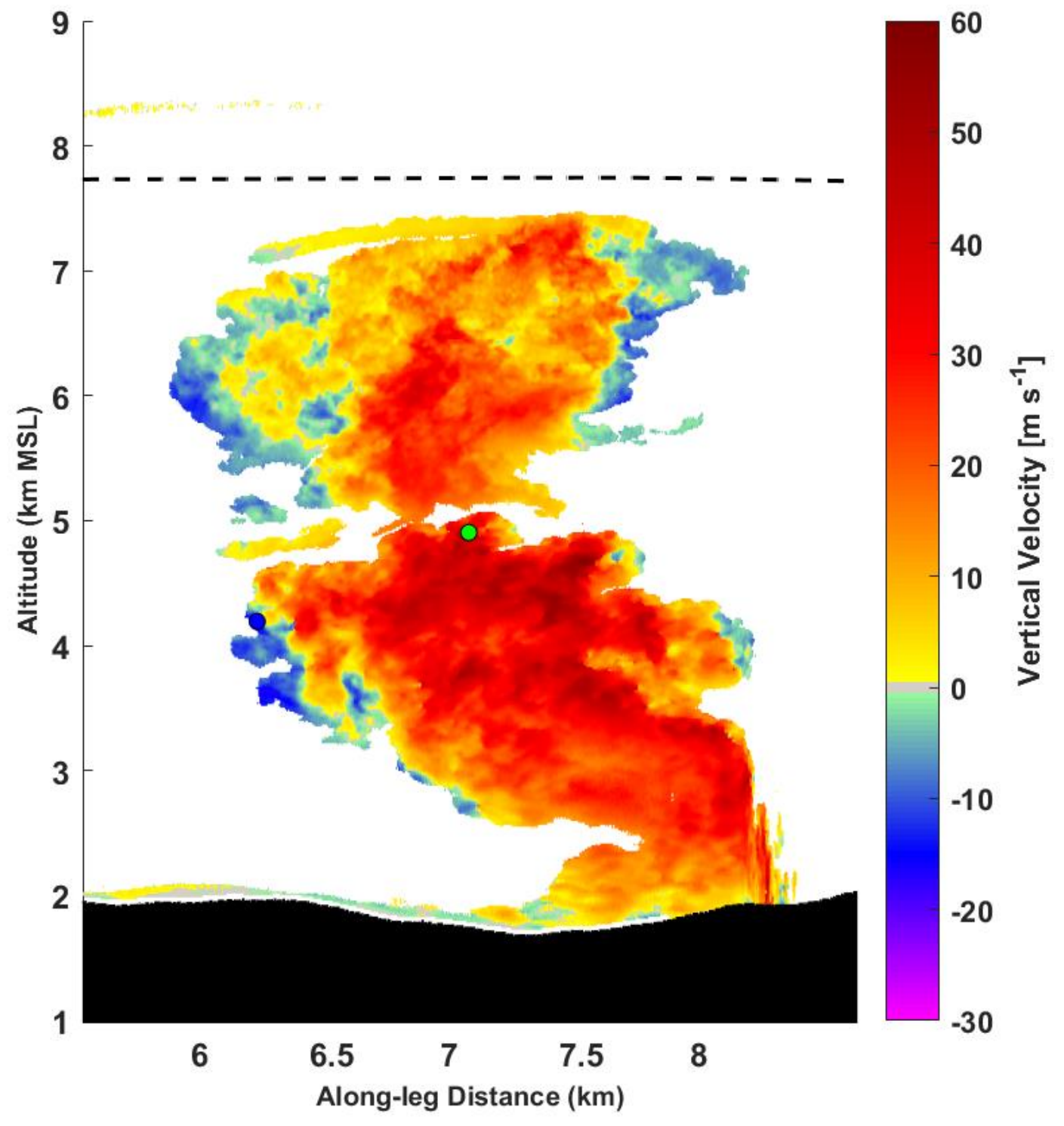

Fig. 10. Cross-sectional view of vertical velocities during cross-wind leg 10 . The strongest updraft (downdraft) locations are marked by a green (blue) dot. 


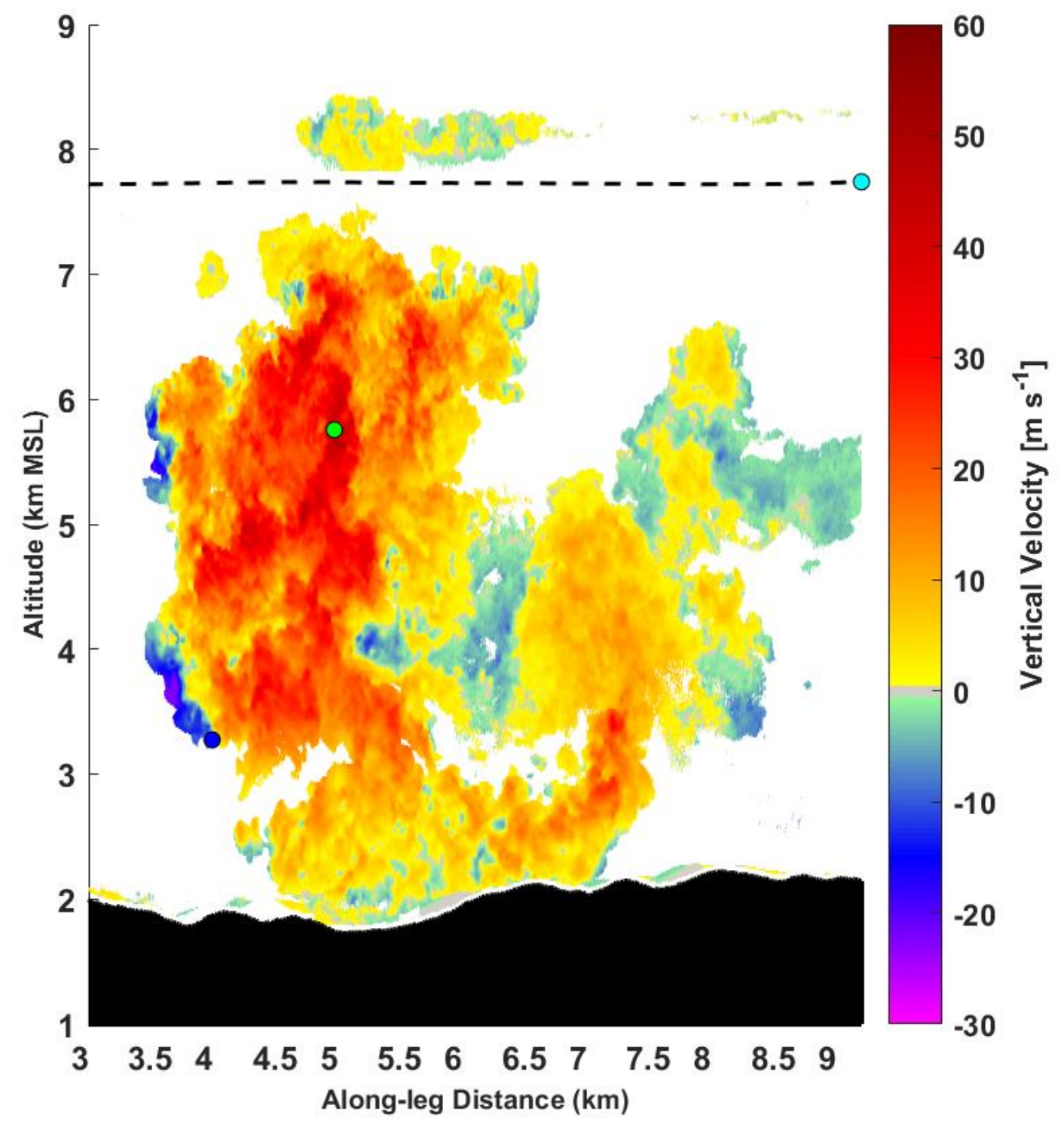

Fig. 11. Cross-sectional view of vertical velocities during cross-wind leg 13. The strongest updraft (downdraft) locations are marked by a green (blue) dot. 


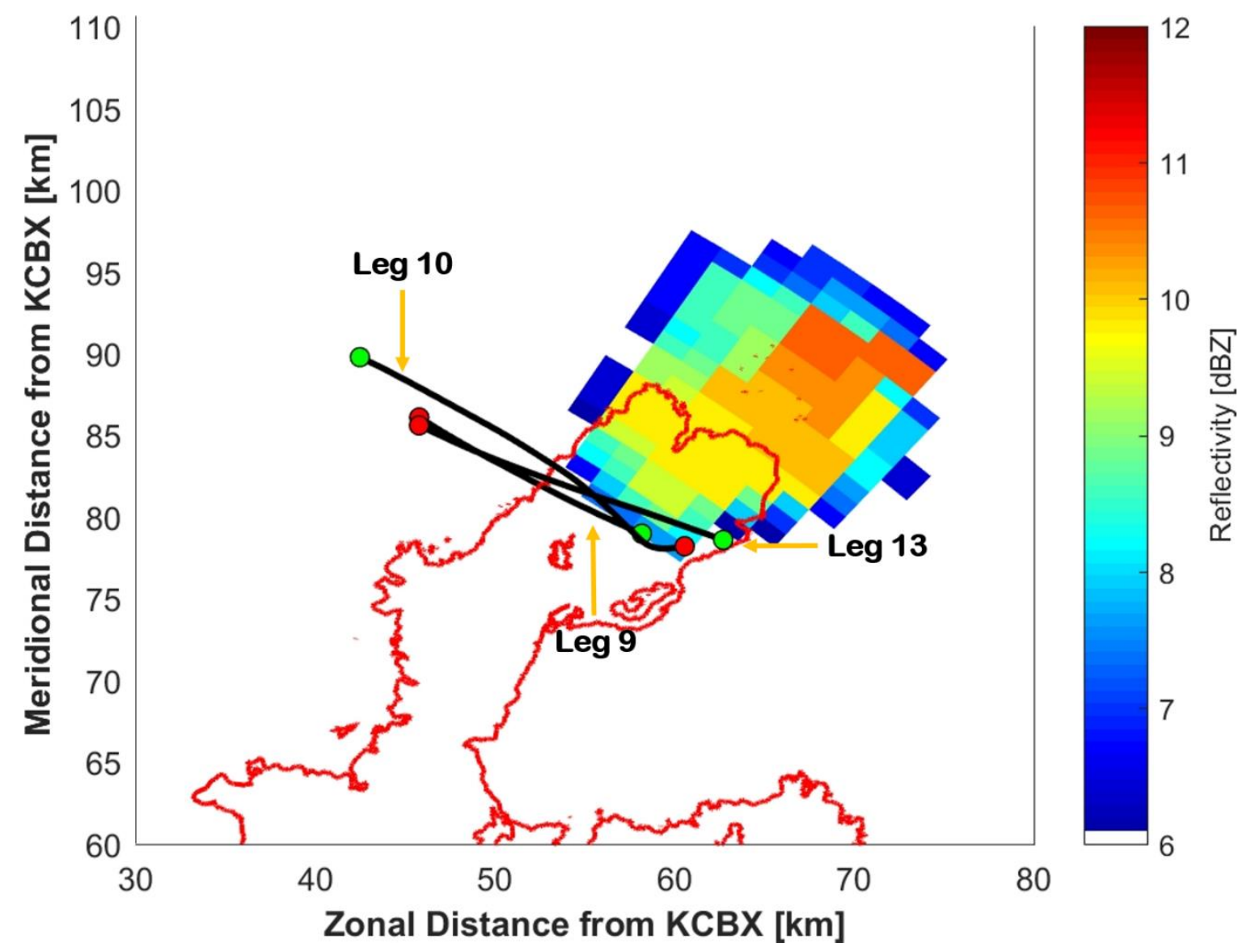

Fig. 12. NEXRAD-derived plume echo tops at the time of the cross-wind overpasses. Green (red) dots represent the origin (end) point of each leg.

The first cross-section (Fig. 9) depicts a relatively young, developing plume with a diameter of approximately $0.5 \mathrm{~km}$ nearest the surface, widening in a conical shape up to $4.5 \mathrm{~km}$. A separate convective element aloft extends from 5 to $7 \mathrm{~km} \mathrm{MSL}$. The appearance of this element aloft as independent from the developing plume beneath suggests it is likely associated with a previous convective "pulse" during a period of high-intensity burning. To a degree, the area devoid of radar returns could also be 
indicative of a horizontally-oriented vortical structure entraining ambient, particle-free air.

The developing plume exhibits a strong central updraft widening with height, flanked by counterrotating vortex rings along the edges of the plume. This plume structure is apparent in all three CW overpasses (Figs. 9-11). Similar structural features have been identified in several studies, and are linked to well-known entrainment theories (Scorer, 1957; Levine, 1959; Woodward, 1959). These ring vortices also contain the strongest downdrafts, with velocities approaching $18 \mathrm{~m} \mathrm{~s}^{-1}$. The maximum updraft during this stage in the plume development was $40.1 \mathrm{~m} \mathrm{~s}^{-1}$ at $4 \mathrm{~km}$ MSL (slightly above $2 \mathrm{~km} \mathrm{AGL).}$

The plume underwent significant vertical growth and intensification between 5:41 PM and 5:47 PM MDT. A maximum vertical velocity of $58.3 \mathrm{~m} \mathrm{~s}^{-1}$ was measured near 5 km MSL (almost $3.5 \mathrm{~km}$ AGL), being the largest vertical velocity observed during the flight campaign. This value eclipses those previously estimated both observationally (e.g. $24 \mathrm{~m} \mathrm{~s}^{-1}$ in Banta et al., 1992) and as part of numerical simulations (e.g. $\sim 35 \mathrm{~m} \mathrm{~s}^{-1}$ in simulations of pyroconvection by Trentmann et al., 2006). In fact, despite being located several kilometers above the surface, it is comparable to the highest statisticallyestimated vertical velocity maxima directly above a fire front $\left(\sim 60 \mathrm{~m} \mathrm{~s}^{-1}\right.$, Coen et al., 2004), where the strongest updraft magnitude is theoretically located. Moreover, despite its magnitude, the $58.3 \mathrm{~m} \mathrm{~s}^{-1}$ updraft was not isolated - numerous updraft cores with velocities exceeding $50 \mathrm{~m} \mathrm{~s}^{-1}$ can be observed. Further aloft (i.e., > $7 \mathrm{~km} \mathrm{MSL),} \mathrm{vertical}$ velocities in excess of $30 \mathrm{~m} \mathrm{~s}^{-1}$ were recorded, suggesting some weakening of updraft intensity with height above the surface. The ring vortices were also more vigorous than 
during the previous flight leg, with both upward and downward components of the rotation increasing in strength. In fact, the strongest downdraft recorded during the campaign occurred at this stage, reaching $-29.3 \mathrm{~m} \mathrm{~s}^{-1}$ in a ring vortex more than $2 \mathrm{~km}$ AGL.

By the third successive flight leg (Fig. 11), the near-surface thermal updrafts had decreased in intensity. However, very strong updrafts continued aloft, with a maximum vertical velocity of $48 \mathrm{~m} \mathrm{~s}^{-1}$ near $6 \mathrm{~km} \mathrm{MSL}$. Downdrafts remained strong during this weakening stage, particularly along the flanking edges of the plume, where downward vertical velocities approached $-25 \mathrm{~m} \mathrm{~s}^{-1}$. Overall, the updrafts appear less cohesive, with frequent pockets of weaker updrafts and even some downdrafts starting to become embedded within the plume core, possibly indicative of more effective entrainment and a decoupling from surface combustion.

Figs. 13-15 present the cross-sectional retrievals of reflectivity obtained during the same CW legs as in Figs. 9-11. In general, the reflectivity appears to vary as a function of height, with the highest reflectivity values (0-5 dBZ) located within $1 \mathrm{~km}$ of the surface. These high reflectivity cores are confined to relatively narrow vertically-aligned cores. Interestingly, there is no one-to-one correspondence between the location of vertical velocity maxima and reflectivity maxima (compare, for example, Figs. 10 and 14). The qualitative reflectivity characteristics of the plume suggest entrainment mechanisms 
played an important role in the dilution of the plume with height, whereas the vertical velocities appeared to be less affected by vortex-induced lateral entrainment.

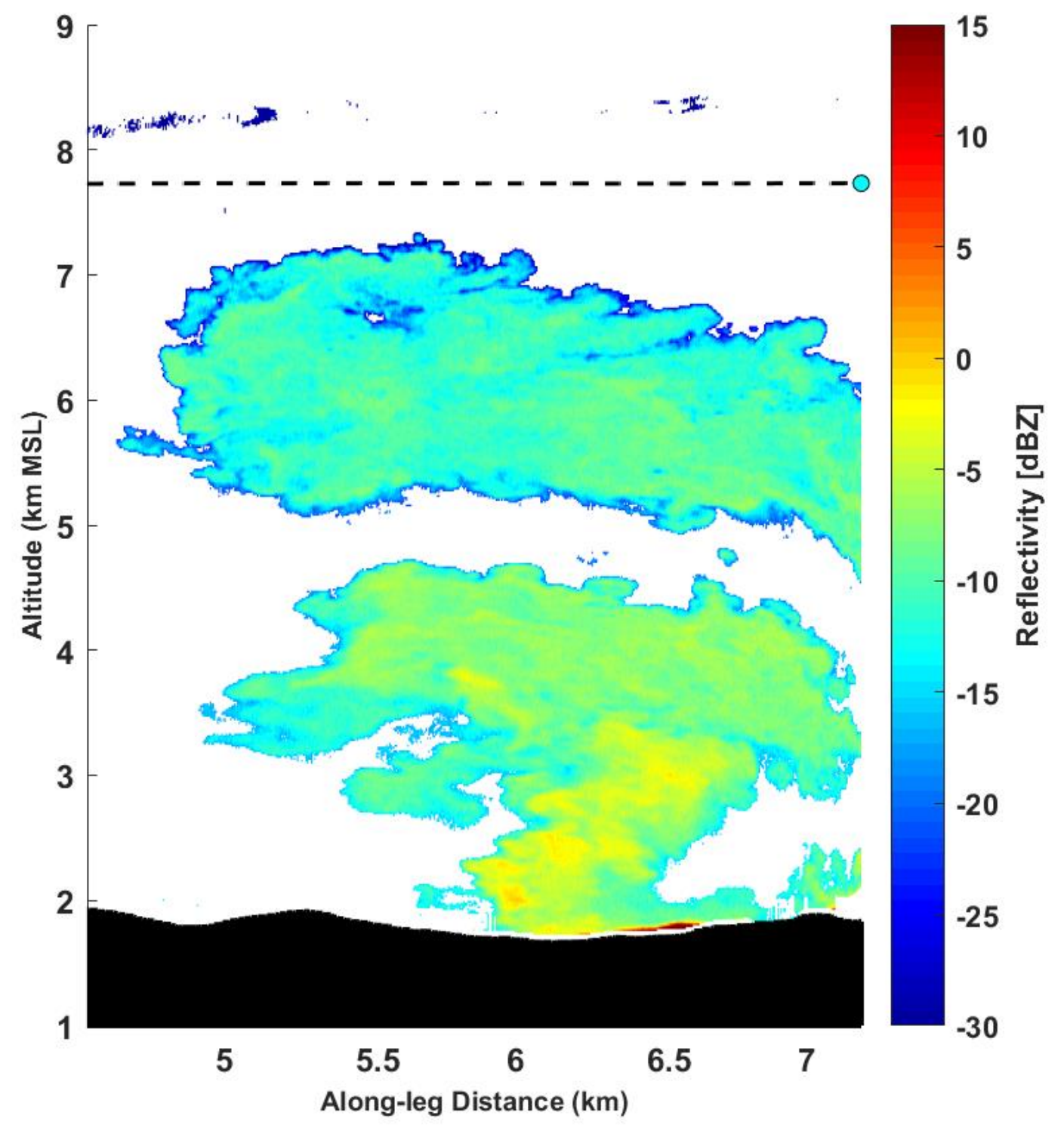

Fig. 13. Cross-sectional view of reflectivity returns during cross-wind leg 9. 


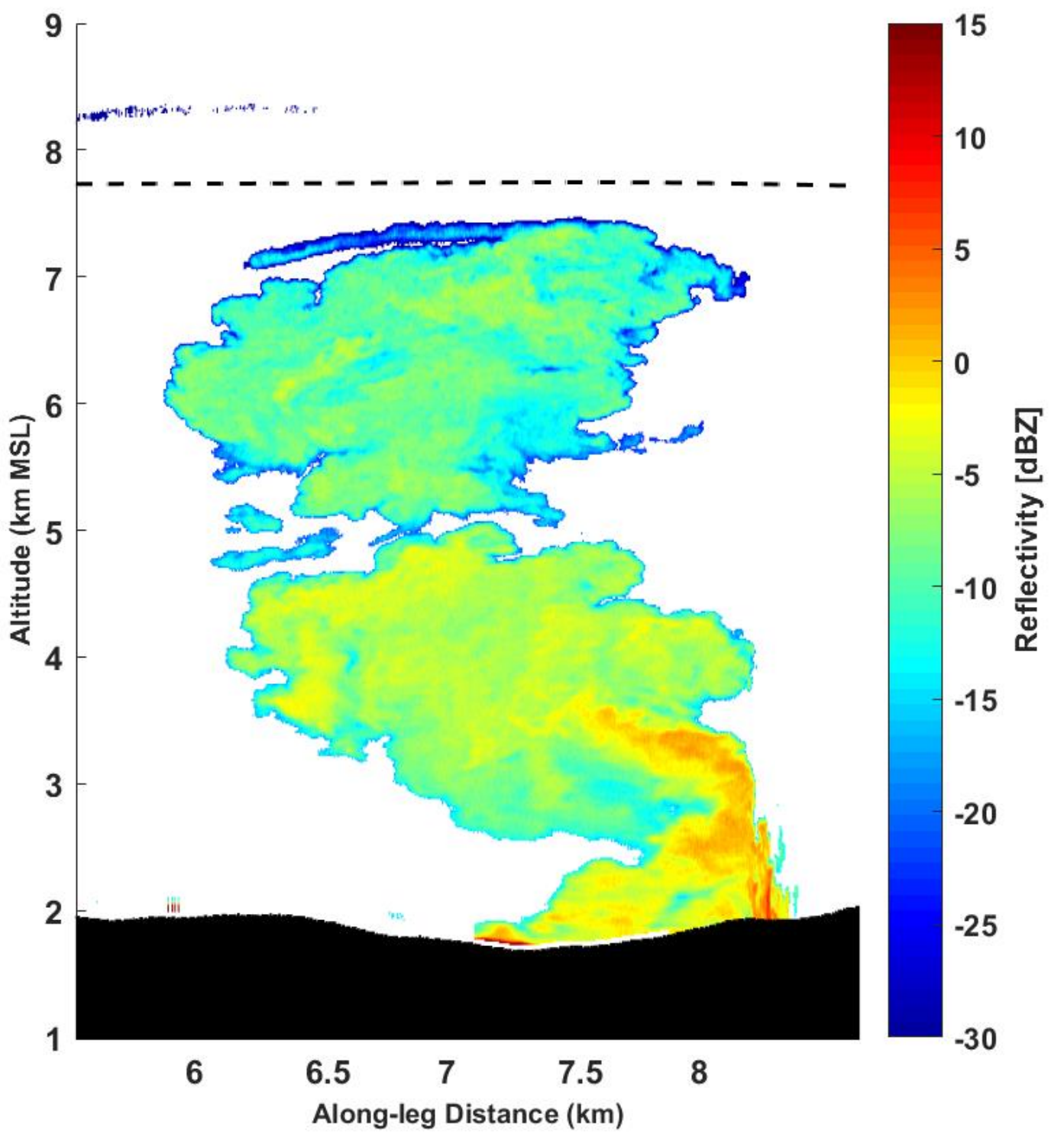

Fig. 14. Cross-sectional view of reflectivity returns during cross-wind leg 10. 


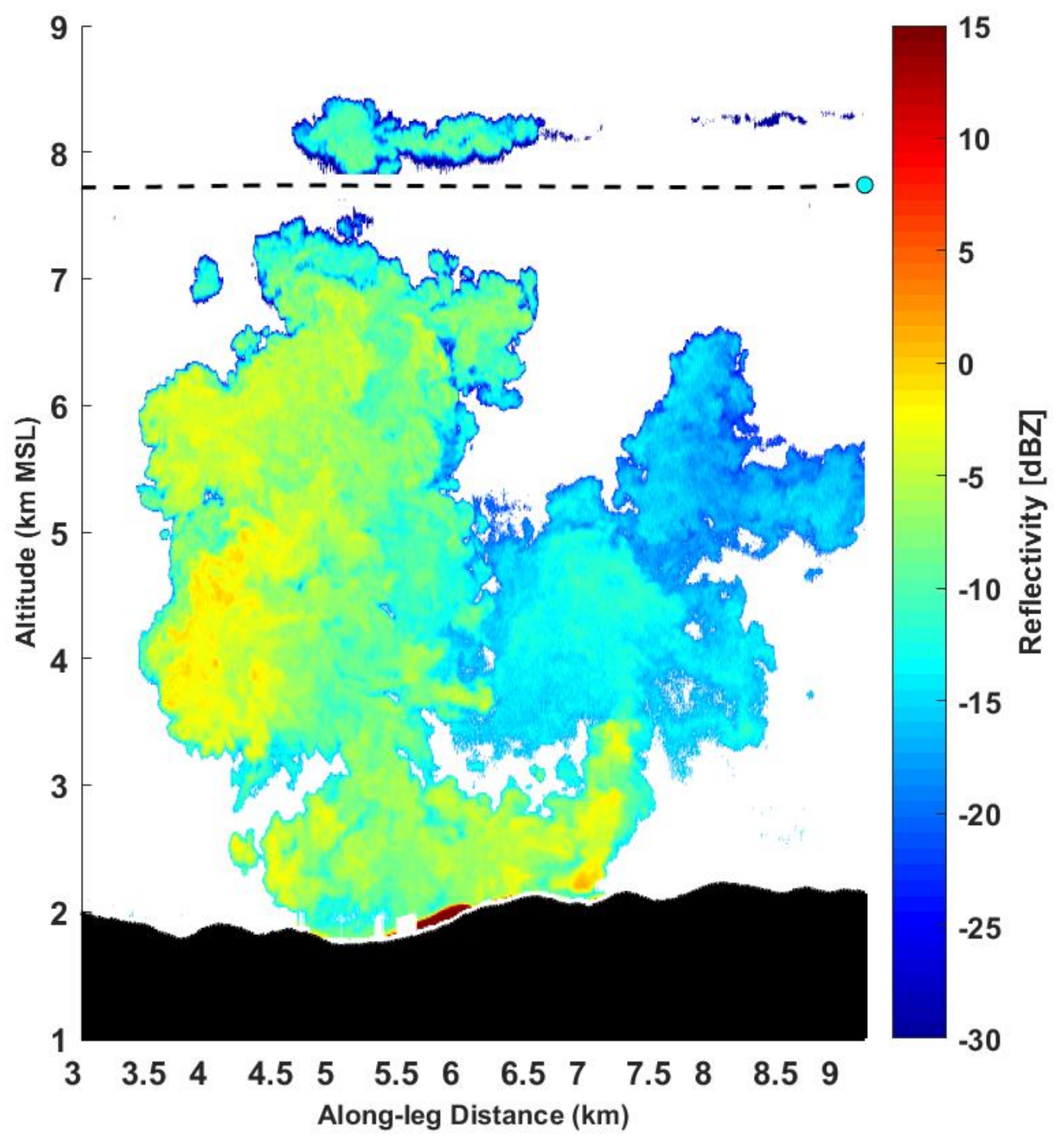

Fig. 15. Cross-sectional view of reflectivity returns during cross-wind leg 13. 


\subsection{Cross-Wind Statistics}

To gain a better quantitative perspective of the vertical distribution of velocities and reflectivity, vertical profiles of the statistical range of observed values were constructed for an aggregate of legs. Fig. 16 displays these statistics for the aggregate of the four CW legs which directly sampled the larger plume (i.e. the data in Figs. 9-11, and 13-14). The vertical velocity and reflectivity values used in these analyses were interpolated to a common height grid.

A quasi-linear increase in mean vertical velocity (solid black line, Fig. 16a) is observed from the surface to $3.2 \mathrm{~km} \mathrm{MSL}$, where a local maxima in the mean updraft magnitude is found. Above this height, the mean vertical velocity remains approximately uniform up to $6.2 \mathrm{~km} \mathrm{MSL}$, with a small decrease thereafter. The strongest downdrafts, located between 3.5 and $4 \mathrm{~km}$ MSL, acted to limit the magnitude of the mean vertical velocity. Both the $90^{\text {th }}$ percentiles and maximum upward velocities show a consistent linear increase from the surface to approximately $5 \mathrm{~km}$ MSL, where the peak updrafts approaching $60 \mathrm{~m} \mathrm{~s}^{-1}$ were located. 

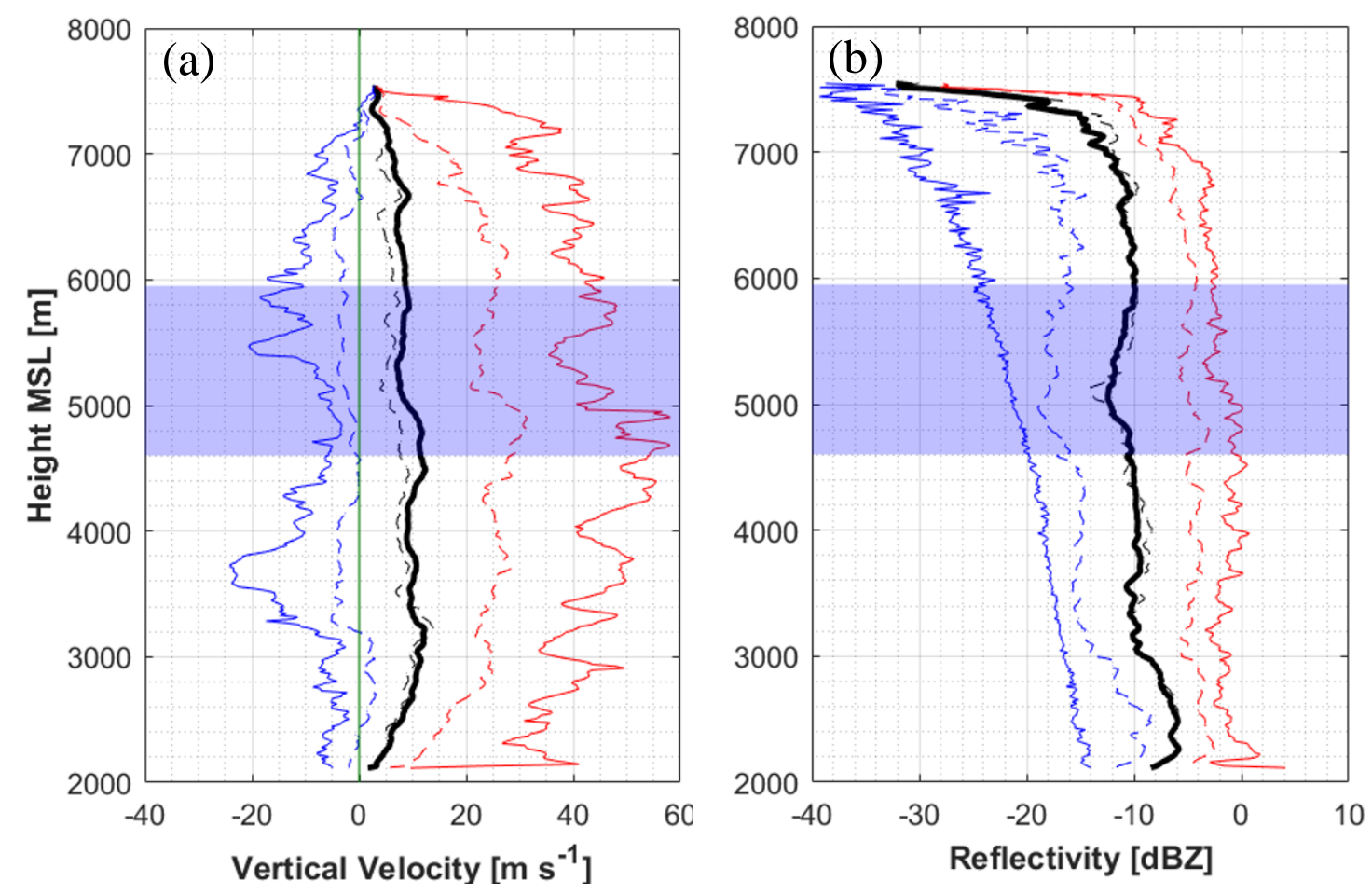

Fig. 16. Profile of (a) vertical velocity statistics and (b) reflectivity statistics for the aggregate of cross-wind legs.

Neither the mean vertical velocity nor the maximum vertical velocity profiles show a decrease in magnitude with height above the surface and below the condensation level. This conflicts with the results of a number of modeling studies on the dynamics of pyrconvective plumes. Freitas et al. (2007), for example, showed a rapid decrease in updraft velocity with height between the surface and LCL, and Trentmann et al. (2006) similarly modeled the strongest updrafts as being located directly above the fire (within $500 \mathrm{~m}$ of the surface), with a decrease below the LCL. However, Banta et al. (1992) estimated a radar-derived peak updraft of $25 \mathrm{~m} \mathrm{~s}^{-1}$ approximately $2 \mathrm{~km}$ AGL, well above the fire, although the height of the condensation level was not immediately clear from the study. 
A second interesting feature in the vertical profile of vertical velocity statistics is the absence of a secondary local maxima in vertical velocity above the CCL, estimated to lie at approximately $6 \mathrm{~km}$ MSL. Maximum updraft strength decreased inconsistently above 6 $\mathrm{km}$ MSL, although both the $90^{\text {th }}$ percentile and mean velocity profiles remain generally homogeneous with height for another $500-700 \mathrm{~m}$, before decreasing as the total number of data points at the higher altitudes is reduced and the plume approaches neutral buoyancy. Thus, the question of why a secondary peak in updraft strength above the condensation level, despite such signatures appearing in numerical simulations, is not observed in this scenario must be given some considerations.

It is unlikely that the CCL experienced significant variations between the first pyroCu penetration (LWC $\sim 1.2 \mathrm{~g} \mathrm{~m}^{-3}$ ) and the time the CW legs were performed (a difference of $40-45$ minutes). With an approximate CCL of $\sim 6 \mathrm{~km}$ and a flight level of $7,700 \mathrm{~m}$, it is estimated that the $1.7 \mathrm{~km}$ of plume growth (immediately below the aircraft) contains condensed water within an actively developing pyroCu.

It is instructive to compare these observations with the simulations in Trentmann et al. (2006). In that study, radiosonde observations used to initialize the numerical simulations depicted a conditionally unstable environment with southwest winds aloft (similar to the present case). However, the atmosphere above $700 \mathrm{mb}$ was closer to saturation in their simulations, and the overall environment more conducive to convective activity. Indeed, widespread thunderstorms were located in the vicinity of the Chisholm fire which the simulations were based on. In contrast, the environmental conditions aloft during the Pioneer fire flight campaign were substantially drier. The thermodynamic 
profile from the Chisholm fire indicates the environment was conducive for significant buoyancy-driven updraft enhancements through a large depth above the CCL. This contribution to the effects of latent heat release doesn't appear to be as likely in the case of the Pioneer fire, which could be one factor for the absence of a secondary updraft peak aloft. Other factors could also have influenced the buoyancy of a rising plume parcel above the condensation level, such as pressure gradient forces induced by local variations in temperature or density within the plume. Additionally, weight from particle loading could serve as a supplementary force acting on a rising parcel. Ultimately, the necessary factors for a rising parcel to become positively buoyant may not have aligned during the Pioneer fire - the possibility of neutral of even negatively buoyant conditions aloft should be considered as a possible explanation for the homogeneity in the vertical velocity as a function of height.

A second important consideration regarding the lack of a secondary peak in vertical velocity aloft relates to the aircraft position relative to the overall plume structure during the CW legs. None of the cross-sectional WCR plots show radar returns above $8.5 \mathrm{~km}$ MSL despite radar-derived echo tops near $11 \mathrm{~km} \mathrm{MSL}$ at the time of the overpasses. This implies the plume was still exhibiting a tilting structure at this height despite being pyroconvective in nature. Therefore, the possibility exists that returns nearest the aircraft (both above and below) were not representative of the sloping plume "center" where the strongest cores of vertical velocity would most likely be found.

With the above in mind, the WCR observations should not necessarily imply that a secondary peak in updraft strength was not present - it may have simply not been 
observed. Even if such a feature were in fact absent from the Pioneer Fire plume, the observations collected do not indicate an inconsistency with previous modeling studies of pyroconvection, as the environmental conditions in place at the time of the flight campaign were not supportive of widespread moist convection. These observations do, however, suggest that previously observed or simulated peak vertical velocities in pyroconvective environments likely underestimated the strength of fire induced updrafts above the level of condensation. The vertical velocities near $60 \mathrm{~m} \mathrm{~s}^{-1}$ were observed below the CCL, at an altitude where latent heat due to condensation could not be a factor, but above $3 \mathrm{~km}$ AGL where limited fire-induced buoyancy due to sensible heat release, and the increased effects of entrainment of ambient air should act to reduce updraft strength. As such, it would be fair to assume that pyroconvection could quite easily achieve vertical velocities aloft in excess of $60 \mathrm{~m} \mathrm{~s}^{-1}$ under favorable moist and unstable atmospheric conditions.

The reflectivity profiles for the CW legs (Figs. 13-15) show a near-surface maximum in reflectivity, with the mean reflectivity approaching $-5 \mathrm{dBZ}$. The reflectivity $(10 \%$, mean, and 90\%) decreases with height up to $3 \mathrm{~km} \mathrm{MSL} \mathrm{(see} \mathrm{Fig.} \mathrm{13),} \mathrm{is} \mathrm{approximately}$ constant with height (in the mean) up to $7 \mathrm{~km} \mathrm{MSL}$, and then decreases with height again further aloft. The reflectivity peak near the surface is consistent with larger ash, other debris and undiluted smoke immediately above the combustion source. Given the large updraft magnitudes and associated lateral shear, it is likely that entrainment processes were the primary driver behind the subsequent decline in reflectivity values with height. Particle fallout may have played a secondary role here, however, in contrast to the 
reflectivity data, the vertical velocity data lack a signature indicative of particle fallout (decrease in vertical velocity with height). The approximately homogeneous profiles between 3 and $7 \mathrm{~km}$ indicate comparatively little dilution of the plume with height, and therefore reduced entrainment effects in the upper portion of the plume. In this regard, plume width could play a role in limiting entrainment effects on the plume core. The width of the plume exceeds $1.5 \mathrm{~km}$ over a significant depth. In fact at times, a core of vertical velocities generally greater than $35 \mathrm{~m} \mathrm{~s}^{-1}$ extends more than $1 \mathrm{~km}$ horizontally (for example, Fig. 10). It bears questioning whether such a wide structure of enhanced velocities may act to reduce the penetrative potential of ambient air into the plume (and thereby diluting plume quantities), thus promoting the maintenance of the high velocity updrafts near the plume core. In terms of the reflectivity, the consistent linear decrease in the minimum radar reflectivity is likely an artifact of the increasing sensitivity of the WCR at shorter distances from the instrument, and thus not representative of the actual profile.

\subsection{Along-Wind Statistics}

The majority of the flight legs were oriented in an along-wind (AW) direction. A small subset of these legs is shown in Figs. 17-19 in the form of vertical velocity crosssections. Appendix A shows the remainder of the flight legs, including the reflectivity values. The cross-sectional views reveal a different dynamical structure to the $\mathrm{CW}$ legs. First, the plume tops are lower, suggesting fire intensity and buoyancy fluxes are weaker along the fire flank than in the head fire that produced the deeper plumes sampled during the CW legs. To be specific, the vertical development of these smaller plumes only 
continued to heights of 5-6 km MSL, with the plume then tilting horizontally and advecting in the mean southwesterly wind. The peak vertical velocities are also lower than in the CW legs, with maximum velocities of $\sim 25 \mathrm{~m} \mathrm{~s}^{-1}$, consistent with the expected lower sensible heat release and resultant positive buoyancy.

Regarding the interpretation of the AW plots, it is important to note that the observed velocity and reflectivity returns may not necessarily correspond to a single fire source due to the nature of flanking fire edges - there were likely multiple heat sources at the surface each generating individual smoke plumes. The "mean Y" values on the figures are intended to aid this process by reflecting each leg's displacement along the ydirection relative to the mean orientation of all AW legs combined. This nuance aside, the overall interpretation of any given AW leg remains the same, with the prevailing southwesterly wind and low fire intensity resulting in a highly tilted plume, mostly absent of ring vortices along the plume edges, and with a mean plume detrainment level of approximately $5.5 \mathrm{~km}$ MSL with widespread downdrafts aloft indicative of the plume approaching neutral buoyancy. 


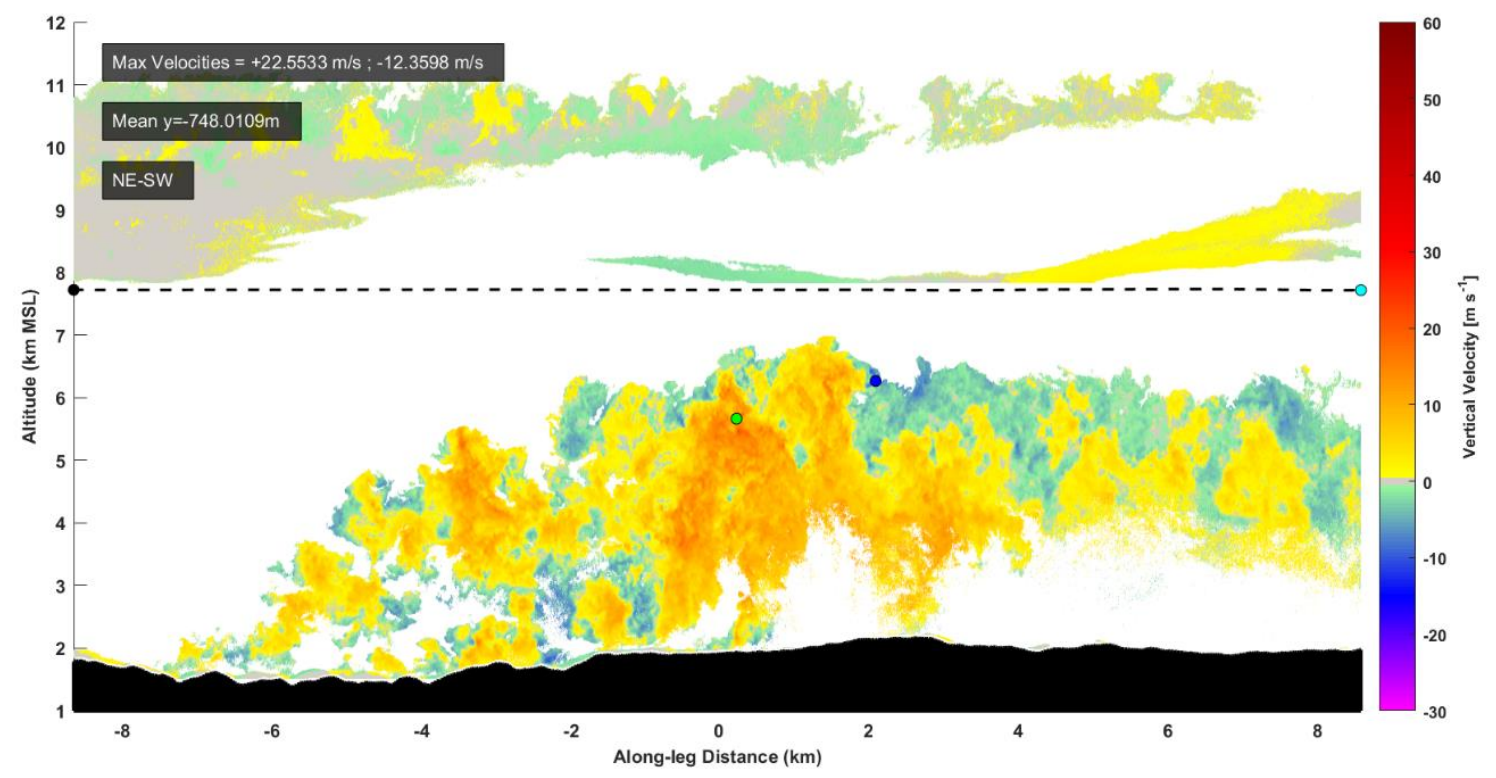

Fig. 17. Cross-sectional view of vertical velocity during along-wind leg 16 . The strongest updraft (downdraft) locations are marked by a green (blue) dot. 


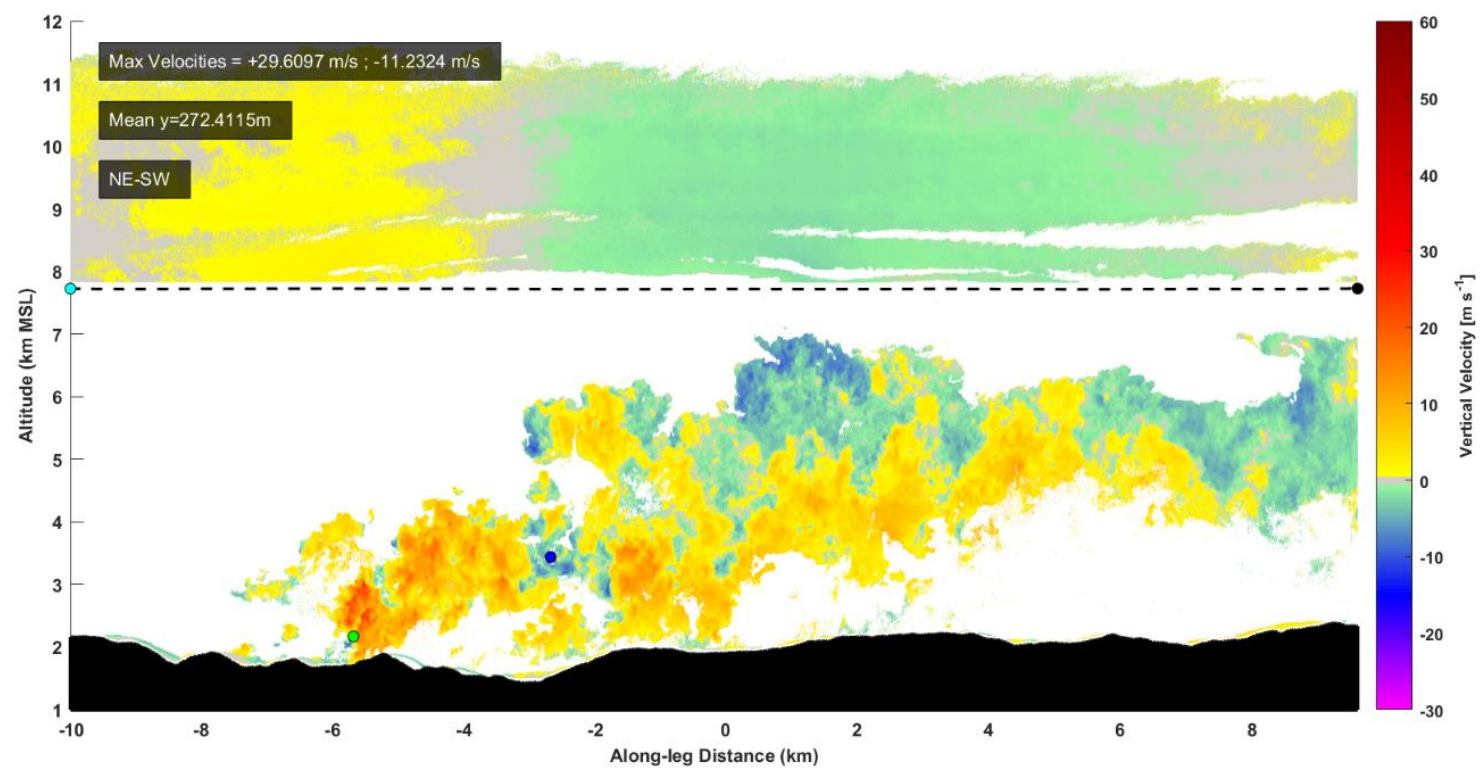

Fig. 18. Cross-sectional view of vertical velocity during along-wind leg 21. The strongest updraft (downdraft) locations are marked by a green (blue) dot.

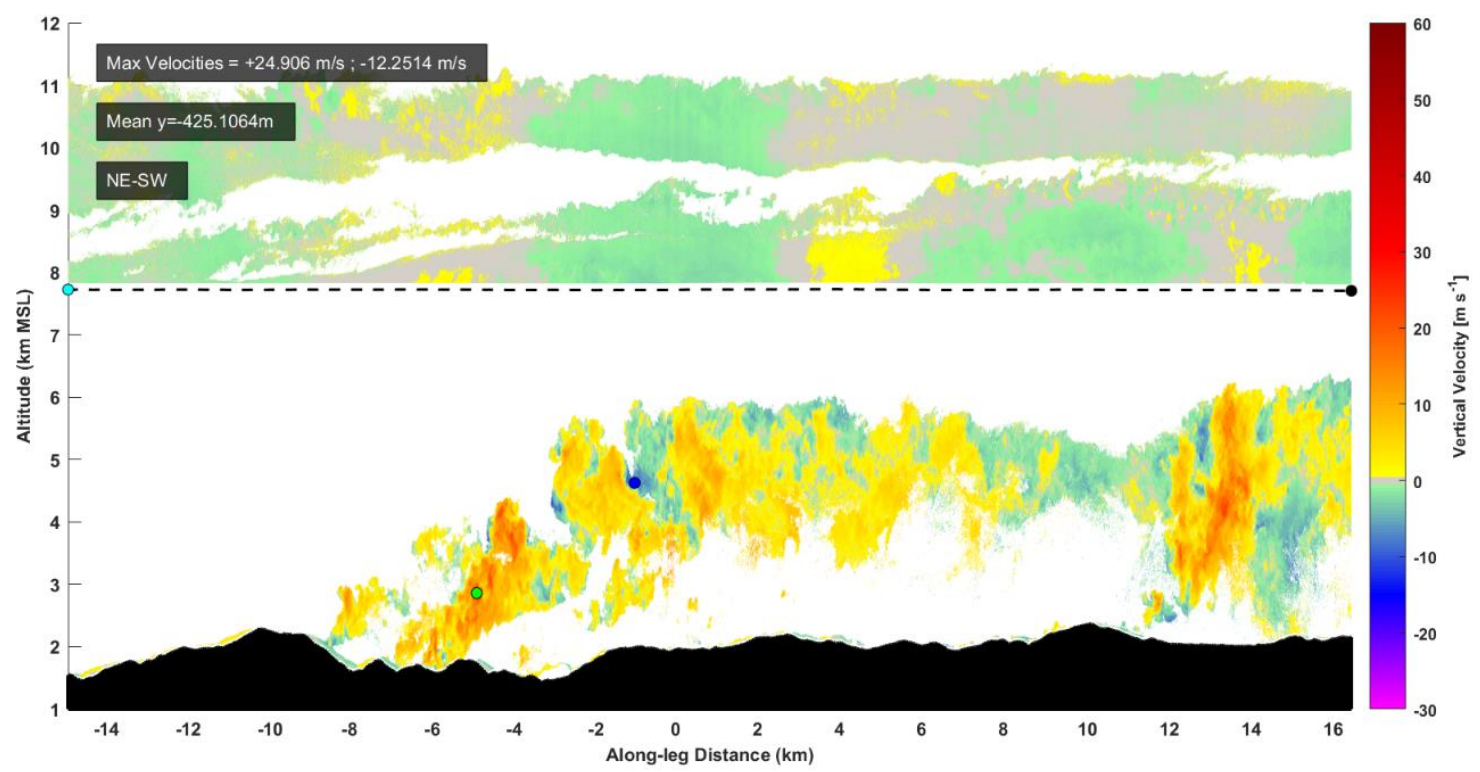

Fig. 19. Cross-sectional view of vertical velocity during along-wind leg 25 . The strongest updraft (downdraft) locations are marked by a green (blue) dot. 
As was done with the $\mathrm{CW}$ legs, vertical profiles of statistical parameters were computed and are shown in Fig. 20-22 for both vertical velocity and reflectivity data. As outlined in the methodology section, the AW data were subdivided into three groups according to horizontal displacement from the manually-identified combustion source. Fig. 20 provides a comparison of the smaller plumes from the flanking fire with the deeper plume from the head fire, by limiting the data to those points lying within $4 \mathrm{~km}$ either side of the plume source, and thus representing the most upright portion of the plume.
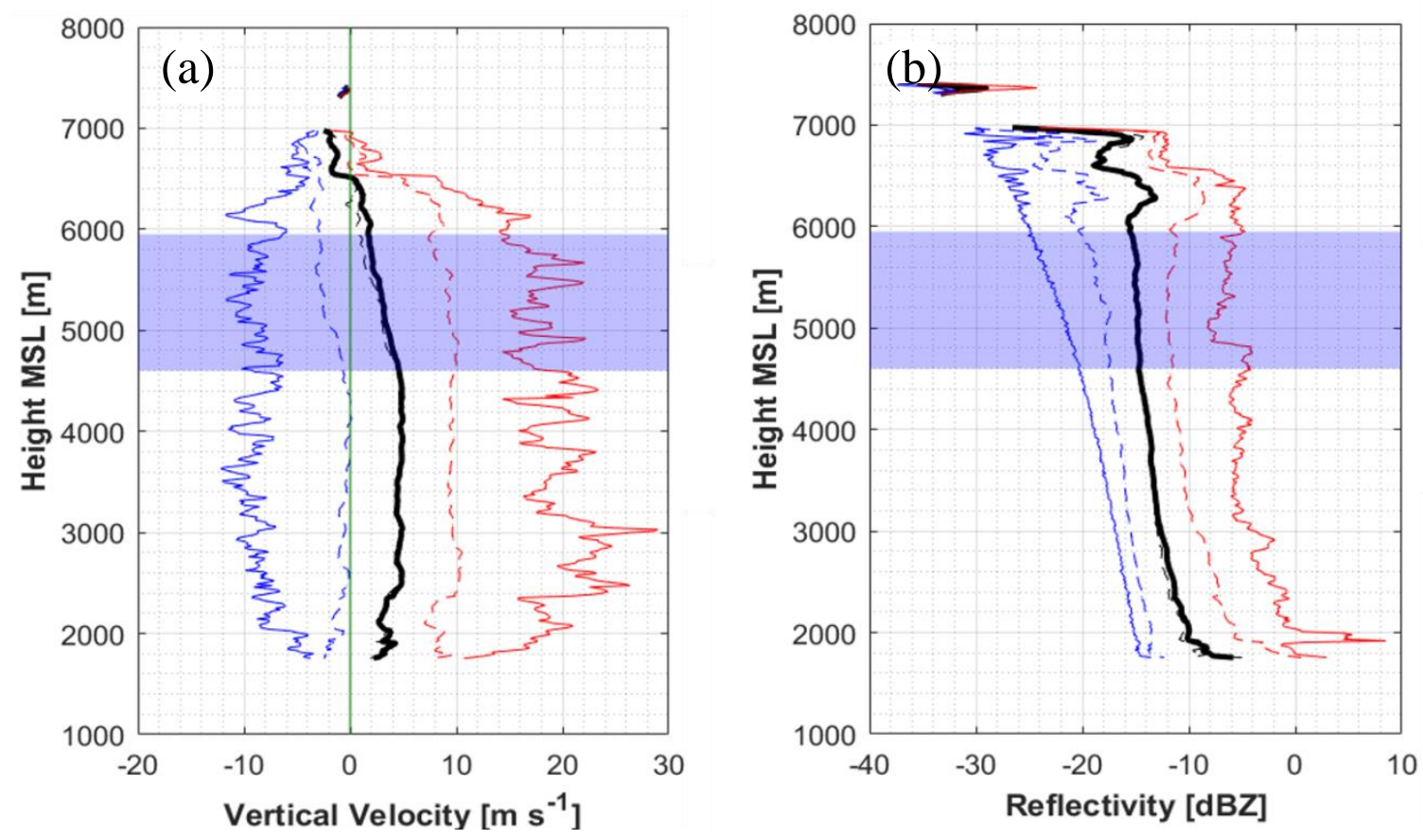

Fig. 20. Profile of (a) vertical velocity statistics and (b) reflectivity statistics for areas within 4 $\mathrm{km}$ either side of the defined plume source for the aggregate of along-wind legs. 

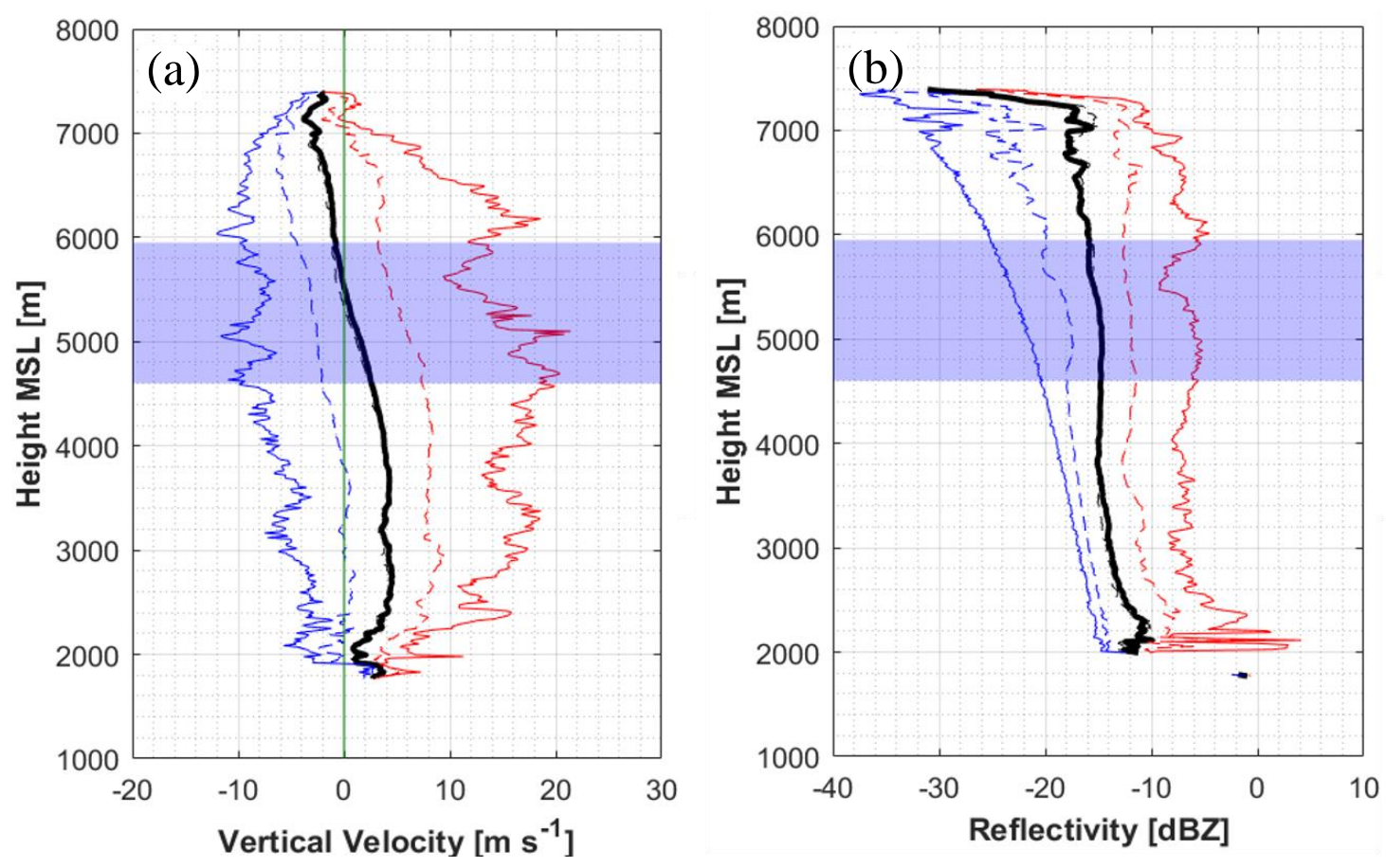

Fig. 21. Profile of (a) vertical velocity statistics and (b) reflectivity statistics for areas within 4$8 \mathrm{~km}$ either side of the defined plume source for the aggregate of along-wind legs.
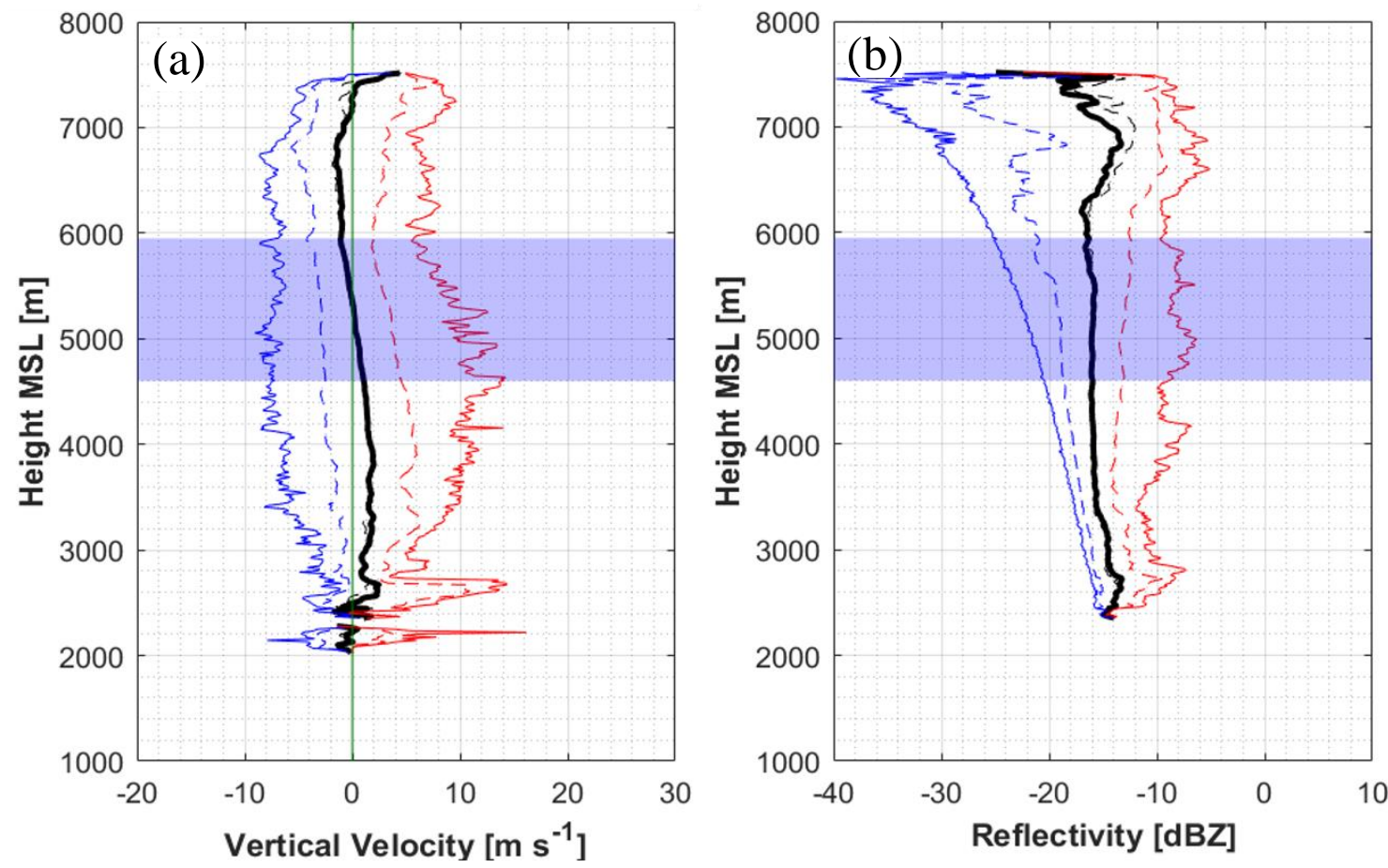

Fig. 22. Profile of (a) vertical velocity statistics and (b) reflectivity statistics for areas within 8-12 $\mathrm{km}$ either side of the defined plume source for the aggregate of along-wind legs. 
These observations shared some similarities with the CW legs, most notably the mean vertical velocity profile remaining positive for almost the entirety of the plumes height. Moreover, no secondary peak in vertical velocity is observed, as was the case with the CW legs. However, the two cases also exhibit numerous differing characteristics. For instance, despite a similar near-surface increase in velocity with height, the peak updrafts were observed at significantly lower heights (3 km MSL versus $5 \mathrm{~km}$ MSL with similar underlying terrain height). Second, the AW legs show homogeneity with height in the $10^{\text {th }}$ and $90^{\text {th }}$ percentiles, as well as the mean vertical velocity, through approximately 5 km MSL (Fig. 20). Although the CW legs also exhibited a relatively uniform mean vertical velocity profile, there was significantly more variability in the strongest updrafts $\left(90^{\text {th }}\right.$ percentile and peak values), consistent with the more turbulent nature of the plume. An additional important difference is the observed linear decay in updraft magnitude above $5 \mathrm{~km}$ MSL for the AW legs, which contrasts with the CW legs profile, which exhibited constant vertical velocity with height between 3 and $7 \mathrm{~km}$. Further, for the AW plumes, the mean vertical velocity profile becomes negative for the highest $500 \mathrm{~m}$, suggesting convective overshoot above the equilibrium level.

A reduction in the spread of vertical velocities (particularly in the minimum, maximum, and mead values) with horizontal distance from the plume source is apparent in Figs. 21-22. Moreover, the homogeneity in the mean velocity that is characteristic of the upright plume sections is lost as the plume aloft becomes decoupled from the surface fire and is advected by the mean wind - both of the latter profiles exhibit a mostly linear decrease in vertical velocities that beings nearer the surface with distance from the fire. It 
should also be noted that the total number of data points at levels under $3.5 \mathrm{~km}$ MSL drops off significantly (Fig. 23), thereby making the profile data below this level somewhat less meaningful than that above $3.5 \mathrm{~km}$.

The reflectivity profiles for the AW legs also show interesting features. The most upright portion of the plume (Fig. 20b) exhibits an exponential decay in reflectivity with height directly above the surface. This differs from the $\mathrm{CW}$ legs where reflectivity linearly decreases with height, and only after near-constant reflectivity with height in the first $500 \mathrm{~m}$ AGL. This enhanced dilution of the plume's reflectivity characteristics in the AW legs could be an additional indication that a wide $(\sim 1 \mathrm{~km})$ core of strong upward vertical velocities (as observed during the $\mathrm{CW}$ legs) may act to limit entrainment, relative to less cohesive and vigorous plume scenarios (i.e. AW legs). As such, one hypothesis would be that entrainment processes more effective in penetrating the AW plumes, contributing to plume dilution near the surface. Aside from this key distinction between the pyroCb and smaller plume, there do not appear to be any significant differences in the reflectivity profiles between the two. As a whole, the observed reflectivities remain very uniform with height, particularly at the mean detrainment level ( 5,000 m MSL, see Fig. 23). A brief signature of increased mean reflectivity values is present aloft in the AW legs, however potential causal factors are not immediately clear. Once again, the 
minimum reflectivity profile appears to decrease consistently with height, but is assumed to relate to the radar sensitivity.
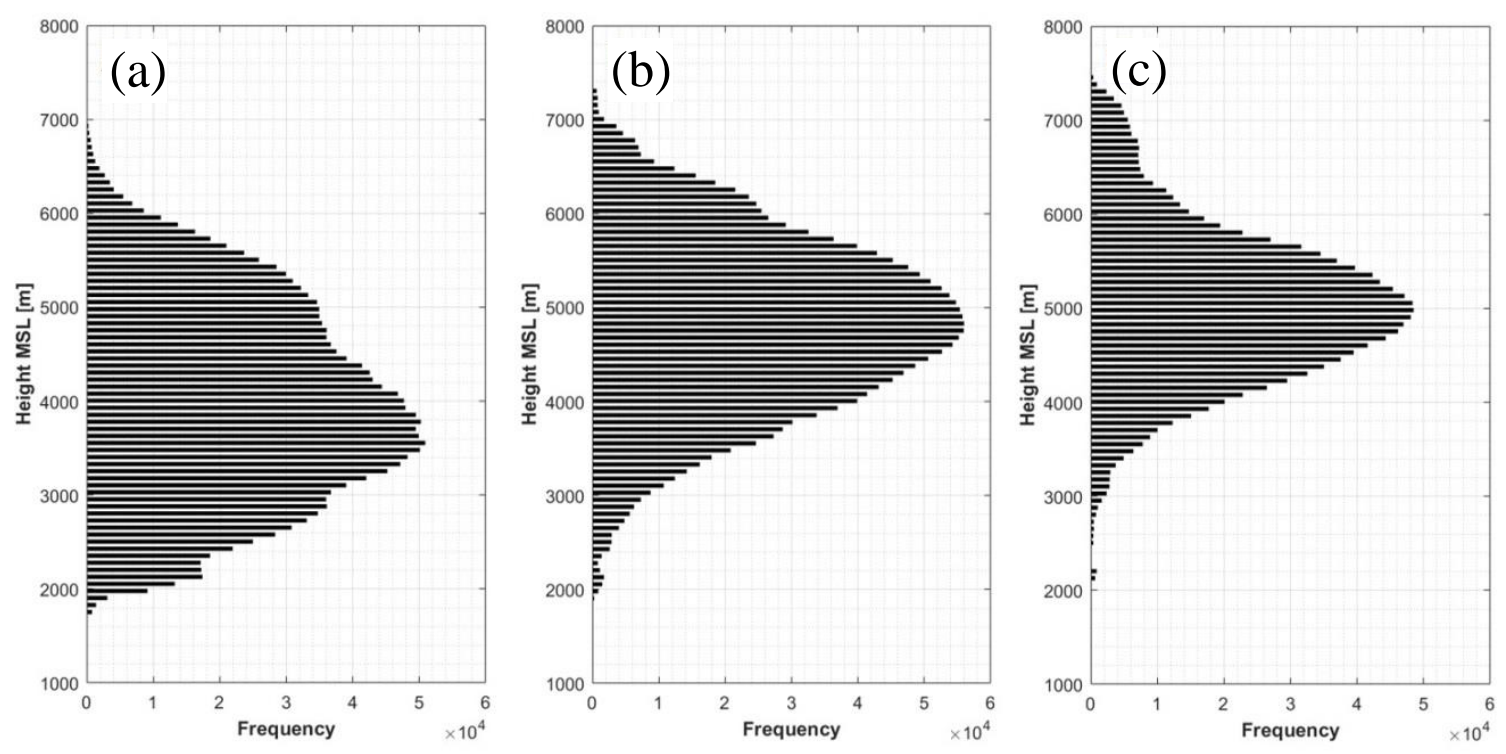

Fig. 23. Vertical frequency distributions of number of data points by altitude for the three horizontal groupings identified for the along-wind legs - (a) represents 0-4 km, (b) represents 4-8 $\mathrm{km}$, and (c) represents 8-12 km.

\subsection{Frequency Distributions}

Finally, additional context is provided in the form of frequency distributions for both velocity and reflectivity at three distinct levels for each plume (Figs. 24-25) - lower plume $(3,000 \mathrm{~m})$, mid-plume $(\sim 5,000 \mathrm{~m})$ and upper plume $(\sim 7,000 \mathrm{~m})$. These frequencies were normalized by the total data points at each vertical level, such that the frequency distributions are displayed in terms of density. 

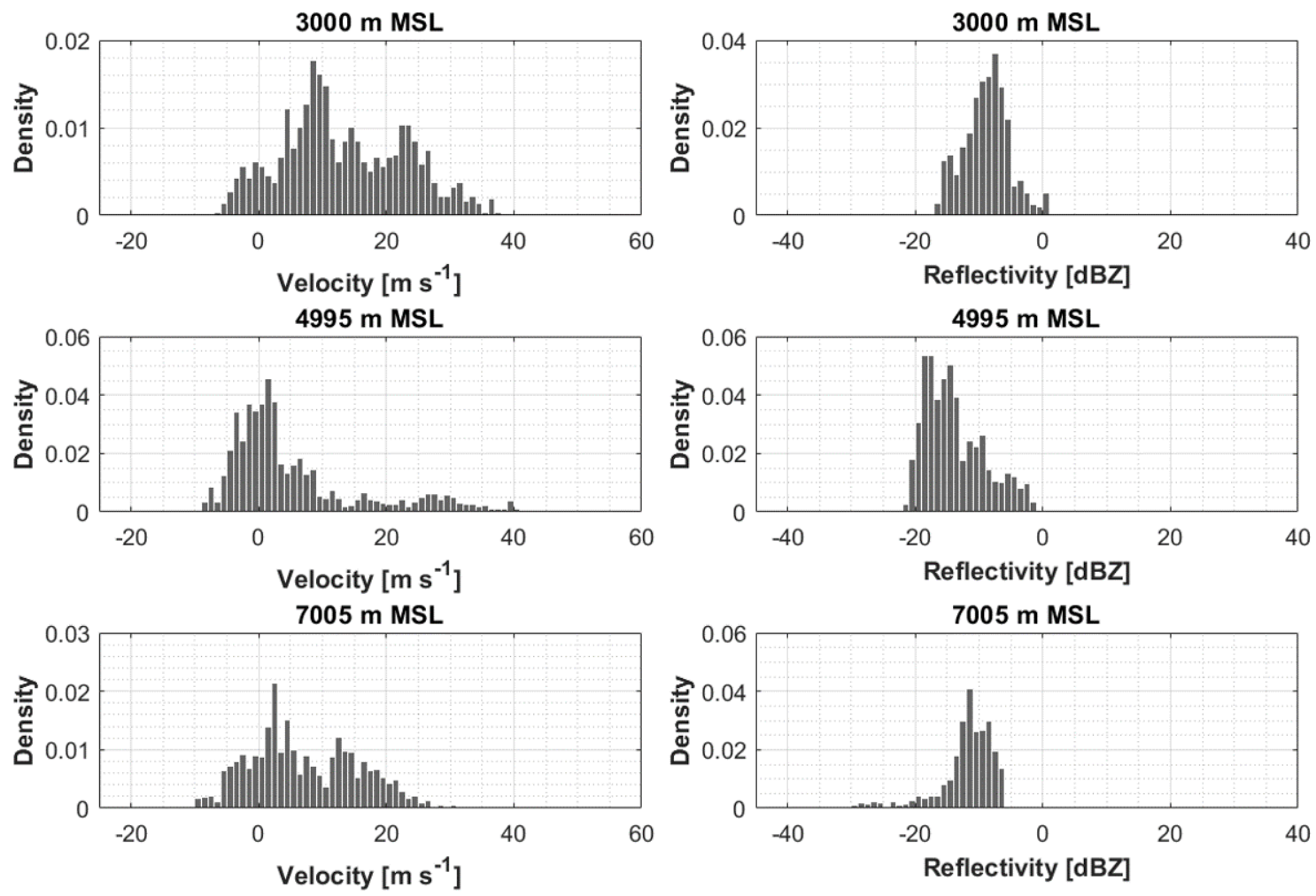

Fig. 24. Frequency distributions of vertical velocity and reflectivity for lower, middle, and upper portions of the plume sampled in a cross-wind direction. 

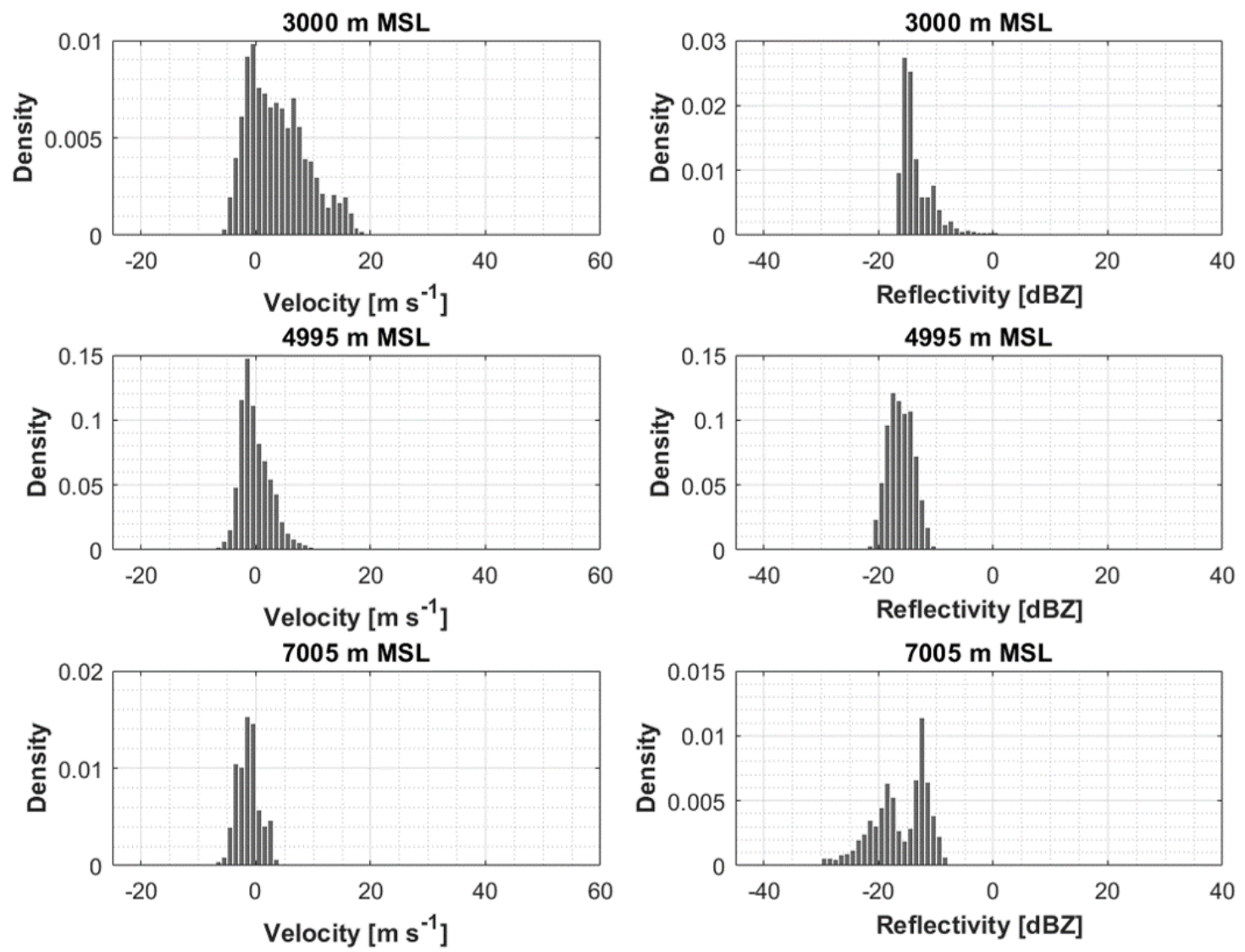

Fig. 25. Frequency distributions of vertical velocity and reflectivity for lower, middle, and upper portions of the plume sampled in an along-wind direction.

One difference between the AW and CW legs is that the latter exhibit broader distributions in vertical velocity at all levels. Although sample size (significantly more legs were sampled AW versus CW) may be a factor, the broader distributions are likely linked to the fire intensity and plume dimensions that led to the observed extreme vertical velocities. This difference is most apparent at $3 \mathrm{~km}$ MSL where the AW legs exhibit a mode near $0 \mathrm{~m} \mathrm{~s}^{-1}$, whereas the $\mathrm{CW}$ legs have a mode of $\sim 10 \mathrm{~m} \mathrm{~s}^{-1}$. for the $\mathrm{CW}$ legs). Interestingly, the modal velocities are closely aligned in the case of the mid- and upperlevels of the plumes, but differ in skewness, with an extended tail of strong positive vertical velocities for CW legs. The AW distributions are less skewed and more 
Gaussian, with less noticeable tails and a general lack of bimodal characteristics, with the exception of the upper-level reflectivity distribution. 


\section{Summary and Conclusions}

This study presents the first direct measurements of the kinematic structure within a deep pyroconvective plume, collected using an airborne Doppler radar platform. The objective of this experimental mission was twofold: to evaluate the capability of such a mobile platform as it applies to observational sampling within a turbulent pyroconvective environment, and to develop a better understanding of the kinematic processes and dynamical mechanisms at play in wildfire plumes. Vertical velocity measurements within the entire depth of a pyroconvective plume had never before been collected, with plumerise model simulations providing the majority of updraft magnitude estimates to date. The cross-sectional profiles of vertical velocity and reflectivity data obtained using the radars' dual-beam configuration resolved numerous structural features in great detail, such as

flanking edge ring vortices. Further quantitative analyses revealed a number of interesting characteristics of the vertical velocity data, some of which appear to conflict with results of previous studies.

Two separate plumes were sampled by the University of Wyoming King Air (UWKA) - a smaller plume along the fires' flanking edge reaching approximately 6-7 $\mathrm{km}$ MSL, and a large plume originating from the main fire front, which extended up to 11 km MSL per NEXRAD-derived echo tops. The latter was shown to be moist pyroconvective in nature, with liquid water content of $\sim 1.2 \mathrm{~g} \mathrm{~m}^{-3}$ and relative humidity peaking at $100 \%$ during a brief penetration at $7.7 \mathrm{~km}$. With a condensation level estimated near $6 \mathrm{~km}$ based on upper-air and surface thermodynamic observations, the $\sim 1.5 \mathrm{~km}$ deep portion of the plume directly below the UWKA was deemed to be 
pyroconvective. This larger plume, which was sampled in a cross-wind (CW) direction, yielded several interesting observations, including:

- Vigorous updrafts throughout the depth of the plume, peaking at $58.3 \mathrm{~m} \mathrm{~s}^{-1}$. This is the highest vertical velocity ever observed in a wildfire plume, and is unprecedented at such heights above the surface (over $3 \mathrm{~km}$ AGL).

- Strong downdrafts peaking at $-29.3 \mathrm{~m} \mathrm{~s}^{-1}$, concentrated mostly in vortex ring formations along the flanking edges of the plume.

- An increase in the vertical velocity between the surface and the condensation level, which is in disagreement with previous studies suggesting a decrease with height should be observed.

- The absence of a secondary peak in vertical velocity above the level of condensation. This also appears inconsistent with previous studies, in which it is hypothesized that latent heat release due to condensation should result in an increase in vertical velocity aloft.

- Mostly homogeneous mean values of vertical velocity as a function of height.

A number of possible explanations for the lack of a secondary peak in vertical velocity aloft were proposed. The mechanisms required to maximize positive buoyancy generation above the condensation level may have simply not been in place, such as a more favorable environmental thermodynamic profile. Localized temperature and density variations may have generated pressure gradient forces opposing buoyancy, keeping rising parcels above the condensation level neutrally or even negatively buoyant. In 
addition, the sampling location of the UWKA relative to the tilted plume may have contributed to an underestimation of vertical velocities in the 500-1,000 m directly below the aircraft. In summary, the absence of a secondary local maxima in vertical velocities aloft during the Pioneer Fire should not imply that it cannot occur under more favorable scenarios.

Equally as interesting is the fact that vertical velocity was found to increase with height above the surface, with updraft magnitude peaking slightly below the condensation level. This is also inconsistent with observational campaigns and numerical simulations alike, which have consistently suggested a significant decrease if updraft intensity should occur as a function of height above the surface. The large plume width, coupled with strong vertical velocities extending up to $1.5 \mathrm{~km}$ horizontally at times, was hypothesized as a possible factor in reducing the entrainment of ambient air, particularly above the 1 km AGL level. In essence, it is possible that the updraft core was isolated from lateral entrainment processes near the plume edges, preventing vertical velocities from decreasing. The homogeneity of the reflectivity data as a function of height (with the exception of the region nearest the surface) appears to support this idea. However, more information and analysis would be required in order to conclude this with some confidence.

Considering all of the above, it would be reasonable to assume that the observed vertical velocities during this exploratory campaign do not represent the potential peak velocities under situations in which all velocity-enhancing mechanisms align. Thus, it 
would not be surprising if under certain cases of intense pyroconvection, vertical velocities could exceed $60 \mathrm{~m} \mathrm{~s}^{-1}$.

The airborne Doppler radar platform performed well despite the vigorous and highly turbulent nature of the Pioneer Fire plumes, providing a detailed, high-resolution view of the kinematic structure of a deep pyroconvective plume, with the ability to resolve smallscale features well. This exploratory campaign has demonstrated the usefulness and applicability of this type of mobile platform in the study of pyroconvective dynamics. Despite some experimental limitations such as sample size, the observations obtained have helped contextualize previous studies dealing with plume kinematics, and have yielded several unique kinematic characteristics. Ultimately, the findings presented in this study could serve as a reference for both current and future studies of pyroconvection. It is clear that many processes remain poorly understood as they relate to pyrogenesis, and additional research and discussion (from both an observational and modeling standpoint) is necessary to further our comprehension of these. Considering the implications of pyroconvection across many scales, from micro-scale near-surface processes to regional climatic influences, it is vital that we strive to better resolve the key dynamical processes governing this phenomena commonly associated with extreme fire behavior. 


\section{References}

Andreae, M. O., D. Rosenfeld, P. Artaxo, A. A. Costa, G. P. Frank, K. M. Longo, and M. A. F. Silva-Dias, 2004: Smoking rain clouds over the Amazon. Science, 303, 1337-1342.

Banta, R. M., L. D. Olivier, E. T. Holloway, R. A. Kropfli, B. W. Bartram, R. E. Cupp, and M. J. Post, 1992: Smoke-column observations from two forest fires using doppler lidar and doppler radar. J. Appl. Meteor. Climatol., 31, 1328-1349.

Barbero, R., J. T. Abatzoglou, N. K. Larkin, C. A. Kolden, and B. Stocks, 2015: Climate change presents increases potential for large fires in the contiguous United States. Int. J. Wildland Fire, 24, 892-899, http://dx.doi.org/10.1071/WF15083.

Bargen, D. W. and R. C. Brown, 1980: Interactive radar velocity unfolding. Preprints, $19^{\text {th }}$ Conf. on Radar Meteor., Miami Beach, FL, Amer. Meteor. Soc., 278-283.

Charland, A. M. and C. B. Clements, 2013: Kinematic structure of a wildland fire plume observed by Doppler lidar. J. Geophys. Res., 118, 3200-3212, doi:10.1002/jgrd.50308.

Clark, T. L., M. A. Jenkins, J. Coen, and D. Packham, 1996: A coupled fire-atmosphere model: convective feedback on fire-line dynamics. J. Appl. Meteor. Climatol., 35, 875-901, https://doi.org/10.1175/15200450(1996)035<0875:ACAMCF>2.0.CO;2.

Clark, T. L., L. Radke, J. Coen, and D. Middleton, 1999: Analysis of small-scale convective dynamics in a crown fire using infrared video camera imagery. $J$. Appl. Meteor. Climatol., 38, 1401-1420, https://doi.org/10.1175/15200450(1999)038<1401:AOSSCD>2.0.CO;2.

Clements, C. B., and Coauthors, 2007: Observing the dynamics of wildland grass fires: FireFlux - A field validation experiment. Bull. Amer. Meteor. Soc., 88, 13691382, https://doi.org/10.1175/BAMS-88-9-1369.

Clements, C. B., N. P. Lareau, D. E. Kingsmill, C. L. Bowers, C. P. Camacho, R. Bagley, and B. Davis, 2018: RaDFIRE - The Rapid Deployments to Wildfires Experiment: observations from the fire zone. Bull. Amer. Meteor. Soc., https://doi.org/10.1175/BAMS-D-17-0230.1.

Coen, J., S. Mahalingam, J. Daily, 2004: Infrared imagery of crown-fire dynamics during FROSTFIRE. J. Appl. Meteor. Climatol., 43, 1241-1259, https://doi.org/10.1175/1520-0450(2004)043<1241:IIOCDD>2.0.CO;2. 
Dowdy, A. J., M. D. Fromm, and N. McCarthy, 2017: Pyrocumulonimbus lightning and fire ignition on Black Saturday in southeast Australia. J. Geophys. Res., 122, 7342-7354, https://doi.org/10.1002/2017JD026577.

Eilts, M. D. and S. D. Smith, 1990: Efficient dealiasing of doppler velocities using local environment constraints. J. Atmos. Oceanic Technol., 7, 118-128, https://doi.org/10.1175/1520-0426(1990)007<0118:EDODVU>2.0.CO;2.

Forthofer, J. M., and S. L. Goodrick, 2011: Review of vortices in wildland fire. J. Combustion, 2011, 14 pages, https://dx.doi.org/10.1155/2011/984363.

Freitas, S. R., and Coauthors, 2007: Including the sub-grid scale plume rise of vegetation fires in low resolution atmospheric transport models. Atmos. Chem. Phys., 7, 3385-3398, https://doi.org/10.5194/acp-7-3385-2007.

Fromm, M., A. Tupper, D. Rosenfeld, R. Servranckx, and R. McRae, 2006: Violent pyroconvective storm devastates Australia's capital and pollutes the stratosphere. Geophys. Res. Lett., 33(5), https://doi.org/10.1029/2005GL025161.

Gerber, H., B. G. Arends, and A. S. Ackerman, 1994: New microphysics sensor for aircraft use. Atmos. Res., 31(4), 235-252, https://doi.org/10.1016/01698095(94)90001-9.

Gillett, N. P., A. J. Weaver, F. W. Zwiers, and M. D. Flannigan, 2004: Detecting the effect of climate change on Canadian forest fires. Geophys. Res. Lett., 31, L18211, doi:10.1029/2004GL020876.

Gonzi, S., P. I. Palmer, R. Paugam, M. Wooster, and M. N. Deeter, 2015: Quantifying pyroconvective injection heights using observations of fire energy: sensitivity of spaceborne observations of carbon monoxide. Atmos. Chem. Phys., 15, 43394355, https://doi.org/10.5194/acp-15-4339-2015.

Haase, G., and T. Landelius, 2004: Dealiasing of doppler radar velocities using a torus mapping. J. Atmos. Oceaic Technol., 21, 1566-1573, https:/doi.org/10.1175/15200426(2004)021<1566:DODRVU>2.0.CO;2.

Haimov, S. and A. R. Rodi, 2013: Fixed-antenna pointing-angle calibration of airborne doppler cloud radar. J. Atmos. Oceanic Technol., 30, 2320-2335, https://doi.org/10.1175/JTECH-D-12-00262.1.

Hammer, R. B., V. C. Radeloff, J. S. Fried, and S. I. Stewart, 2007: Wildland-urban interface housing growth during the 1990s in California, Oregon, and Washington. Int. J. Wildland Fire, 16, 255-265. 
ISO, 2016: Wildland-urban interface risks are increasing. [Available online at https://www.isomitigation.com/spring-2016/wildland-urban-interface-risks-areincreasing.html]

James, C. N. and R. A. Houze Jr., 2001: A real-time four-dimensional doppler dealiasing scheme. J. Atmos. Oceanic. Technol., 18, 1674-1683, https://doi.org/10.1175/1520-0426(2001)018<1674:ARTFDD>2.0.CO;2.

Jian, Y., and T.-M. Fu, 2014: Injection heights of springtime biomass-burning plumes over peninsular Southeast Asia and their impacts on long-range pollutant transport. Atmos. Chem. Phys., 14, 3977-3989, https://doi.org/10.5194/acp-143977-2014.

Koo, E., P. J. Pagni, D. R. Weise, and J. P. Woycheese, 2010: Firebrands and spotting ignition in large-scale fires. Int. J. Wildland Fire, 19, 818-843, https://doi.org/10.1071/WF07119.

Jensen, E., A. S. Ackerman, and A. Fridlind, 2004: Microphysics of pyrocumulonimbus clouds. 14th International Conference on Clouds and Precipitation (ICCP).

Johnson, B. T., S. R. Osborne, J. M. Haywood, and M. A. J. Harrison, 2008: Aircraft measurements of biomass burning aerosol over West Africa during DABEX. $J$. Geophys. Res., 113, https://doi.org/10.1029/2007JD009451.

Karl, T., A. Guenther, R. J. Yokelson, J. Greenberg, M. Potosnak, D. R. Blake, and P. Artaxo, 2007: The tropical forest and fire emissions experiments: Emission, chemistry, and transport of biogenic volatile organiz compounds in the lower atmosphere over Amazonia. J. Geophys. Res., 112, https://doi.org/10.1029/2007JD008539.

Kasischke, E. S. and M. R. Turetsky, 2006: Recent changes in the fire regime across the North American boreal region - Spatial and temporal patterns of burning across Canada and Alaska. Geophys. Res. Lett., 33, L09703, doi:10.1029/2006GL025677.

Lareau, N. P. and C. B. Clements, 2015: Cold Smoke: smoke-induced density currents cause unexpected smoke transport near large wildfires. Atmos. Chem. Phys., 15, 11513-11520, https://doi.org/10.5194/acp-15-11513-2015.

Lareau, N. P. and C. B. Clements, 2016: Environmental controls on pyrocumulus and pyrocumulonimbus initiation and development. Atmos. Chem. Phys., 16, 40054022, https://doi.org/10.5194/acp-16-4005-2016.

Latham, D. J., 1994: PLUMP, a plume predictor and cloud model for fire managers. USDA Forest Service General Technical Report, 15. 
Levine, J., 1959: Spherical vortex theory of bubble-like motion in cumulus clouds. $J$. Atmos. Sci., 16, 653-662, https://doi.org/10.1175/15200469(1959)016<0653:SVTOBL>2.0.CO;2.

Luderer, G., J. Trentmann, and M. O. Andreae, 2009: A new look at the role of firereleased moisture on the dynamics of atmospheric pyro-convection. Int. J. Wildland Fire, 18, 544-562, https://doi.org/10.1071/WF07035.

McRae, D. J. and M. D. Flannigan, 1990: Development of large vortices on prescribed fires. Can. J. Forest Res., 20, 1878-1887, https://doi.org/10.1139/x90-252.

Miao, Q., B. Geerts, and M. LeMone, 2005: Vertical velocity and buoyancy characteristics of coherent echo plumes in the convective boundary layer, detected by a profiling airborne radar. J. Appl. Meteor. Climatol., 45, 838-855, https://doi.org/10.1175/JAM2375.1.

NIFC, 2017: Suppression costs (1985-2017). Accessed 26 March 2018, https://www.nifc.gov/fireInfo/fireInfo_documents/SuppCosts.pdf

Palmer, T. J., 1981: Large fire winds, gases and smoke. Atmos. Env., 15, 2079-2090, https://doi.org/10.1016/0004-6981(81)902241-9.

Paugam, R., M. Wooster, S. Freitas, and M. Val Martin, 2016: A review of approaches to estimate wildfire plume injection height within large-scale atmospheric chemical transport models. Atmos. Chem. Phys., 13, 907-925, https://doi.org/10.5194/acp16-907-2016.

Peace, M., L. McCaw, B. Santos, J. D. Kepert, N. Burrows, and R. J. B. Fawcett, 2017: Meteorological drivers of extreme fire behavior during the Waroona bushfire, Western Australia, January 2016. J. Southern Hemisphere Earth Sys. Sci., 67, 79106.

Peterson, D. A., E. J. Hyer, J. R. Campbell, M. D. Fromm, J. W. Hair, C. F. Butler, and M. A. Fenn, 2015: The 2013 Rim Fire: Implications for predicting extreme fire spread, pyroconvection, and smoke emissions. Bull. Amer. Meteor. Soc., 96, 229247, https://doi.org/10.1175/BAMS-D-14-00060.1.

Potter, B. E., 2005: The role of released moisture in the atmospheric dynamics associated with wildland fires. Int. J. Wildland Fire, 14, 77-84, https://doi.org/10.1071/WF04045.

Ray, P. S., and C. Ziegler, 1977: De-aliasing first-moment doppler estimates. J. Appl.

Meteor., 16(5), 563-564, https://doi.org/10.1175/1520-

0450(1977)016,0563:DAFMDE>2.0.CO;2. 
Rosenfeld, D., M. Fromm, J. Trentmann, G. Luderer, M. O. Andreae, and R. Servranckx, 2007: The Chisholm firestorm: observed microstructure, precipitation and lightning activity of a pyro-cumulonimbus. Atmos. Chem. Phys., 7, 645-659, https://doi.org/10.5194/acp-7-645-2007.

Rothermel, R. C., 1991: Predicting behavior and size of crown fires in the northern Rocky Mountains. USDA Forest Service, Res. Pap. INT-438

Rudlosky, S. D., and H. E. Fuelberg, 2011: Seasonal, regional, and storm-scale variability of cloud-to-ground lightning characteristics in Florida. Monthly Wea. Rev., 139, 1826-1843, https://doi.org/10.1175/2010MWR3585.1.

Scorer, R. S., 1957: Experiments on convection of isolated masses of buoyant fluid. $J$. Fluid. Mech., 2, 583-594, https://doi.org/10.1017/S0022112057000397.

Tabary, P., G. Scialom, and U. Germann, 2000: Real-time retrieval of the wind from aliased velocities measured by doppler radars. J. Atmos. Oceanic Technol., 18, 875-882, https://doi.org/10.1175/15200426(2001)018<0875:RTROTW>2.0.CO;2.

Tory, K. J., W. Thurston, and J. D. Kepert, 2018: Thermodynamics of pyrocumulus: a conceptual study. Monthly Wea. Rev., 146, 2579-2598, https://doi.org/10.1175/MWR-D-17-0377.1.

Trentmann, J., and Coauthors, 2006: Modeling of biomass smoke injection into the lower stratosphere by a large forest fire (Part I): reference simulation. Atmos. Chem. Phys., 6, 6041-6080, https://doi.org/10.5194/acp-6-5247-2006.

Val Martin, M., J. A. Logan, R. A. Kahn, F.-Y. Leung, D. L. Nelson, and D. J. Diner, 2010: Smoke injection heights from fires in North America: analysis of 5 years of satellite observations. Atmos. Chem. Phys., 10, 1491-1510, https://doi.org/10.5194/acp-10-1491-2010.

Val Martin, M., R. A. Kahn, J. A. Logan, R. Paugam, M. Wooster, and C. Ichoku, 2012: Space-based observational constraints for 1-D fire smoke plume-rise models. $J$. Geophys. Res., 117, https://doi.org/10.1029/2029/2012JD018370.

Verri, A., F. Girosi, and V. Torre, 1990: Differential techniques for optical flow. J. Optical Soc. Amer., 7, 912-922, https://doi.org/10.1364/JOSAA.7.000912.

Wang, Z., and Coauthors, 2006: Single aircraft integration of remote sensing and in situ sampling for the study of cloud microphysics and dynamics. Bull. Amer. Meteor. Soc., 93(5), 653-668, https://doi.org/10.1175/BAMS-D-11-00044.1. 
Westerling, A. L., H. G. Hidalgo, D. R. Cayan, and T. W. Swetnam, 2006: Warming and earlier spring increase western U.S. forest wildfire activity. Science, 313, 940943.

Woodward, B., 1959: The motion in and around isolated thermals. Quart. J. Roy. Meteor. Soc., 85, https://doi.org/10.1002/qj.49708536407.

Yokelson, R. J., T. J. Christian, T. G. Karl, and A. Guenther, 2008: The tropical forest and fire emissions experiment: laboratory fire measurements and synthesis of campaign data. Atmos. Chem. Phys., 8, 3509-3527, https://doi.org/10.5194/acp-83509-2008. 


\section{Appendix A}

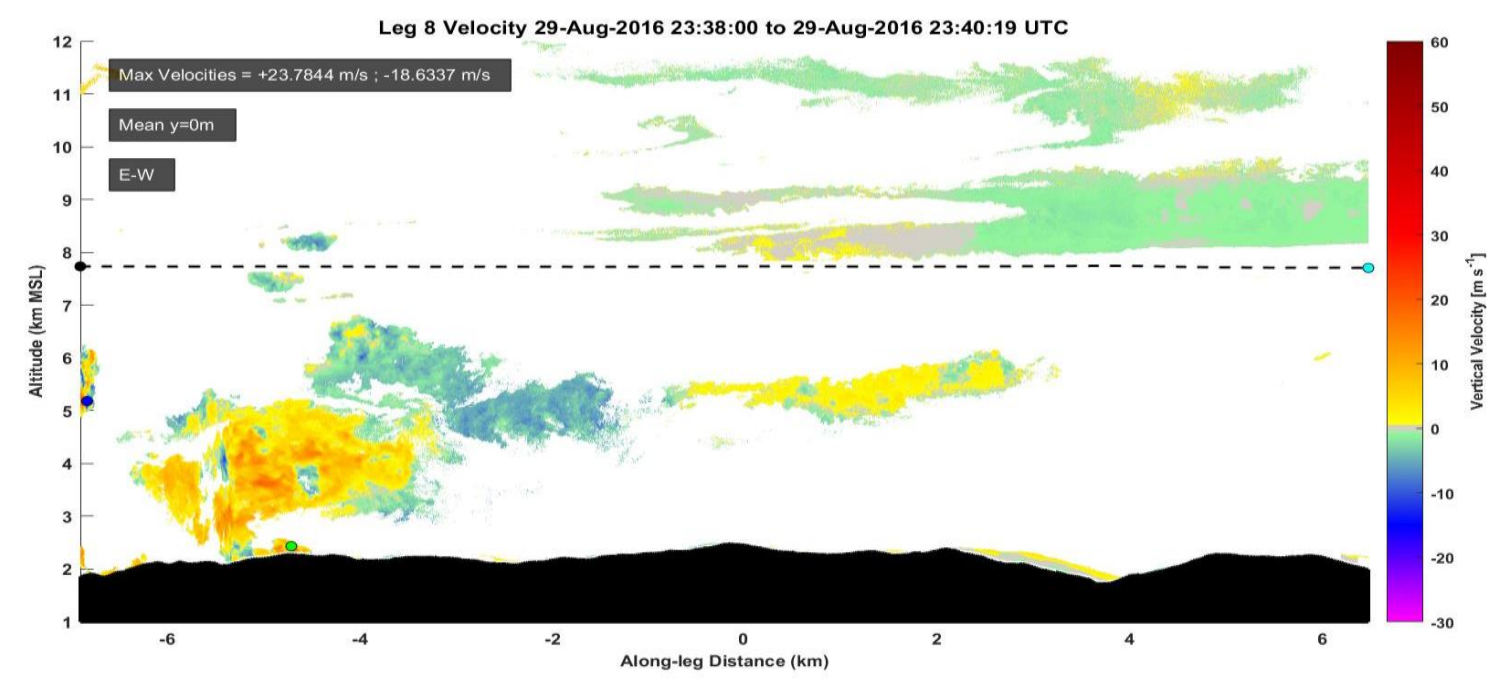

Fig. 26. Cross-section of vertical velocity for cross-wind leg 8.

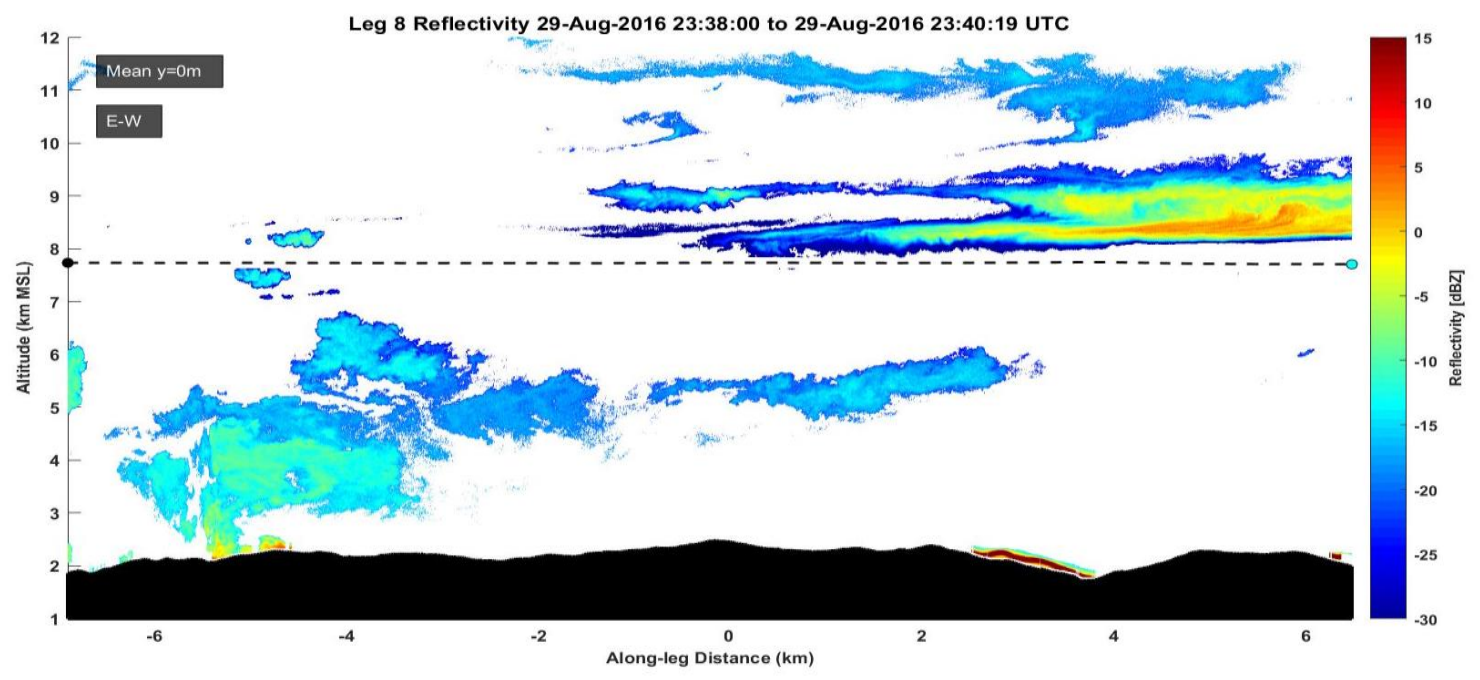

Fig. 27. Cross-section of reflectivity for cross-wind leg 8 . 


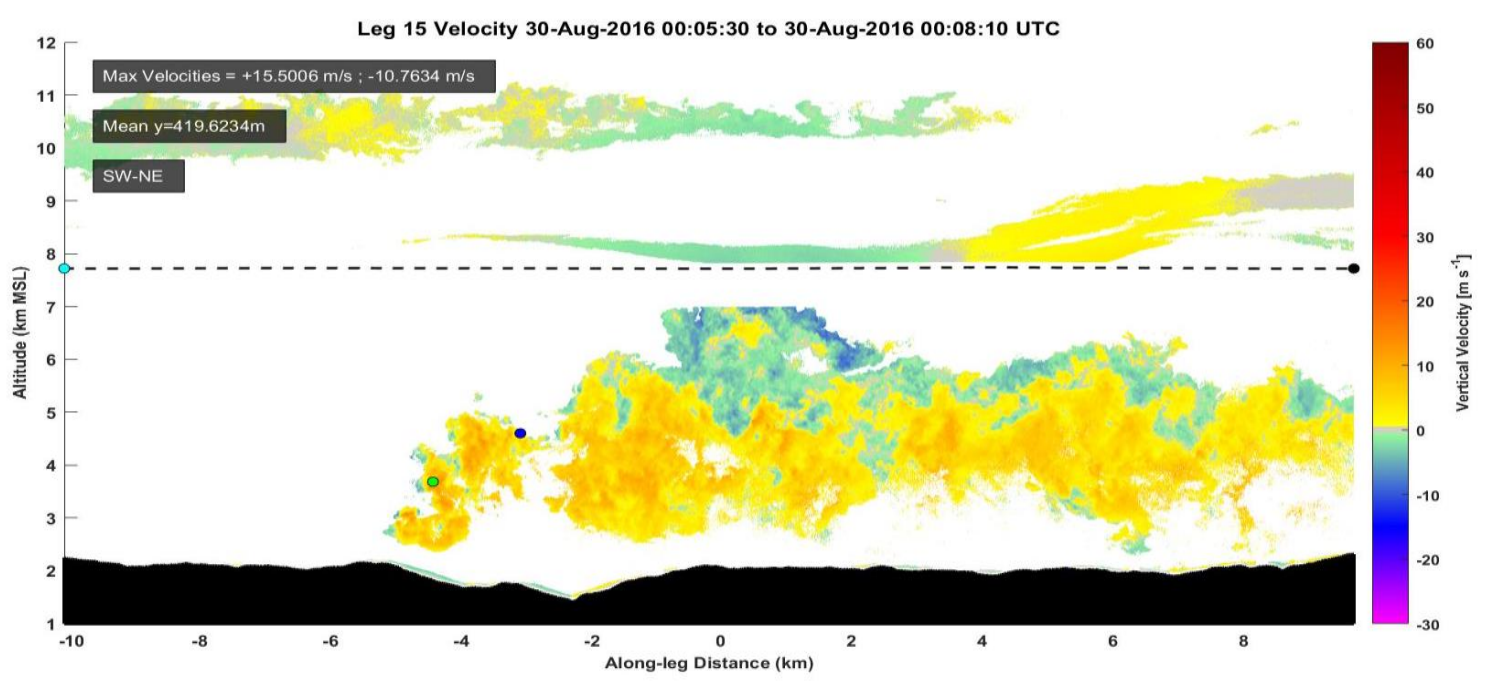

Fig. 28. Cross-section of vertical velocity for along-wind leg 15.

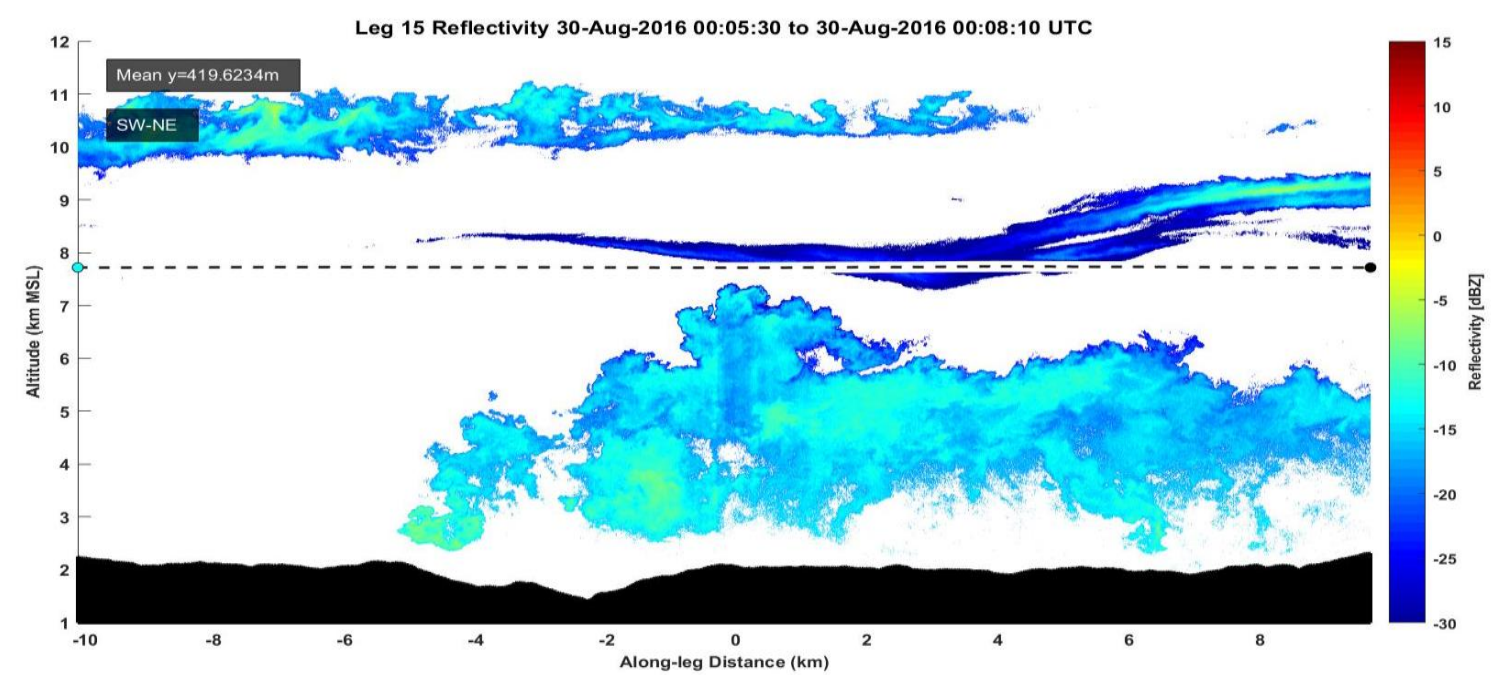

Fig. 29. Cross-section of reflectivity for along-wind leg 15. 
Leg 17 Velocity 30-Aug-2016 00:15:00 to 30-Aug-2016 00:18:20 UTC

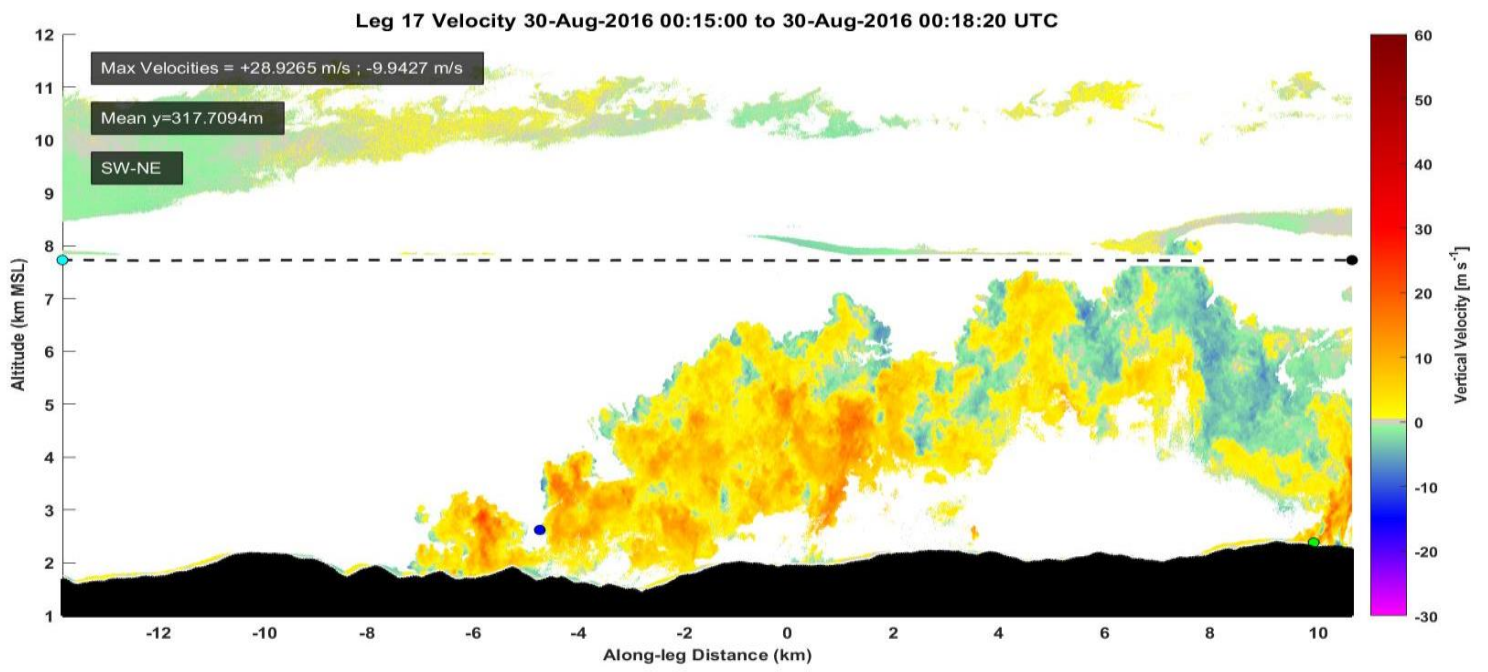

Fig. 30. Cross-section of vertical velocity for along-wind leg 17.

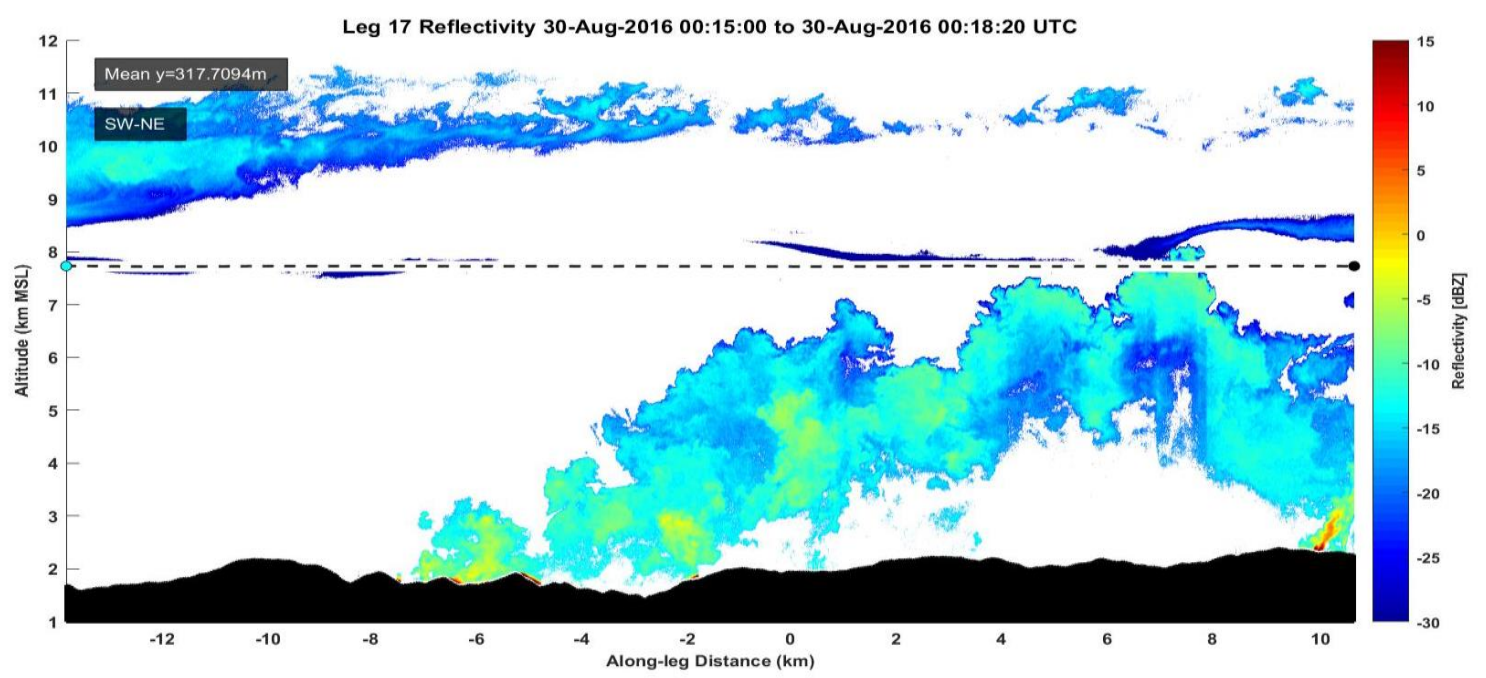

Fig. 31. Cross-section of reflectivity for along-wind leg 17. 


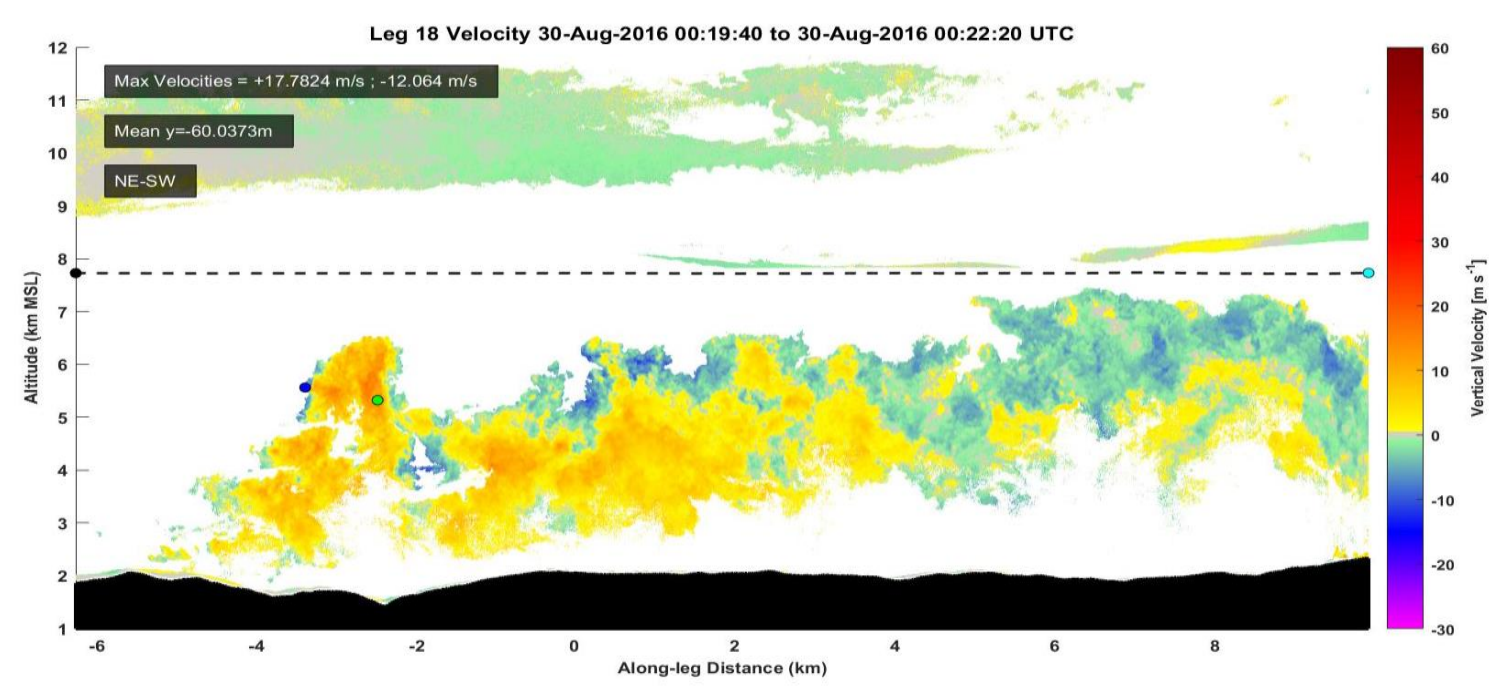

Fig. 32. Cross-section of vertical velocity for along-wind leg 18.

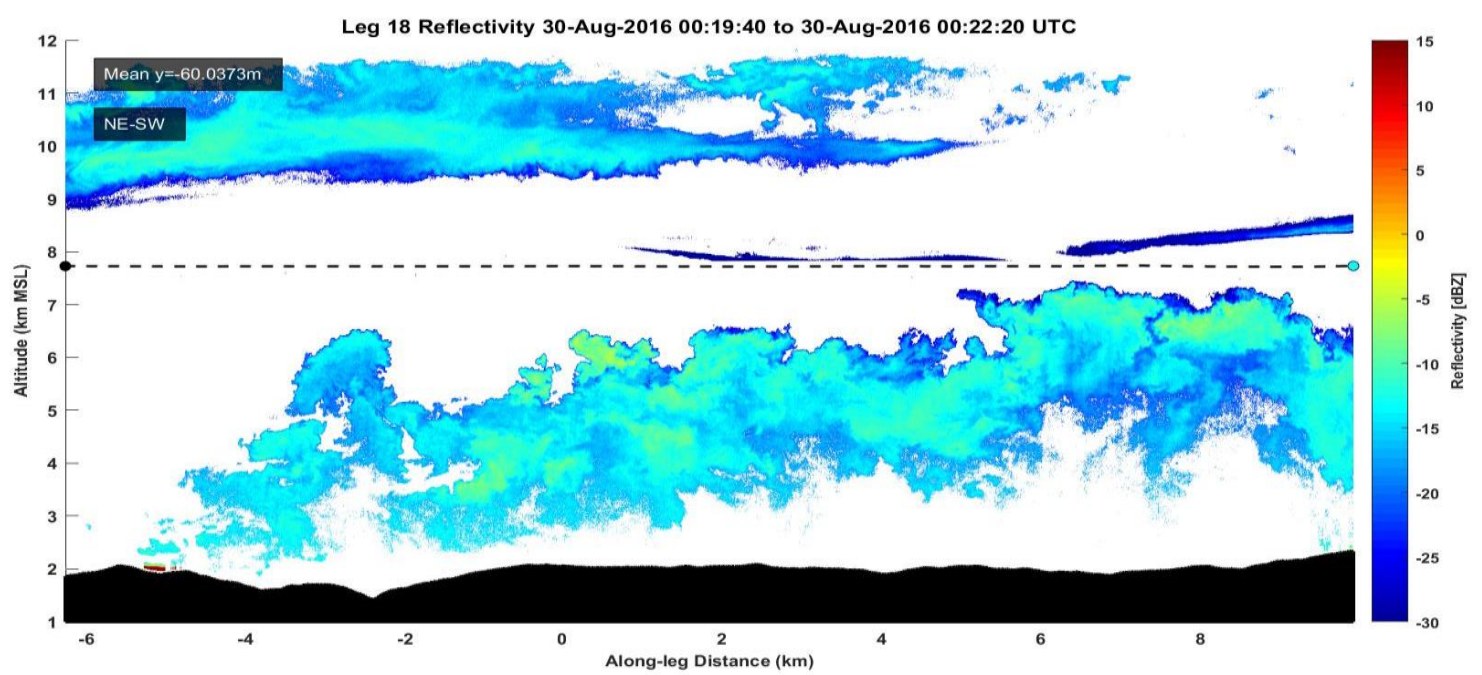

Fig. 33. Cross-section of reflectivity for along-wind leg 18. 


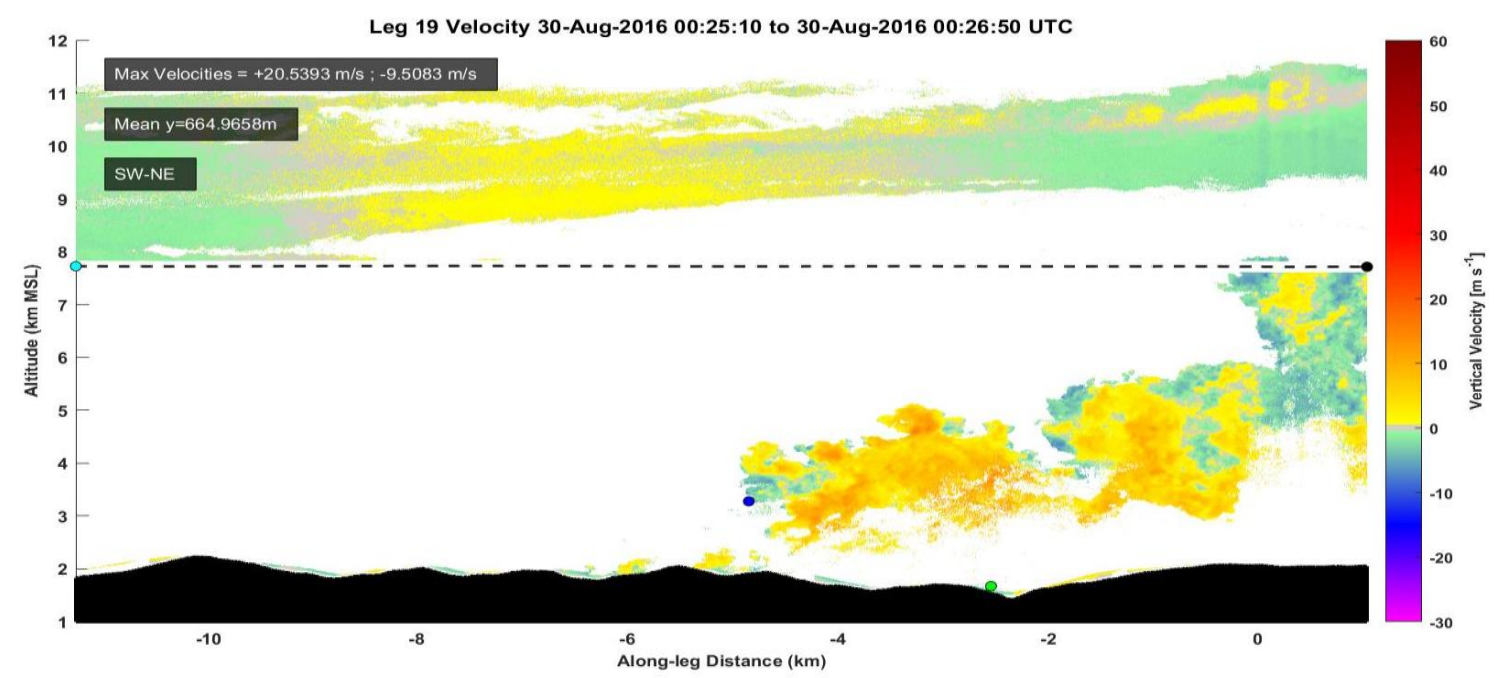

Fig. 34. Cross-section of vertical velocity for along-wind leg 19.

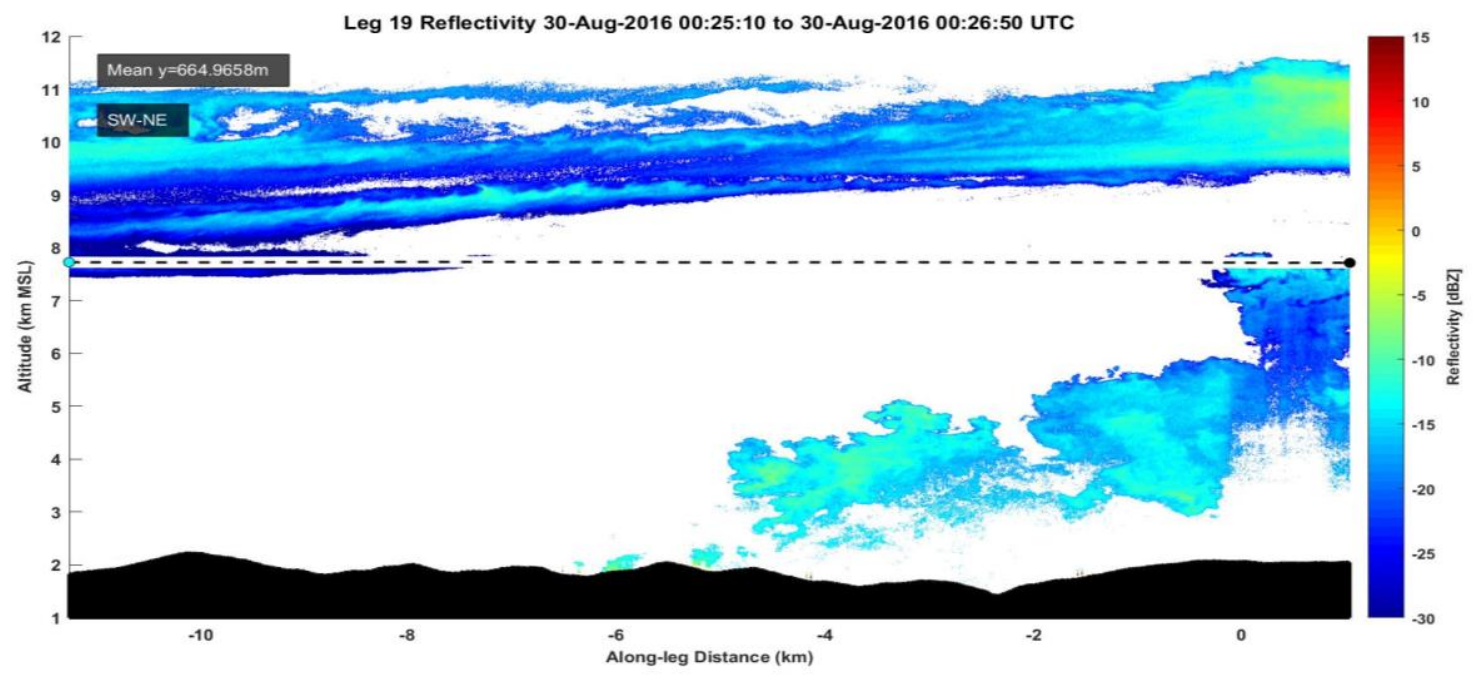

Fig. 35. Cross-section of reflectivity for along-wind leg 19. 


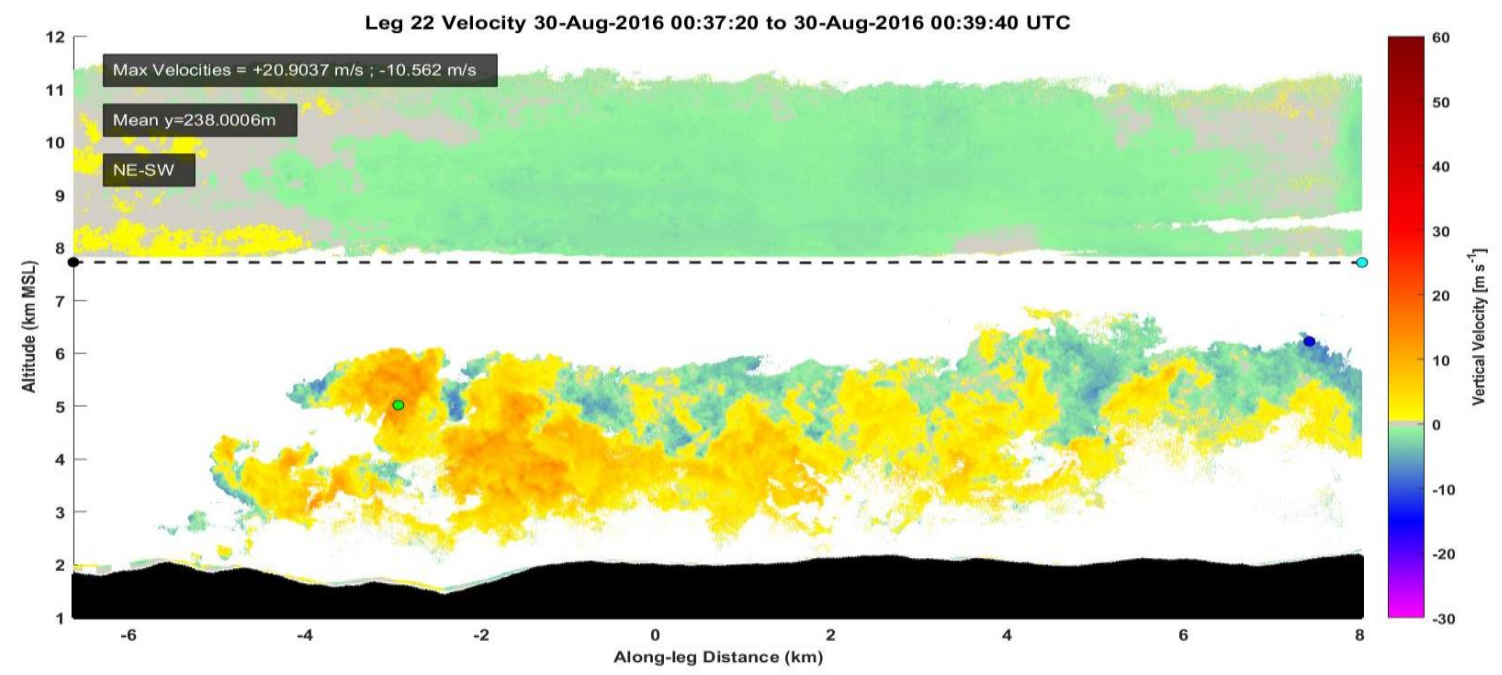

Fig. 36. Cross-section of vertical velocity for along-wind leg 22.

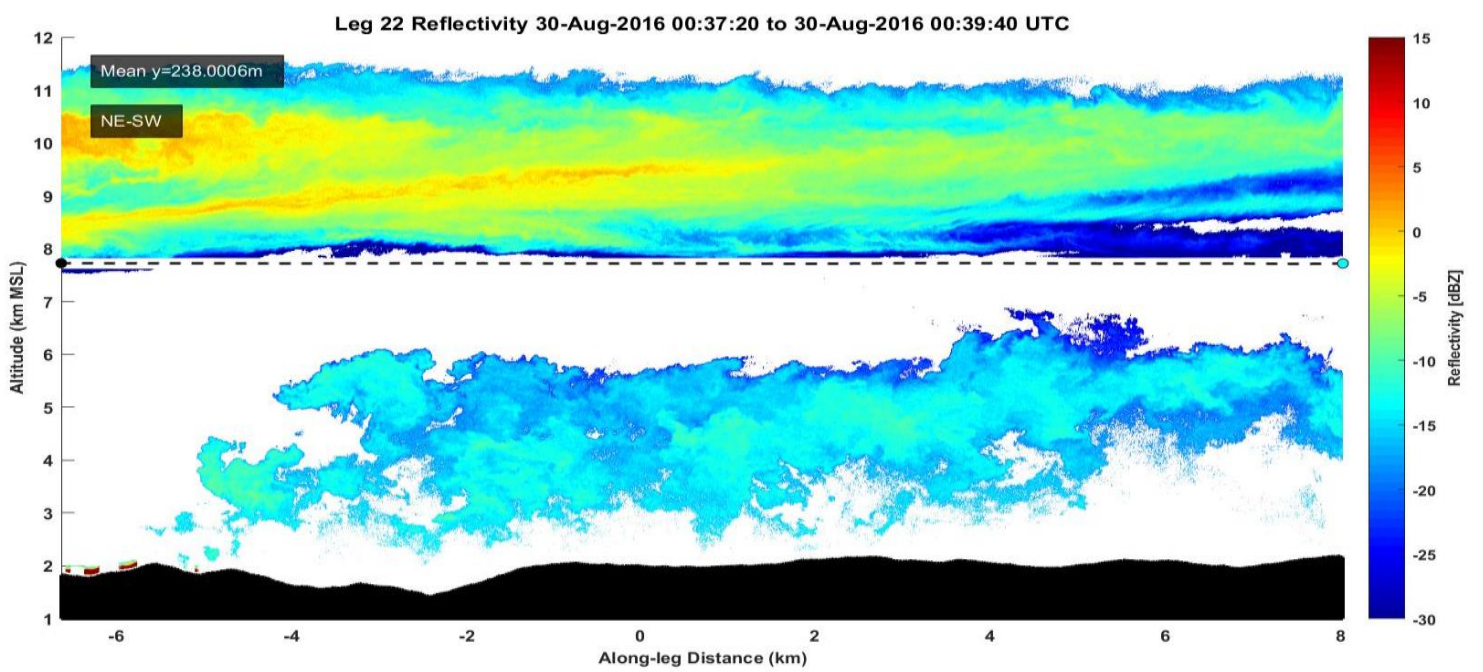

Fig. 37. Cross-section of reflectivity for along-wind leg 22. 


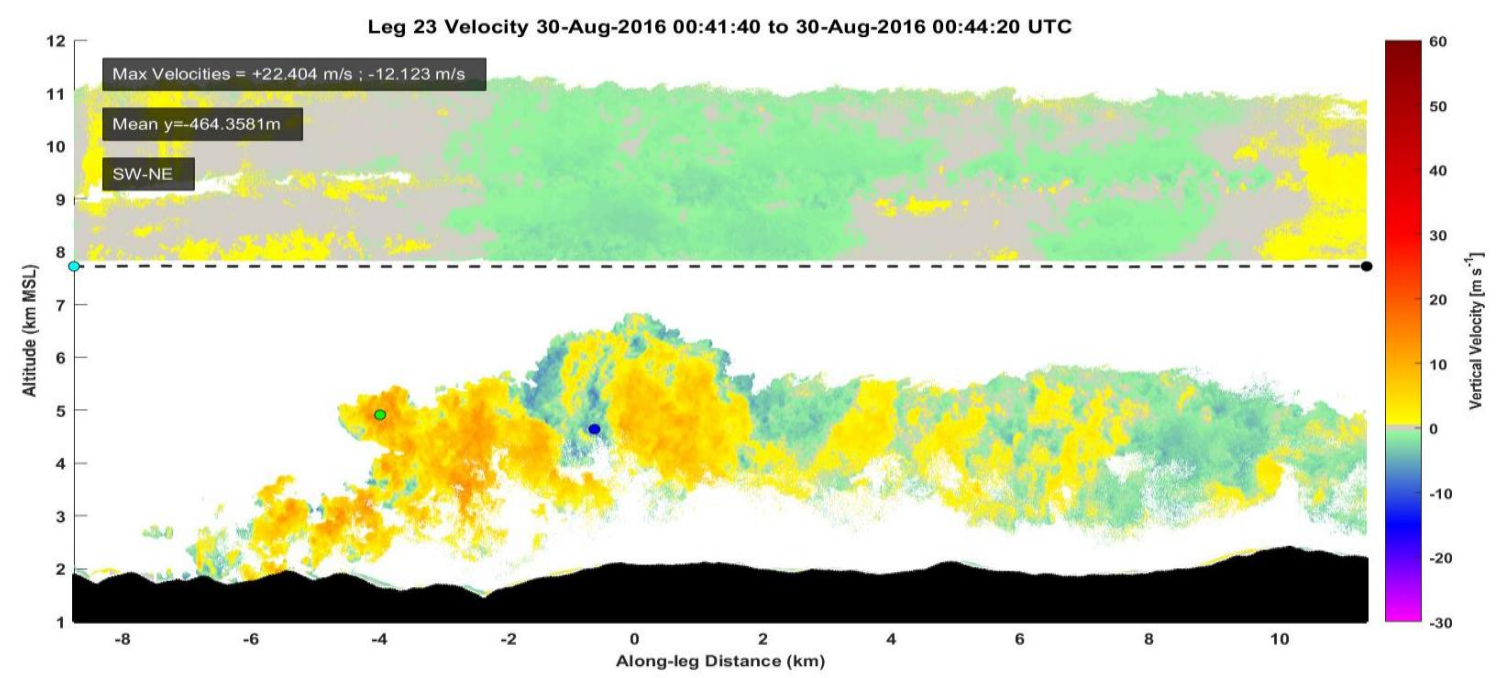

Fig. 38. Cross-section of vertical velocity for along-wind leg 23.

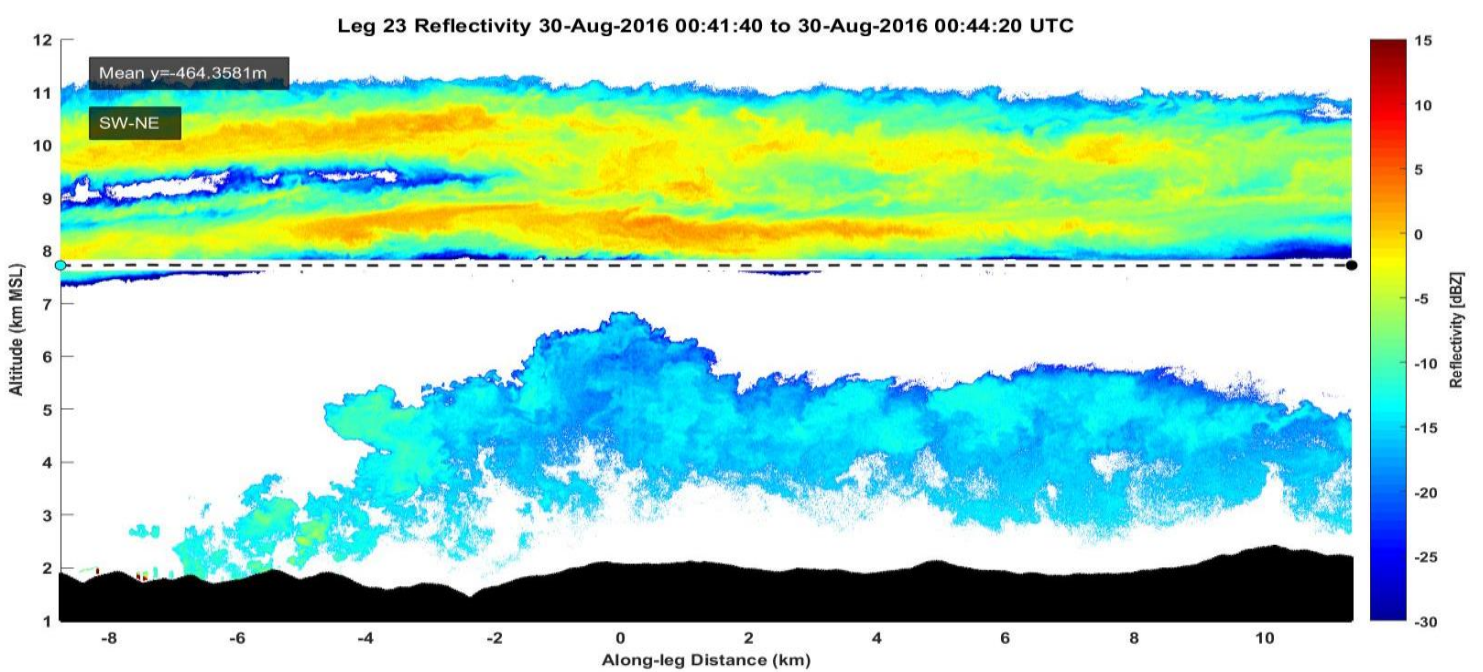

Fig. 39. Cross-section of reflectivity for along-wind leg 23. 


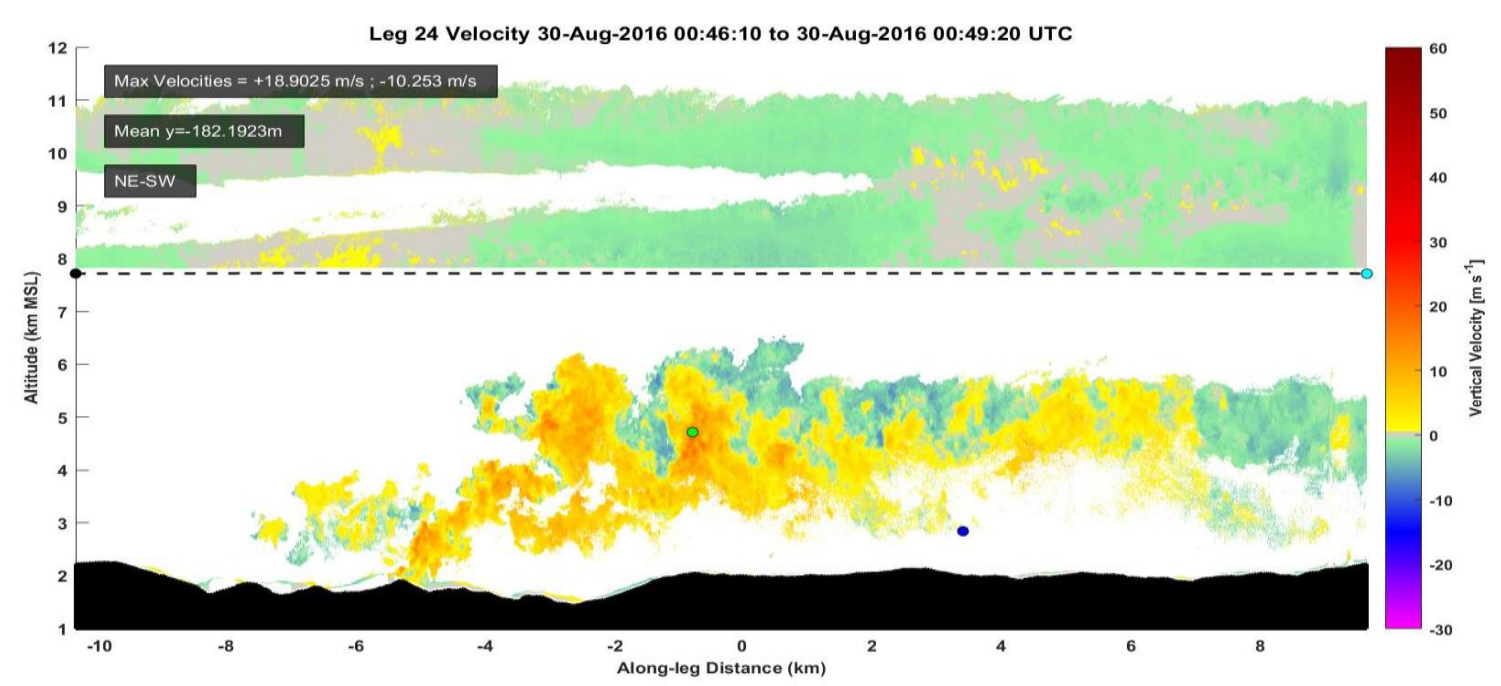

Fig. 40. Cross-section of vertical velocity for along-wind leg 24.

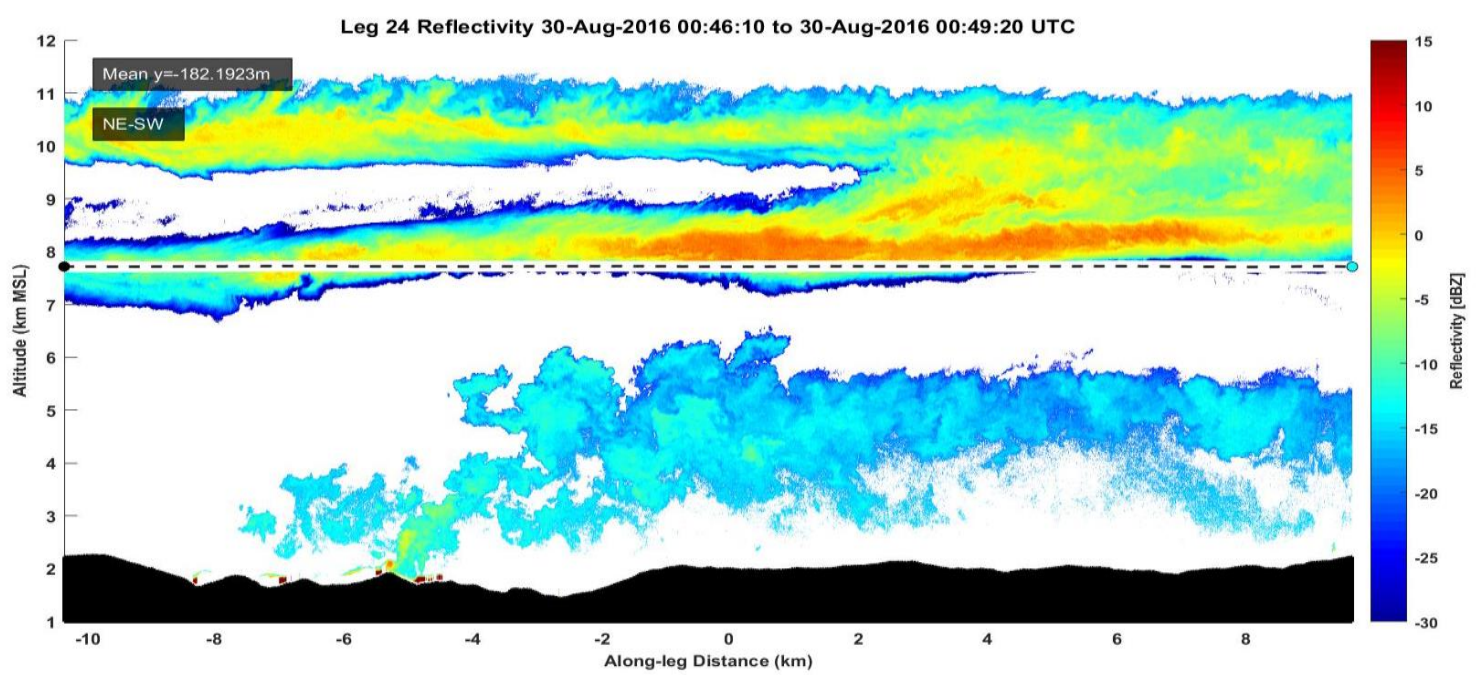

Fig. 41. Cross-section of reflectivity for along-wind leg 24. 


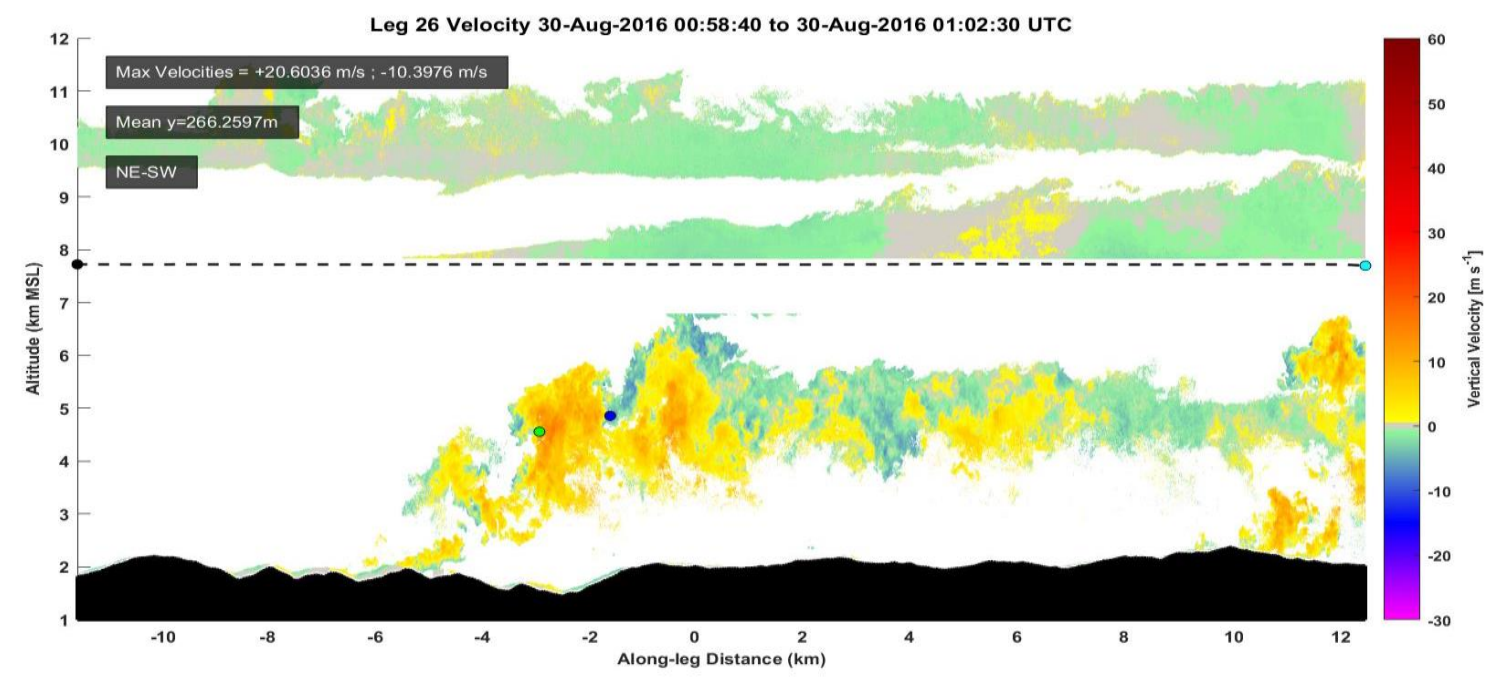

Fig. 42. Cross-section of vertical velocity for along-wind leg 26.

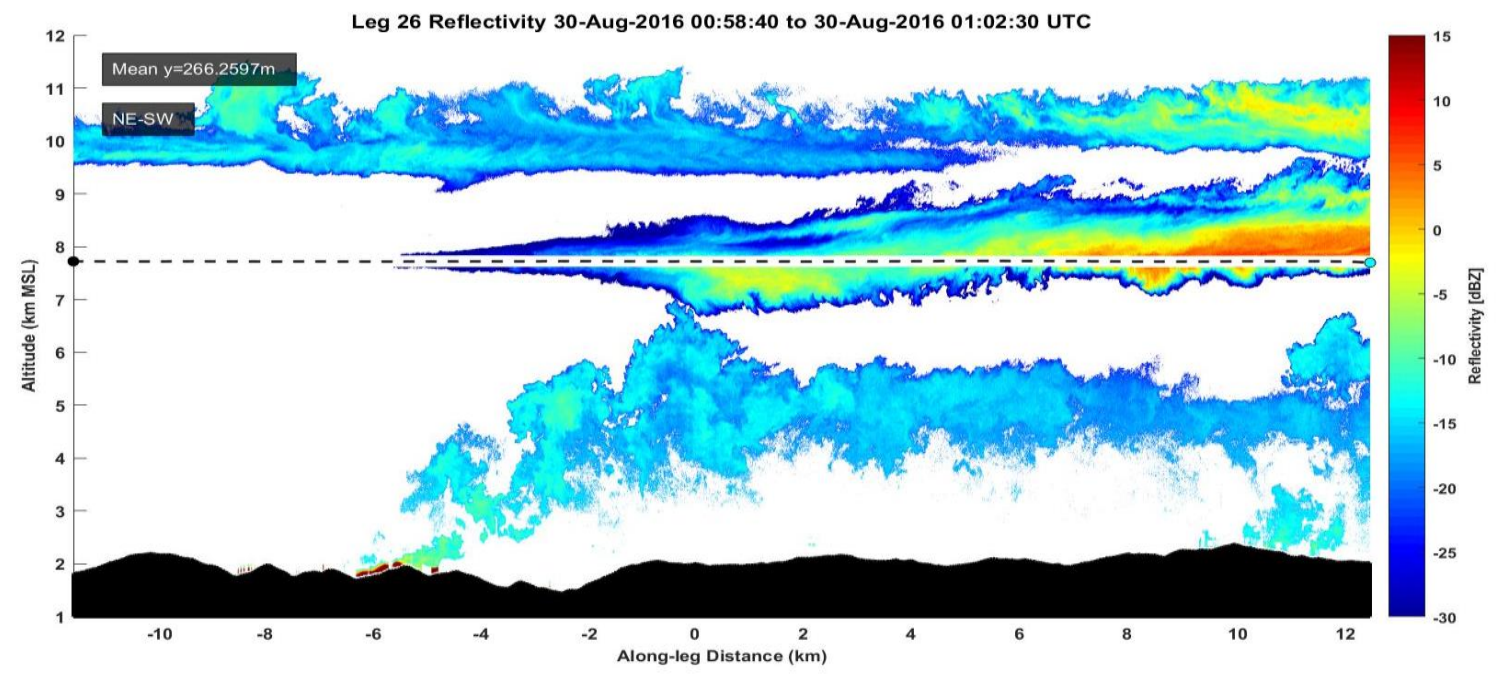

Fig. 43. Cross-section of reflectivity for along-wind leg 26. 


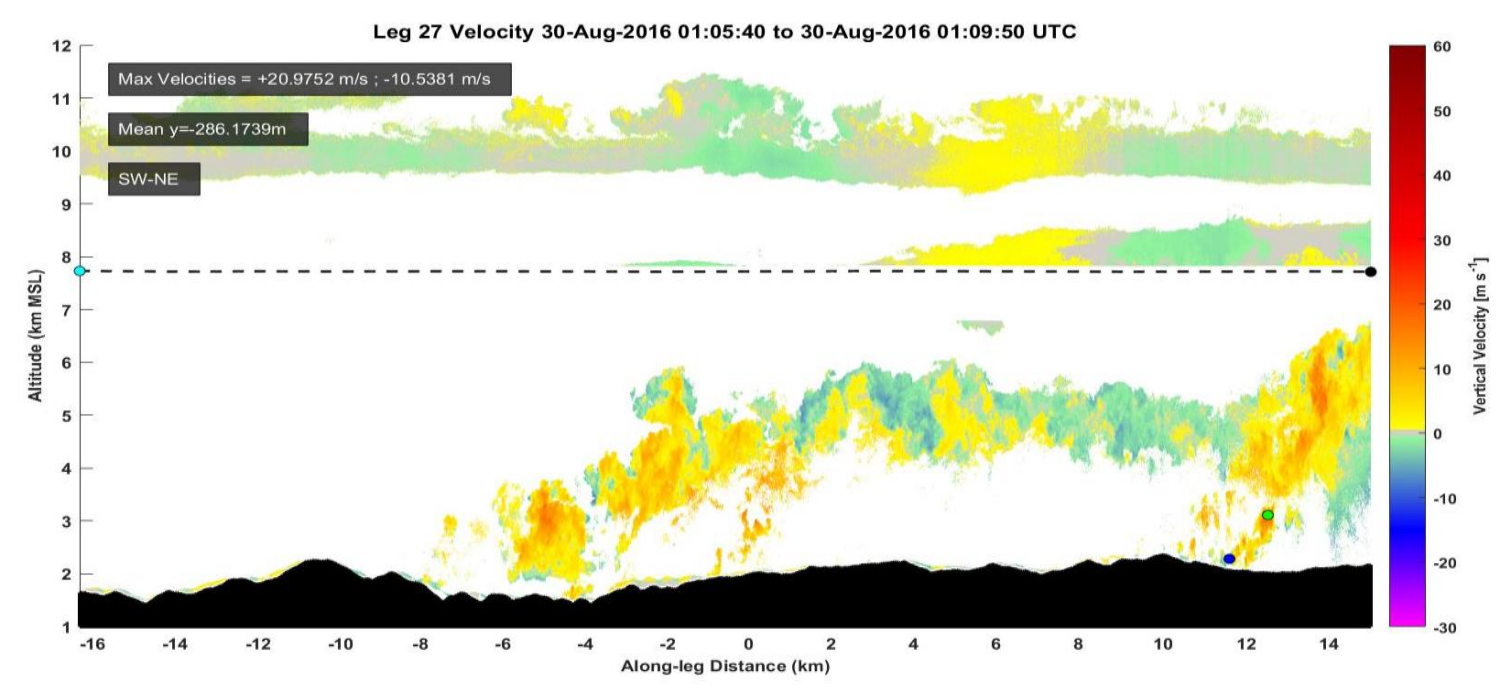

Fig. 44. Cross-section of vertical velocity for along-wind leg 27.

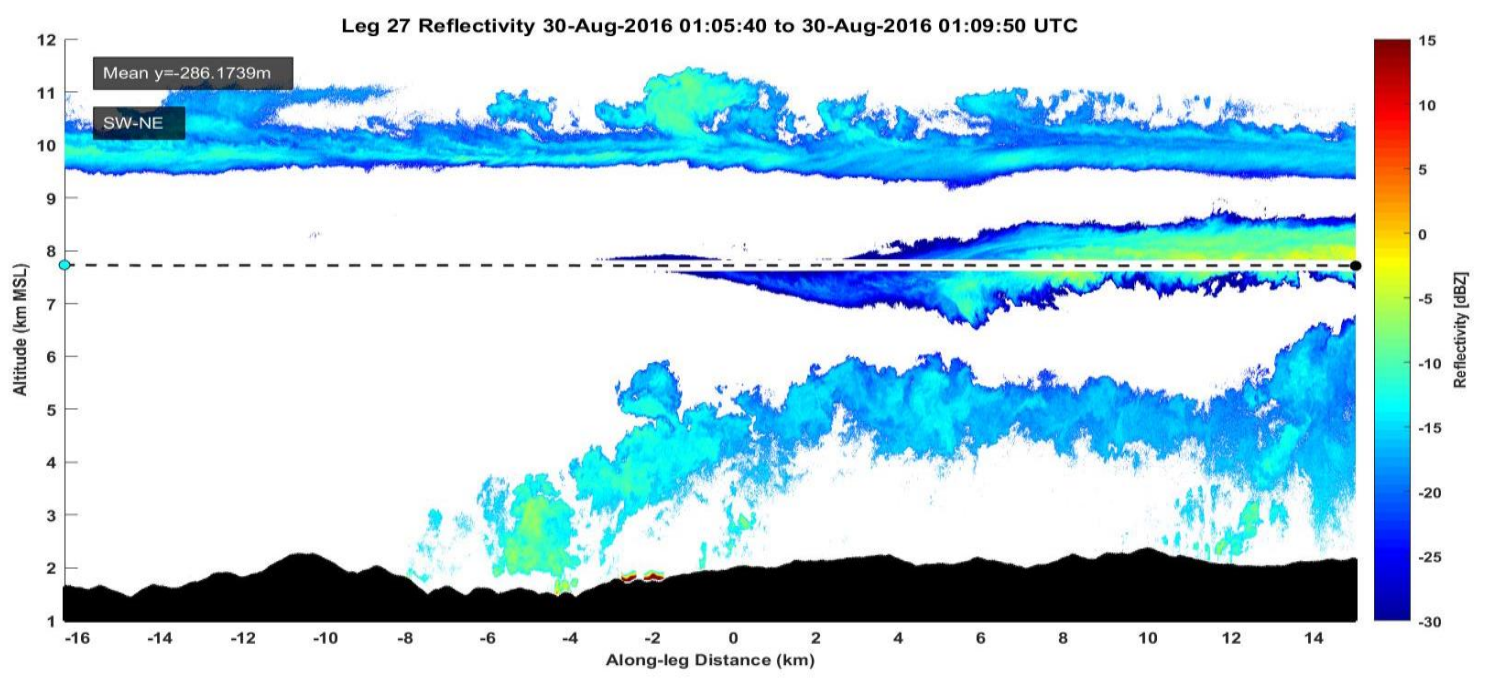

Fig. 45. Cross-section of reflectivity for along-wind leg 27. 


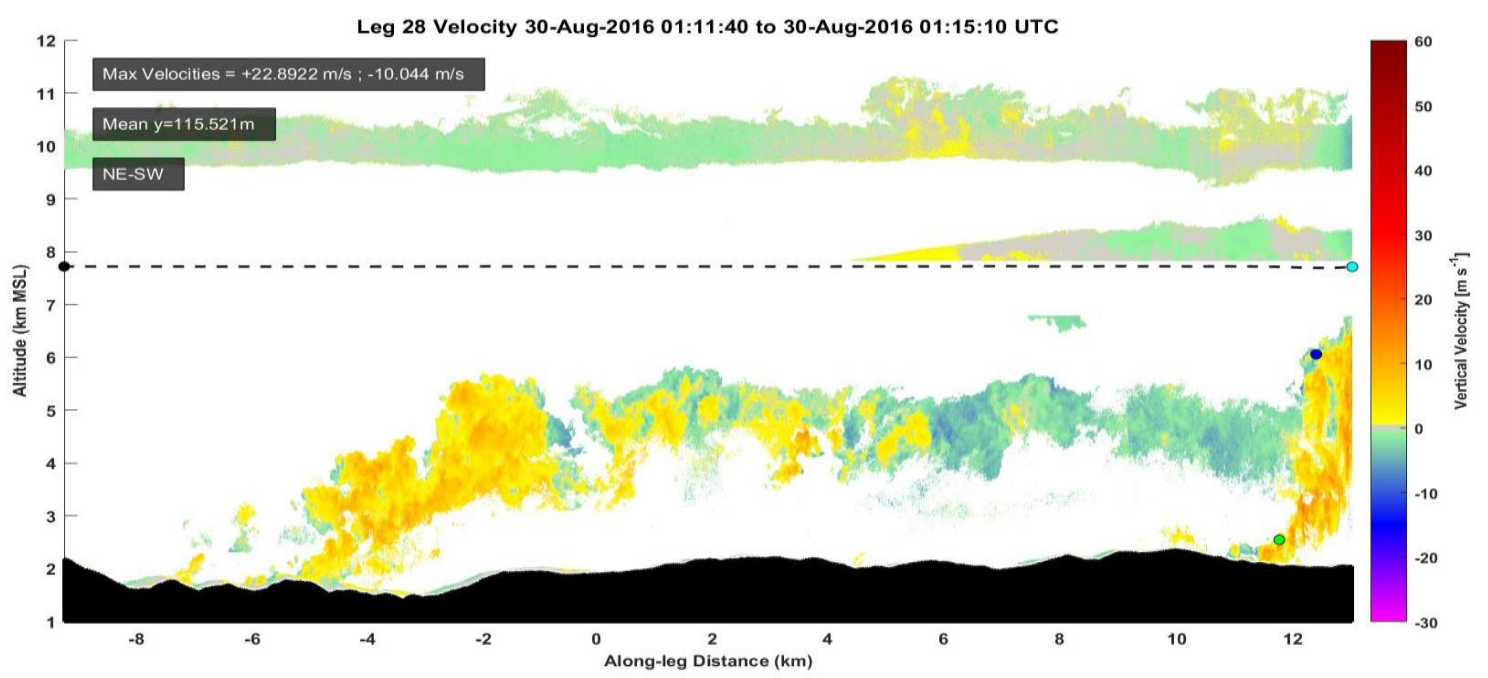

Fig. 46. Cross-section of vertical velocity for along-wind leg 28.

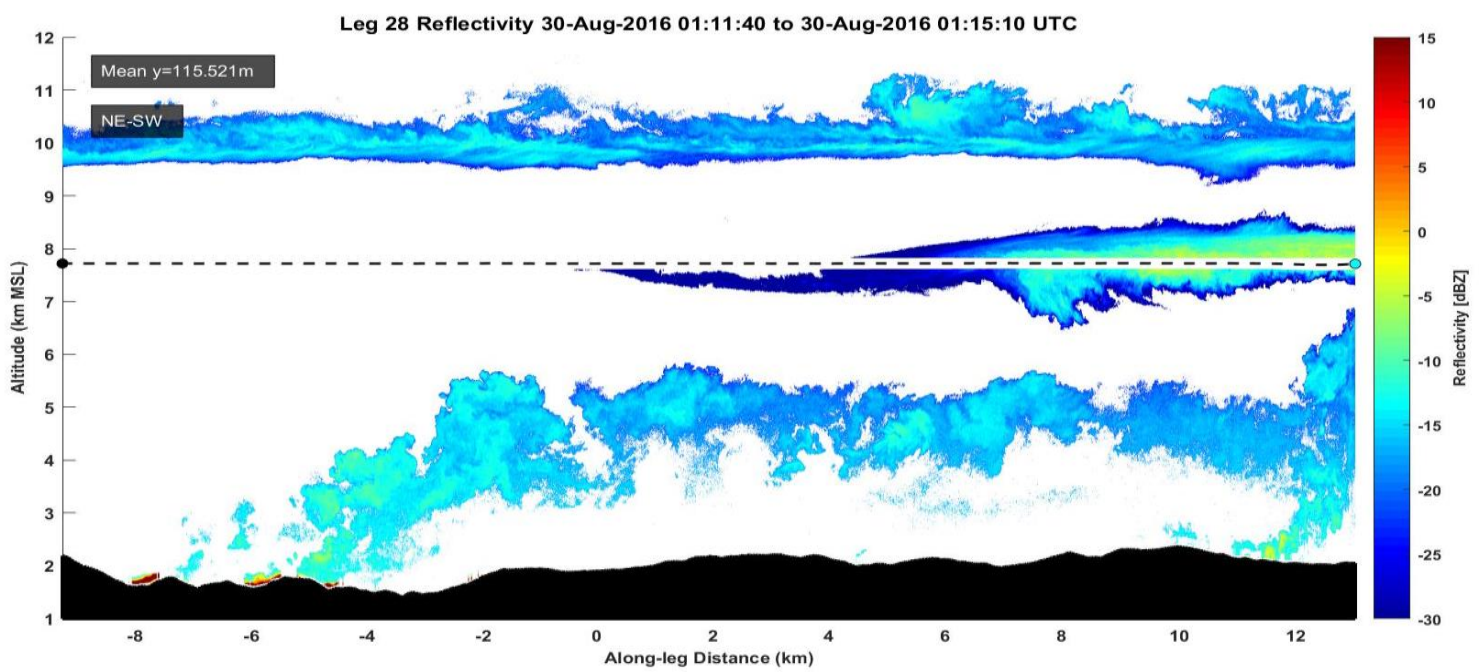

Fig. 47. Cross-section of reflectivity for along-wind leg 28. 


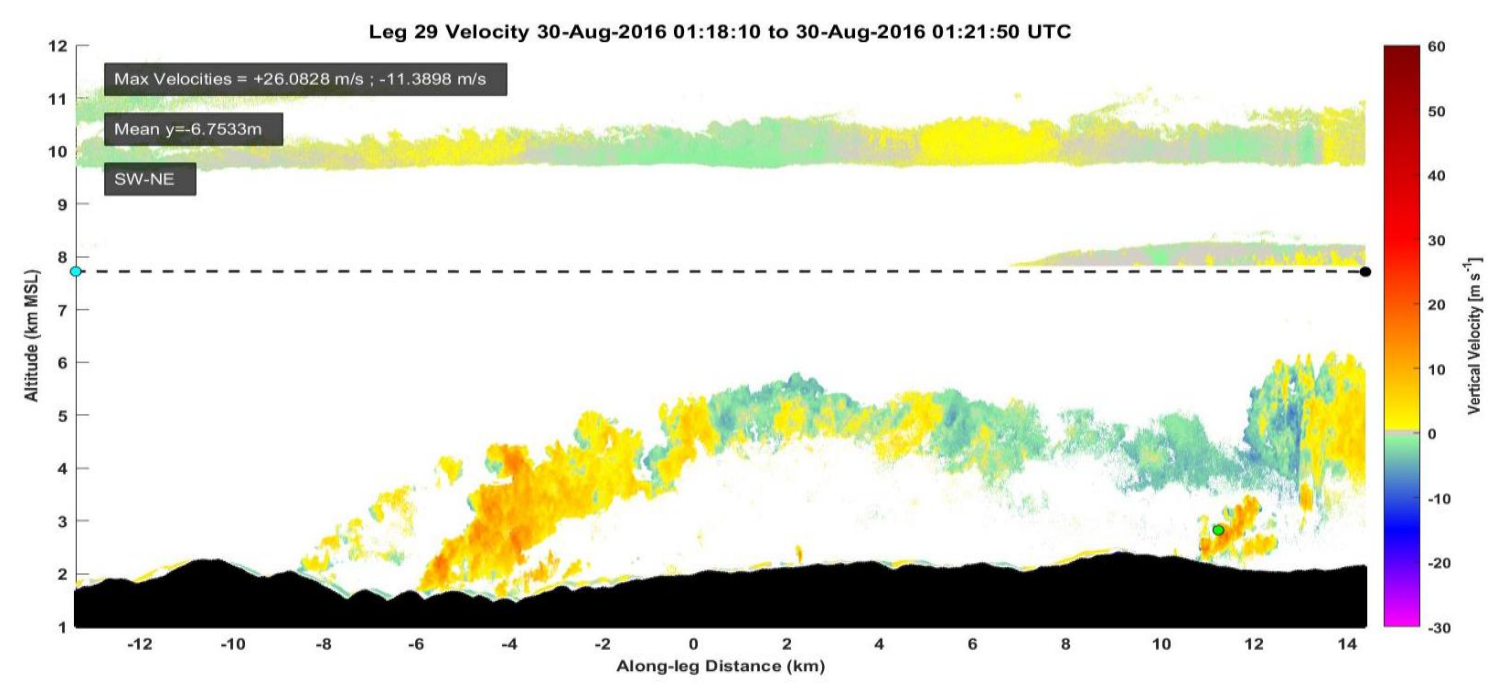

Fig. 48. Cross-section of vertical velocity for along-wind leg 29.

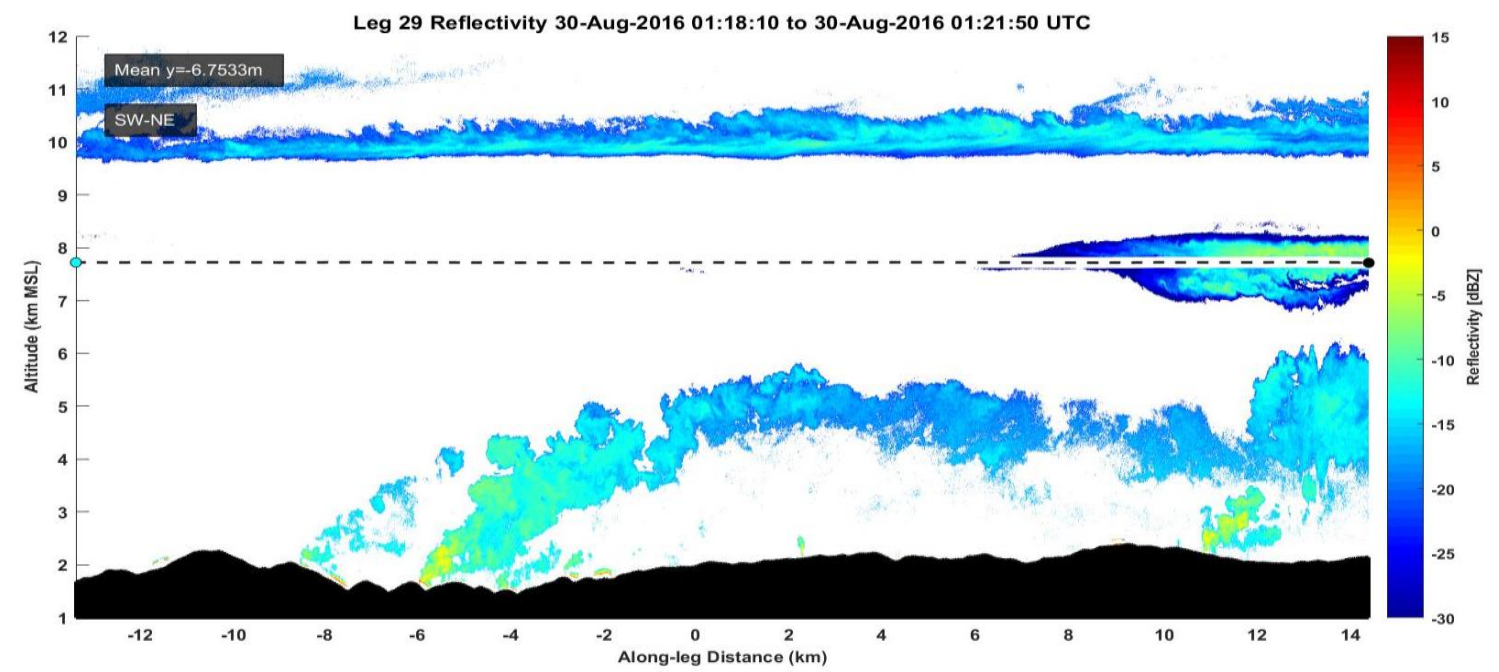

Fig. 49. Cross-section of reflectivity for along-wind leg 29. 


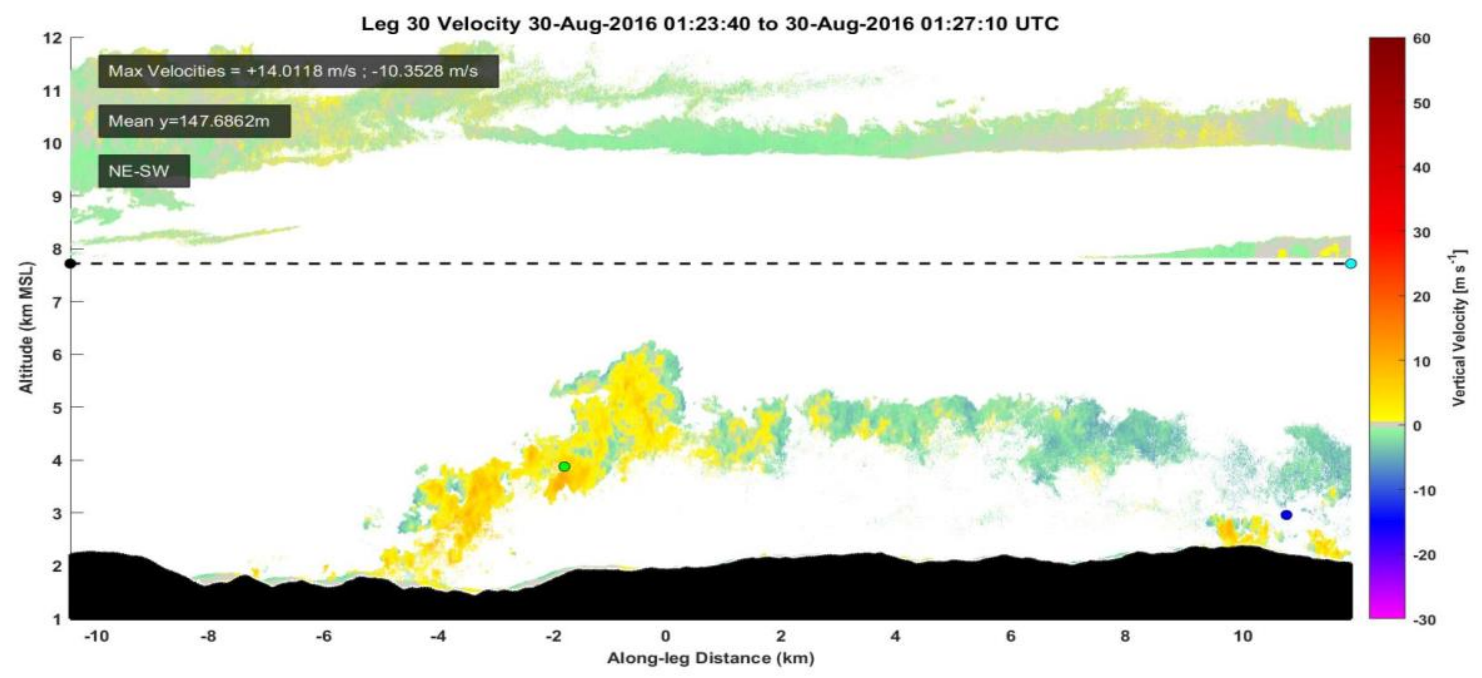

Fig. 50. Cross-section of vertical velocity for along-wind leg 30.

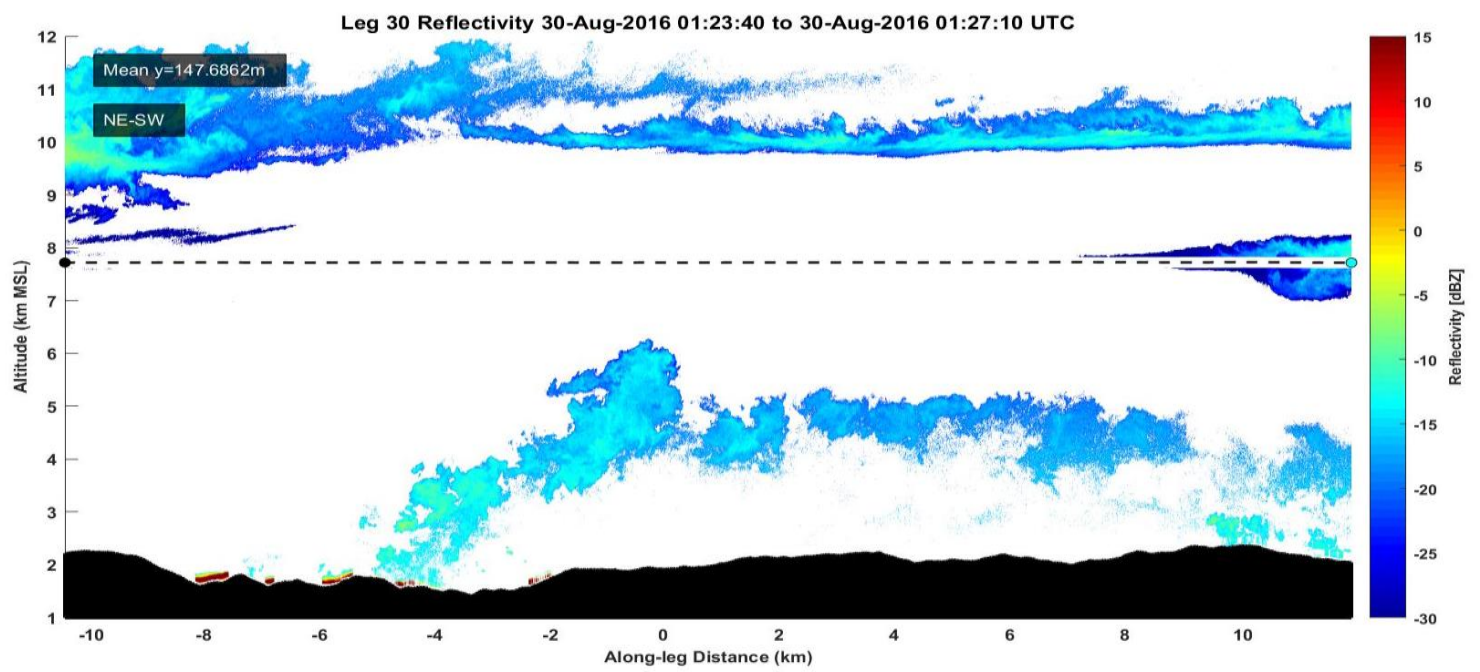

Fig. 51. Cross-section of reflectivity for along-wind leg 30. 